\title{
STORAGE OF CHILLED NATURAL GAS IN BEDDED SALT STORAGE CAVERNS
}

Revision 1

Topical Report RSI-1354

DE-AC26-97FT34350

\author{
prepared for \\ United States Department of Energy \\ National Energy Technology Laboratory \\ 626 Cochrans Mill Road \\ Pittsburgh, Pennsylvania 15236
}

November 2001
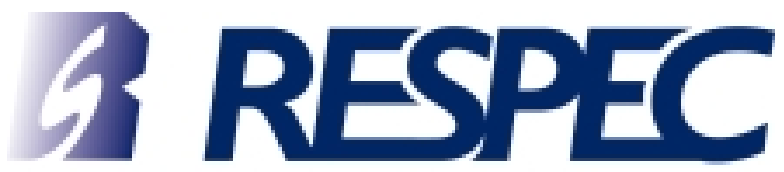

An Integrated Consulting and Services Company 
This report was prepared as an account of work sponsored by an agency of the United States Government. Neither the United States Government nor any agency thereof, nor any of their employees, makes any warranty, express or implied, or assumes any legal liability or responsibility for the accuracy, completeness, or usefulness of any information, apparatus, product, or process disclosed, or represents that its use would not infringe privately owned rights. Reference herein to any specific commercial product, process, or service by tradename, trademark, manufacturer, or otherwise does not necessarily constitute or imply its endorsement, recommendation, or favoring by the United States Government or any agency thereof. The views and opinions of authors expressed herein do not necessarily state or reflect those of the United States Government or any agency thereof.

Available to the public from the National Technical I nformation Service, U.S. Department of Commerce, 5285 Port Royal Road, Springfield, VA 22161; phone orders accepted at (703) 487-4650. 


\title{
STORAGE OF CHILLED NATURAL GAS IN BEDDED SALT STORAGE CAVERNS
}

Revision 1

Topical Report RSI-1354

DE-AC26-97FT34350

\author{
by \\ Joel D. Nieland \\ Kirby D. Mellegard \\ RESPEC \\ P.O. Box 725 \\ Rapid City, South Dakota 57709
}

Roger S. Schalge

Sofregaz US Inc.

200 WestLake Park Boulevard

Suite 1100

Houston, Texas 77079

Hugh D. Kaiser

IDS Engineering

600 Century Plaza Drive

Building No. 140

Houston, Texas 77073

prepared for

United States Department of Energy

National Energy Technology Laboratory

626 Cochrans Mill Road

Pittsburgh, Pennsylvania 15236

November 2001 


\begin{abstract}
This report provides the results of a two-phase study that examines the economic and technical feasibility of converting a conventional natural gas storage facility in bedded salt into a refrigerated natural gas storage facility for the purpose of increasing the working gas capacity of the facility. The conceptual design used to evaluate this conversion is based on the design that was developed for the planned Avoca facility in Steuben County, New York. By decreasing the cavern storage temperature from $43^{\circ} \mathrm{C}$ to $-29^{\circ} \mathrm{C}\left(110^{\circ} \mathrm{F}\right.$ to $\left.-20^{\circ} \mathrm{F}\right)$, the working gas capacity ${ }^{1}$ of the facility can be increased by about 70 percent (from $1.2 \times 10^{8} \mathrm{Nm}^{3}$ or 4.4 billion cubic feet (Bcf) to $2.0 \times 10^{8} \mathrm{Nm}^{3}$ or $7.5 \mathrm{Bcf}$ ) while maintaining the original design minimum and maximum cavern pressures. In Phase I of the study, laboratory tests were conducted to determine the thermal conductivity of salt at low temperatures. Finite element heat transfer calculations were then made to determine the refrigeration loads required to maintain the caverns at a temperature of $-29^{\circ} \mathrm{C}\left(-20^{\circ} \mathrm{F}\right)$. This was followed by a preliminary equipment design and a cost analysis for the converted facility. The capital cost of additional equipment and its installation required for refrigerated storage is estimated to be about $\$ 13,310,000$ or $\$ 160$ per thousand $\mathrm{Nm}^{3}$ (\$4.29 per thousand cubic feet (Mcf)) of additional working gas capacity. The additional operating costs include maintenance refrigeration costs to maintain the cavern at $-29^{\circ} \mathrm{C}$ $\left(-20^{\circ} \mathrm{F}\right)$ and processing costs to condition the gas during injection and withdrawal. The maintenance refrigeration cost, based on the current energy cost of about $\$ 13.65$ per megawatthour (MW-hr) ( $\$ 4$ per million British thermal units (MMBtu)), is expected to be about $\$ 316,000$ after the first year and to decrease as the rock surrounding the cavern is cooled. After 10 years, the cost of maintenance refrigeration based on the $\$ 13.65$ per $\mathrm{MW}-\mathrm{hr}$ ( $\$ 4$ per MMBtu) energy cost is estimated to be $\$ 132,000$. The gas processing costs are estimated to be $\$ 2.05$ per thousand $\mathrm{Nm}^{3}$ ( $\$ 0.055$ per $\mathrm{Mcf}$ ) of gas injected into and withdrawn from the facility based on the $\$ 13.65$ per MW-hr (\$4 per MMBtu) energy cost. In Phase II of the study, laboratory tests were conducted to determine mechanical properties of salt at low temperature. This was followed by thermomechanical finite element simulations to evaluate the structural stability of the cavern during refrigerated storage. The high thermal expansion coefficient of salt is expected to result in tensile stresses leading to tensile failure in the roof, walls, and floor of the cavern as it is cooled. Tensile fracturing of the cavern roof may result in loss of containment of the gas and/or loss of integrity of the casing shoe, deeming the conversion of this facility not technically feasible.
\end{abstract}

\footnotetext{
${ }_{1}^{1}$ Natural gas quantities are expressed in terms of normal cubic meters $\left(\mathrm{N} \mathrm{m}^{3}\right)$ with reference conditions of $0^{\circ} \mathrm{C}$ and $0.101325 \mathrm{MPa}$ and in terms of standard cubic feet (cf) with reference conditions of $60^{\circ} \mathrm{F}$ and $14.73 \mathrm{psi}$. Gas-related computations were made assuming a gas composition of 100 percent methane.
} 


\section{TABLE OF CONTENTS}

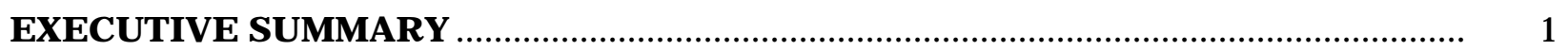

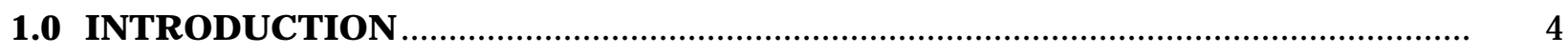

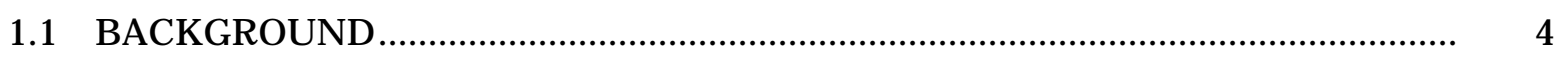

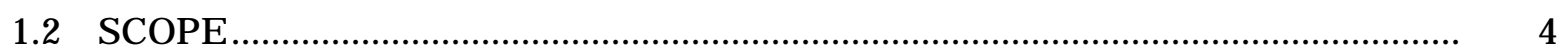

1.3 REPORT ORGANIZATION ....................................................................... 5

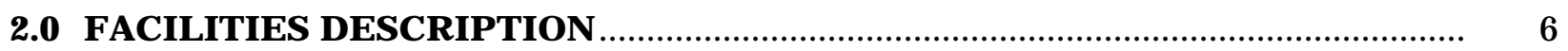

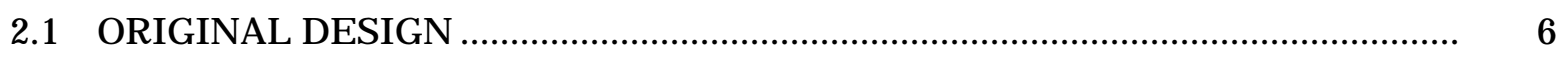

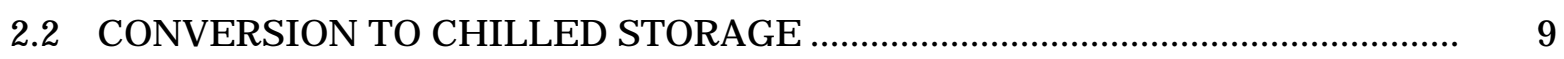

3.0 ECONOMIC FEASIBILITY ............................................................................... 10

3.1 DETERMINATION OF SALT THERMAL CONDUCTIVITY AT LOW TEMPERATURES

3.1.1 Test Procedures and Equipment ........................................................... 10

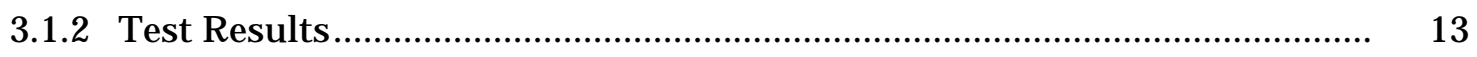

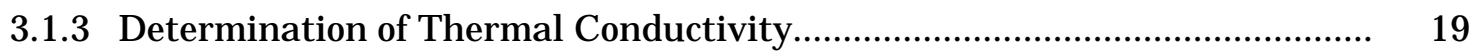

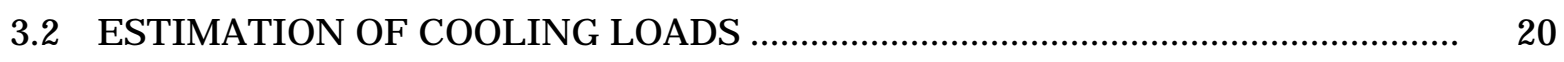

3.2.1 Finite Element Model ....................................................................... 20

3.2.2 Overall Cooling Load ........................................................................... 22

3.2.3 Thermal Effects of Gas I njection and Gas Withdrawal .............................. 23

3.3 PRELIMINARY DESIGN AND COST ANALYSIS .......................................... 27

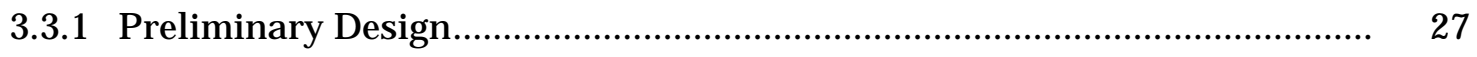

3.3.1.1 Measurement ............................................................................ 27

3.3.1.2 Compression ............................................................................... 28

3.3.1.3 Dehydration .................................................................... 28

3.3.1.4 Refrigeration ......................................................................... 29

3.3.1.5 Gas Heating ......................................................................... 31

3.3.1.6 Emergency Shutdown System................................................ 31

3.3.1.7 Facility Layout...................................................................... 31

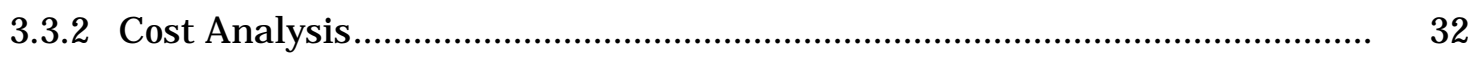

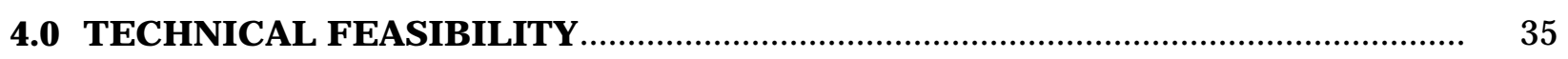

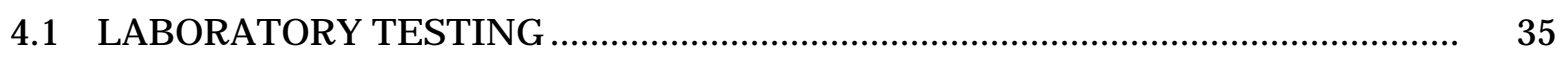

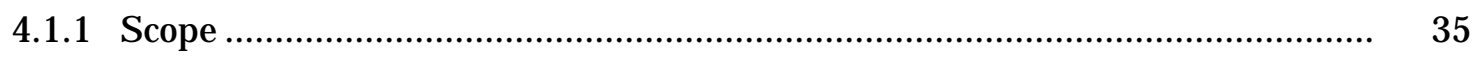

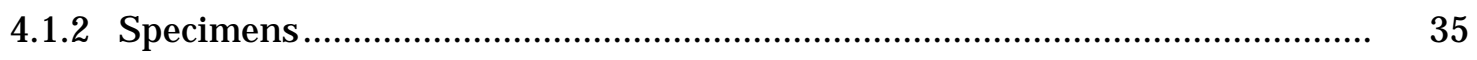

4.1.3 Equipment and Procedures................................................................ 36 


\section{TABLE OF CONTENTS \\ (Continued)}

4.1.3.1 Quasi-Static Triaxial Compression Testing................................... 36

4.1.3.2 Constant Stress Creep Testing …………………............................ 38

4.1.3.3 Refrigerated Temperature Considerations ..................................... 40

4.1.4 Results .................................................................................. 42

4.1.4.1 Constant Strain Rate Results ................................................... 42

4.1.4.2 Constant Mean Stress Results ...................................................... 47

4.1.4.3 Creep Test Results ......................................................................... $\quad 47$

4.1.5 Discussion of Laboratory Results ....................................................... 52

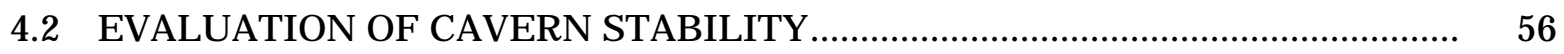

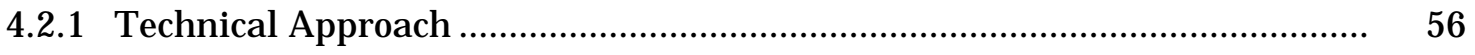

4.2.1.1 Finite Element Program .............................................................. 57

4.2.1.2 Material Properties ................................................................. 57

4.2.1.3 In Situ Conditions ..................................................................... 61

4.2.1.4 Properties of Well Fluids ............................................................. 66

4.2.1.5 Criteria for Evaluating Technical Feasibility .................................. 67

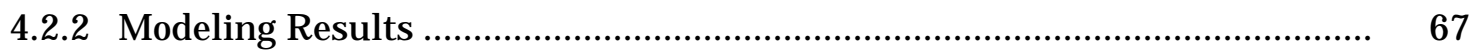

4.2.2.1 Leaching and Dewatering............................................................ $\quad 68$

4.2.2.2 Conversion to Refrigerated Storage............................................... 68

4.2.2.3 Discussion of Results ............................................................... 72

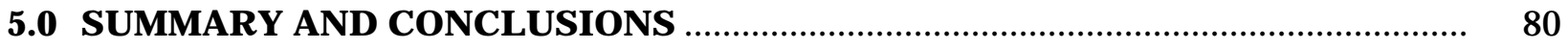

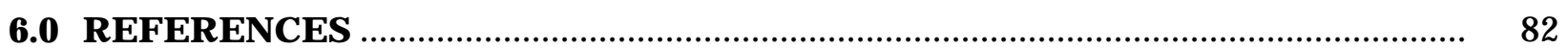

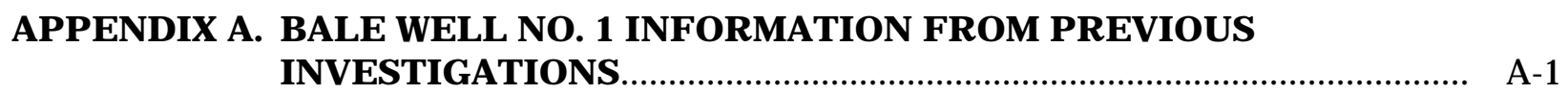

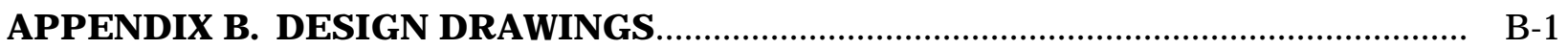




\section{LIST OF TABLES}

TABLE

PAGE

3-1 Thermal Conductivity Test Matrix for Bedded Salt ......................................... 14

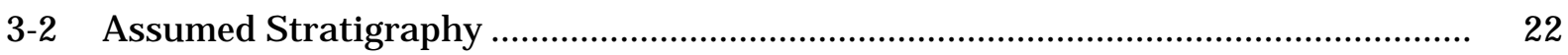

3-3 Thermal Properties for Salt and Shale............................................................. 23

3-4 Additional Equipment and Construction Cost Summary ..................................... 32

3-5 Additional Processing Cost Summary (SI Units)................................................ 33

3-6 Additional Processing Cost Summary (U.S. Industry Units) ................................. 34

3-7 Maintenance Refrigeration Cost Summary........................................................ 34

4-1 Summary of Constant Strain Rate Test Results................................................ 47

4-2 Estimates of the Munson-Dawson Creep Parameters for Bale Well No. 1 Salt....... 62

A-1 Elastic Properties Determined From Quasi-Static Compression Testing of Bale

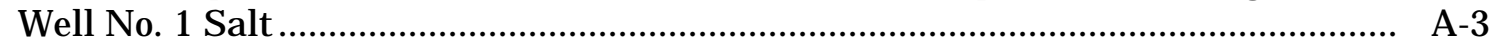

A-2 Elastic Properties Determined From Quasi-Static Compression Testing of Bale

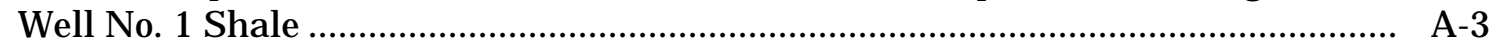

A-3 Results of Indirect Tension Tests on Bale Well No. 1 Salt..................................... A-4

A-4 Results of Indirect Tension Tests on Bale Well No. 1 Shale.................................... A-5

A-5 Results of Unconfined and Confined Quasi-Static Compression Tests on Bale Well

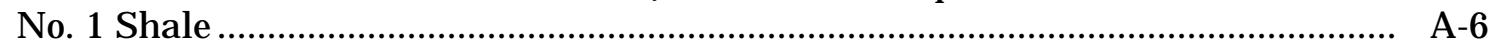

A-6 Strength and Dilation Stress Measures for Bale Well No. 1 Salt........................... A-9

A-7 Creep Test Matrix for Bale Well No. 1 Salt ............................................................... A-11

A-8 Estimates of Munson-Dawson Creep Parameters for Cayuta Salt .......................... A-16 


\section{LIST OF FIGURES}

FIGURE

PAGE

2-1 Logs of Syracuse F ormation From No. 1 Hubbard Well at Avoca .......................... 7

2-2 Cavern Design Selected for the Avoca Natural Gas Storage Facility ...................... 8

3-1 Plan View of the Thermocouple Locations in the Salt Specimen ............................ 11

3-2 Side View of the Thermocouple Locations in the Salt Specimen.......................... 12

3-3 Temperature Versus Time With 100-Watt Loading for Test TC1........................ 15

3-4 Temperature Versus Time With 100-Watt Loading for Test TC2 ........................ 16

3-5 Temperature Versus Time With 100-Watt Loading for Test TC3........................ 17

3-6 Temperature Versus Time With 100-Watt Loading for Test TC4......................... 18

3-7 Finite Element Mesh for Avoca Cavern.............................................................. 21

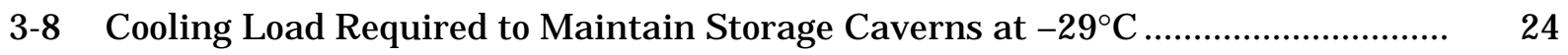

3-9 Temperature Contours Around Cavern at Various Times.................................... 25

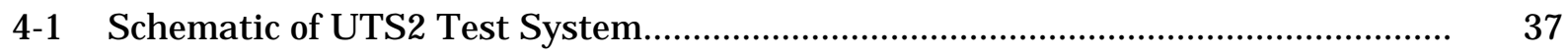

4-2 Schematic of Creep Test System......................................................................

4-3 Typical System Temperature Response for the UTS2 Test System..................... 41

4-4 Stress-Strain Results for a Constant Strain Rate Test on Salt Specimen BAL 1/83/1............................................................................................... 43

4-5 Axial Stress Difference as a Function of Strain for a Constant Strain Rate Test on Specimen BAL 1/87-3/1....

4-6 Axial Stress Difference as a Function of Strain for a Constant Strain Rate Test on Specimen BAL 1/89/3 ........................................................................... 45

4-7 Comparison of Constant Strain Rate Results at Two Temperatures..................... 46

4-8 Constant Mean Stress Test at 6.9 MPa on Specimen BAL 1/88/1......................... 48

4-9 Constant Mean Stress Test at 10.3 MPa on Specimen BAL 1/83/4....................... 49

4-10 Constant Mean Stress Test at 13.8 MPa on Specimen BAL 1/80/2-1 .................... 50

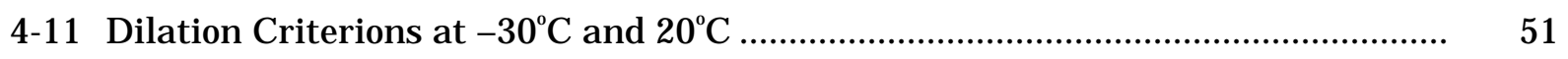

4-12 Total Axial Strain as a Function of Time for Creep Tests at $0^{\circ} \mathrm{C}$.......................... 53

4-13 Total Axial Strain as a Function of Time for Creep Tests at $-20^{\circ} \mathrm{C} \ldots \ldots \ldots \ldots \ldots \ldots \ldots . . . . . . . . . . . . .54$

4-14 Comparison of Creep Response at Different Temperatures ................................. 55

4-15 Measured and Predicted Creep Strain for Creep Tests Conducted at $40^{\circ} \mathrm{C} \ldots \ldots \ldots . . . .63$

4-16 Measured and Predicted Creep Strain for Creep Tests Conducted at $0^{\circ} \mathrm{C} \ldots \ldots . . . . . . .64$

4-17 Measured and Predicted Creep Strain for Creep Tests Conducted at $-20^{\circ} \mathrm{C} \ldots \ldots . . . . \quad 65$ 


\section{LIST OF FIGURES \\ (Continued)}

FIGURE

PAGE

4-18 Contours of Least-Compressive Principal Stress for a 30-Day Conversion to Refrigerated Storage. 69

4-19 Contours of Temperature for a 30-Day Conversion to Refrigerated Storage......... 70

4-20 Contours of Effective Stress for a 30-Day Conversion to Refrigerated Storage......

4-21 Contours of Factors of Safety With Respect to Salt Dilation for a 30-Day Conversion to Refrigerated Storage.

4-22 Contours of Factors of Safety With Respect to Shear Failure in the Shale for a 30-Day Conversion to Refrigerated Storage......

4-23 Contours of Least-Compressive Principal Stress for a 1-Year Conversion to Refrigerated Storage.

4-24 Contours of Temperature for a 1-Year Conversion to Refrigerated Storage.....

4-25 Contours of Factors of Safety With Respect to Salt Dilation for a 1-Year Conversion to Refrigerated Storage.

4-26 Contours of Factors of Safety With Respect to Shear Failure in the Shale for a 1-Year Conversion to Refrigerated Storage.....

A-1 Strength of Bale Well No. 1 Shale.

A-2 Strength and Dilation of Bale Well No. 1 Salt

A-3 Axial, Lateral, and Volumetric Creep Strains for Bale Well No. 1 Salt Specimen I.D. BAL $1 / 87 / 1$

A-4 Axial, Lateral, and Volumetric Creep Strains for Bale Well No. 1 Salt Specimen I.D. BAL $1 / 87 / 2$.

A-5 Axial, Lateral, and Volumetric Creep Strains for Bale Well No. 1 Salt Specimen I.D. BAL $1 / 89 / 1$

A-6 Measured and Predicted Axial Strains for Stage 1 of the Creep Tests on Salt From Bale Well No. 1 


\section{EXECUTIVE SUMMARY}

The concept of chilling gas to dramatically increase the working gas capacity of a given storage volume may be applicable to planned or existing bedded salt storage caverns. Facilities in bedded salt are of particular interest for expansion by chilled gas storage because the salt stock and brine disposal capacity at these facilities are often limited, making expansion by mining of additional caverns uneconomical. A recent study by PB-KBB, Inc. determined that it may be feasible to store chilled natural gas in a mined hard-rock facility. However, the cooling loads required to maintain the stored gas at low temperatures are anticipated to be substantially different in salt storage caverns because the thermal conductivity of salt is typically significantly higher than the thermal conductivities typical of hard rocks such as granite. Also, the thermal expansion coefficient of salt is much higher than most hard rocks, which will result in larger thermally induced stresses and strains.

This report describes the results of a two-phase study to evaluate the economic and technical feasibility of converting typical natural gas storage caverns in bedded salt deposits to refrigerated natural gas storage. Phase I included laboratory testing to determine the thermal conductivity of salt at low temperatures, numerical modeling to estimate cooling loads, a cost analysis, and the development of a preliminary design. In Phase II, laboratory testing was performed to determine physical properties of salt at low temperatures followed by numerical modeling to evaluate cavern stability during refrigerated storage.

The conceptual design used to evaluate chilled gas conversion of a natural gas storage facility in bedded salt is based on the design that was developed for the Avoca facility in Steuben County, New York. Although construction of the Avoca facility has been postponed indefinitely, the cavern design was sufficiently mature to provide confidence in its feasibility. In addition, the design appears to be typical of storage caverns that are being, and will be, devel oped in the salt beds of the Appalachian and Michigan Basins in the northeastern United States.

The Avoca design includes six caverns in the D unit of the Syracuse Formation of the upper Silurian Salina Group. The cavern design is an elongated "peanut-shaped" design developed from two wells connected by horizontal drilling at a depth of about 1,160 meters (3,800 feet). The caverns are designed to have a height of 30.5 meters (100 feet), a long dimension of 244 meters (800 feet), and a roof span of 61 meters ( $200 \mathrm{feet})$ in the short dimension. The facility was designed for a total working gas capacity of $1.2 \times 10^{8} \mathrm{Nm}^{3}$ (4.4 billion cubic feet $(\mathrm{BCf}))$ at an ambient temperature of approximately $43^{\circ} \mathrm{C}\left(110^{\circ} \mathrm{F}\right)$ and operating pressures

\footnotetext{
Natural gas quantities are expressed in terms of normal cubic meters $\left(\mathrm{Nm}^{3}\right)$ with reference conditions of $0^{\circ} \mathrm{C}$ and $0.101325 \mathrm{MPa}$ and in terms of standard cubic feet (cf) with reference conditions of $60^{\circ} \mathrm{F}$ and $14.73 \mathrm{psi}$. Gas-related computations were made assuming a gas composition of 100 percent methane.
} 
ranging between 5.24 and $19.65 \mathrm{MPa}$ (760 and 2,850 psi) at the casing shoe. The total cavern volume required is about $77,000 \mathrm{~m}^{3}\left(2.72 \mathrm{million} \mathrm{ft}^{3}\right)$. The design gas injection and withdrawal rates for the facility are $5.9 \times 10^{6}$ and $1.18 \times 10^{7} \mathrm{~N} \mathrm{~m}^{3} /$ day (220 and 440 million cubic feet per day (MMcfd)), respectively.

Conversion of the facility to a chilled gas storage facility would substantially increase working gas of the facility. Assuming an original cavern temperature of $43^{\circ} \mathrm{C}\left(110^{\circ} \mathrm{F}\right)$ and conversion to a cavern temperature of $-29^{\circ} \mathrm{C}\left(-20^{\circ} \mathrm{F}\right)$, the working gas at the facility can be increased by about 70 percent from $1.2 \times 10^{8}$ to $2.0 \times 10^{8} \mathrm{Nm}^{3}$ (4.4 to $7.5 \mathrm{Bcf}$ ). This also assumes that minimum and maximum gas pressures remain unchanged, at 5.24 and $19.65 \mathrm{MPa}$ (760 and 2,850 psi), respectively, at the casing shoe. The original maximum design gas flow rates for injection $\left(5.8 \times 10^{6} \mathrm{Nm}^{3} /\right.$ day or $\left.220 \mathrm{MMcfd}\right)$ and withdrawal $\left(1.18 \times 10^{7} \mathrm{Nm}^{3} /\right.$ day or $\left.440 \mathrm{MMcfd}\right)$ are also assumed to remain unchanged in the converted facility. Thus the time to fill the caverns from minimum to maximum gas pressure will increase from 20 days to 34 days, and the minimum time to withdraw the gas from maximum to minimum pressure will increase from 10 days to 17 days.

Because of the large difference between the temperature of the stored natural gas $\left(-29^{\circ} \mathrm{C}\right.$ or $-20^{\circ} \mathrm{F}$ ) and that of the surrounding rock $\left(43^{\circ} \mathrm{C}\right.$ or $\left.110^{\circ} \mathrm{F}\right)$, a large amount of heat will be transferred from the rock to the stored gas. This heat gain must be counteracted with refrigeration to maintain a cavern temperature of $-29^{\circ} \mathrm{C}\left(-20^{\circ} \mathrm{F}\right)$. Laboratory testing was performed to determine the thermal conductivity of salt at low temperatures. Finite element heat transfer calculations were then made to determine the cooling load to maintain the cavern at $-29^{\circ} \mathrm{C}$ $\left(-20^{\circ} \mathrm{F}\right)$. The cooling load after 1 year of storage operations is estimated to be about 4.1 megawatts (MW) (14 million British thermal units (MMBtu)/hour). After 10 years of storage operations, the estimated cooling load is reduced to about 1.8 MW (6 MMBtu/hour). The J ouleThompson effect during gas compression results in significant heat gains during gas injection periods and significant heat losses due to gas expansion during gas withdrawal periods. Although these two effects will generally cancel each other out, resulting in no net effect on total cooling load, they will need to be counteracted to maintain a constant cavern temperature.

The total equipment and construction costs for converting the facility from conventional storage to refrigerated storage is estimated to be $\$ 13,310,000$ or $\$ 160$ per thousand $\mathrm{Nm}^{3}$ ( $\$ 4.29$ per thousand cubic feet (Mcf)) of additional working gas capacity. This cost assumes the original design maximum injection and withdrawal rates of $5.9 \times 10^{6}$ and $1.18 \times 10^{7} \mathrm{Nm}^{3} /$ day (220 and $440 \mathrm{MMcfd}$ ), respectively. This increases the minimum pressure to maximum pressure injection time from 20 days to 34 days and the maximum pressure to minimum pressure withdrawal time from 10 days to 17 days. Increasing flow rates would require additional equipment and processing costs. 
The estimated operational costs (those in addition to conventional operation costs) include a maintenance refrigeration cost and additional processing (refrigeration, dehydration, and heating) cost associated with the throughput of gas. The maintenance refrigeration cost based on an energy cost of $\$ 13.65$ per MW-hr ( $\$ 4$ per MMBtu) is estimated to be $\$ 316,000$ per year after the first year and will decrease as the rock surrounding the caverns is cooled. After 10 years, the maintenance cost is estimated to decrease to $\$ 132,000$ per year based on the same energy cost. The throughput operational costs of the facility were estimated per thousand $\mathrm{Nm}^{3}$ of gas injected and withdrawn from the facility. The additional processing costs for refrigerated storage per thousand $\mathrm{Nm}^{3}$ of gas injected and withdrawn is estimated to be $\$ 2.05$ ( $\$ 0.055$ per Mcf) based on an energy cost of $\$ 13.65$ per MW-hr ( $\$ 4$ per MMBtu).

Based on the results of the structural stability study, the conversion of this facility is not technically feasible. Upon conversion to refrigerated storage, tensile fractures are predicted to develop in the cavern roof, walls, and floor. Tensile fracturing of the cavern roof may result in loss of containment of the gas and/or loss of integrity of the casing shoe, deeming the conversion of this facility not technically feasible. Also, because of the large difference in thermal expansion coefficients between the salt and the shale, it is likely that the contact between the roof salt and shale above it will be broken, resulting in collapse of the roof salt.

Although the conversion of the facility examined in this study does not appear to be technically feasible, there may be cases where chilled gas storage in bedded salt is feasible. For example, if a site has a competent nonsalt rock overlying salt that is sufficiently tight to contain gas, it might be used as the cavern roof. 


\subsection{INTRODUCTION}

\subsection{BACKGROUND}

The concept of chilling gas to dramatically increase the working gas capacity of a given storage volume may be applicable to planned or existing bedded salt storage caverns. Facilities in bedded salt are of particular interest for expansion by chilled gas storage because the salt stock and brine disposal capacity at these facilities are often limited, making expansion by mining of additional caverns uneconomical. A recent study by PB-KBB, Inc. [1998] determined that it may be feasible to store chilled natural gas in a mined hard-rock facility. However, the cooling loads required to maintain the stored gas at low temperatures are anticipated to be substantially different in salt storage caverns because the thermal conductivity of salt is typically significantly higher than the thermal conductivities typical of hard rocks such as granite. Also, the thermal expansion coefficient of salt is much higher than most hard rocks, which will result in larger thermally induced stresses and strains.

\subsection{SCOPE}

This report describes the results of a two-phase study to evaluate the feasibility of storing chilled natural gas in storage caverns in bedded salt deposits. The objective of Phase I was to assess the economic feasibility of increasing the working gas capacity in a bedded salt storage facility by chilling the gas to $-29^{\circ} \mathrm{C}\left(-20^{\circ} \mathrm{F}\right)$. In Phase II, the technical feasibility of converting the facility to refriger ated storage was investigated.

The Phase I study included three tasks. In the first task, laboratory testing was performed to determine the thermal conductivity as a function of temperature for bedded salt at temperatures down to $-29^{\circ} \mathrm{C}\left(-20^{\circ} \mathrm{F}\right)$. The thermal conductivity information from the laboratory study was used in the second task to evaluate the cooling loads required to maintain a gas temperature of $-29^{\circ} \mathrm{C}\left(-20^{\circ} \mathrm{F}\right)$. In the third task, a preliminary design and cost analysis were devel oped for converting the facility from standard gas storage to chilled gas storage.

The Phase II study included two tasks. In the first task, laboratory testing was performed to determine the elastic and creep properties of bedded salt at low temperatures. These properties were then used in the second task to perform a geomechanical analysis to evaluate the structural stability of the caverns during chilled gas storage. 


\subsection{REPORT ORGANIZATION}

This report contains six chapters and two appendices. Chapter 2.0 describes the facility used to evaluate the feasibility of chilled natural gas storage in bedded salt. The results of the economic feasibility study are given in Chapter 3.0. Chapter 4.0 presents the results of the technical feasibility study. Chapter 5.0 provides a summary of the two-phase study and the conclusions drawn from it. A list of cited references is given in Chapter 6.0. Appendix A describes previous laboratory testing performed on bedded salt and shale performed at in situ temperatures. Drawings of the preliminary design are contained in Appendix B. 


\subsection{FACILITIES DESCRIPTION}

The conceptual design used to evaluate chilled gas conversion of a natural gas storage facility in bedded salt is based on the design that was developed for the Avoca facility in Steuben County, New York. Although construction of the Avoca facility has been postponed indefinitely, the cavern design was sufficiently mature to provide confidence in its feasibility. Blue Dolphin Energy Company and WBI Southern Inc. recently purchased the Avoca project and are currently considering resuming development. In addition, the design appears to be typical of storage caverns that are being, and will be, developed in the salt beds of the Appalachian and Michigan Basins in the northeastern United States.

\subsection{ORIGINAL DESIGN}

Morrill [1996] provides a description of the Avoca design that is detailed enough for the purposes of the chilled gas feasibility study. The Avoca design includes six caverns in the D unit of the Syracuse Formation of the upper Silurian Salina Group. The facility was designed for a total working gas capacity ${ }^{2}$ of $1.2 \times 10^{8} \mathrm{Nm}^{3}$ (4.4 Bcf) at an ambient temperature of approximately $43^{\circ} \mathrm{C}\left(110^{\circ} \mathrm{F}\right)$ and operating pressures ranging between 5.24 and $19.65 \mathrm{MPa}$ (760 and 2,850 psi) at the casing shoe. The total cavern volume required is about $77,000 \mathrm{~m}^{3}$ $\left(2.72\right.$ million $\left.\mathrm{ft}^{3}\right)$. The design gas injection and withdrawal rates for the facility are $5.9 \times 10^{6}$ and $1.18 \times 10^{7} \mathrm{~N} \mathrm{~m}^{3} /$ day (220 and $440 \mathrm{MMcfd}$ ), respectively. Figure 2-1 shows the logs of the Syracuse F ormation from the No. 1 Hubbard Well at the Avoca site along with the cross section of the cavern design located in the $\mathrm{D}$ salt bed.

The final design for the Avoca caverns was an elongated "peanut-shaped" design developed from two wells connected by horizontal drilling, as shown in Figure 2-2. The design caverns have a height of 30.5 meters (100 feet), a long dimension of 244 meters (800 feet), and a roof span of 61 meters (200 feet) in the short dimension. The facility would require six caverns, each with a volume of $12,800 \mathrm{~m}^{3}\left(450,000 \mathrm{ft}^{3}\right)$. Geomechanical modeling predicted that the minimum factor of safety in the overlying shale at the minimum operating pressure of 5.24 MPa (760 psi) would be approximately 1.5 for roof spans between 60 and 76 meters (200 and 250 feet). The modeling also predicted that the length dimension in the elongated, multiple-well design would not be a critical design component, provided the cavern is oriented properly with respect to the principal directions of the in situ stresses.

\footnotetext{
${ }^{2} \mathrm{~N}$ atural gas quantities are expressed in terms of normal cubic meters $\left(\mathrm{N} \mathrm{m}^{3}\right)$ with reference conditions of $0^{\circ} \mathrm{C}$ and $0.101325 \mathrm{MPa}$ and in terms of standard cubic feet (cf) with reference conditions of $60^{\circ} \mathrm{F}$ and $14.73 \mathrm{psi}$. Gas-related computations were made assuming a gas composition of 100 percent methane.
} 


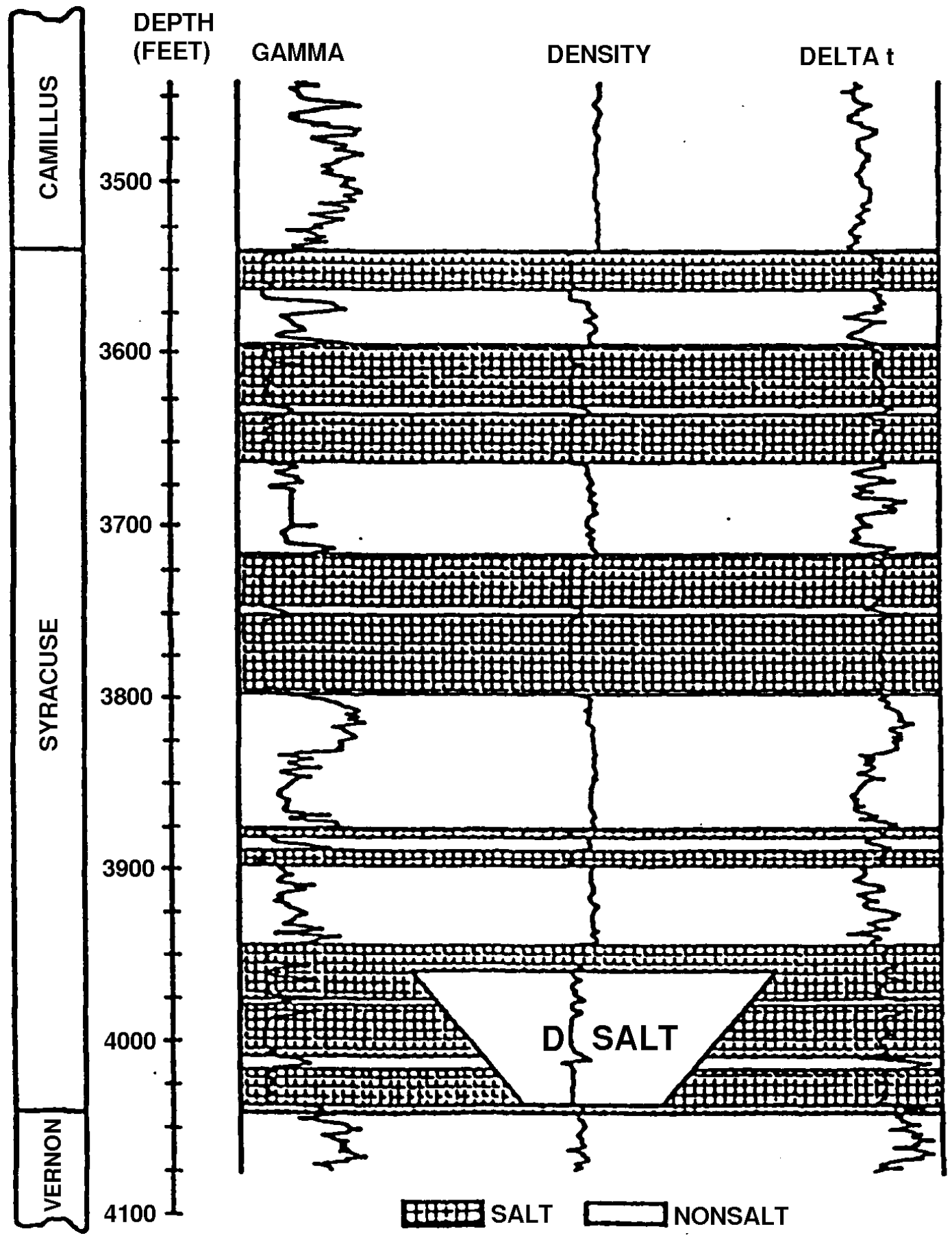

Figure 2-1. Logs of Syracuse Formation From No. 1 Hubbard Well at Avoca [Morrill, 1996]. 

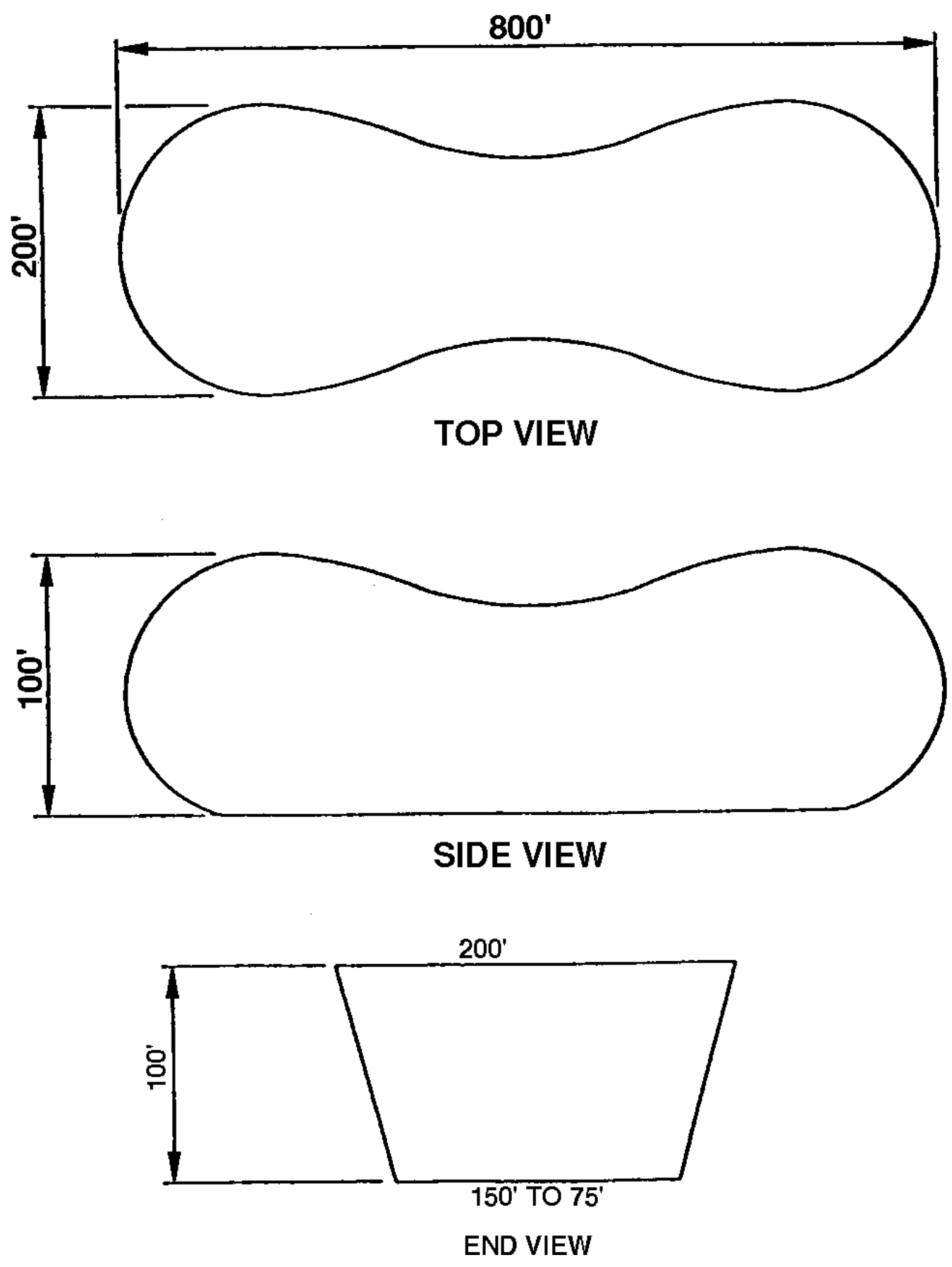

Figure 2-2. Cavern Design Selected for the Avoca Natural Gas Storage Facility [Morrill, 1996]. 


\subsection{CONVERSION TO CHILLED STORAGE}

Conversion of the facility described above to a chilled gas storage facility will substantially increase working gas of the facility. Assuming an original cavern temperature of $43^{\circ} \mathrm{C}\left(110^{\circ} \mathrm{F}\right)$ and conversion to a cavern temperature of $-29^{\circ} \mathrm{C}\left(-20^{\circ} \mathrm{F}\right)$, the working gas at the facility can be increased by about 70 percent from $1.2 \times 10^{8}$ to $2.0 \times 10^{8} \mathrm{Nm}^{3}$ (4.4 to $7.5 \mathrm{Bcf}$ ). This also assumes that minimum and maximum gas pressures remain unchanged at 5.24 and $19.65 \mathrm{MPa}$ (760 and $2,850 \mathrm{psi})$, respectively. The original maximum design gas flow rates for injection $\left(5.9 \times 10^{6}\right.$ $\mathrm{Nm}^{3} /$ day or $\left.220 \mathrm{MMcfd}\right)$ and withdrawal $\left(1.18 \times 10^{7} \mathrm{Nm}^{3} /\right.$ day or $\left.440 \mathrm{M} \mathrm{Mcfd}\right)$ are also assumed to remain unchanged in the converted facility. Thus the time to fill the caverns from minimum to maximum gas pressure will increase from 20 days to 34 days, and the minimum time to withdraw the gas from maximum to minimum pressure will increase from 10 days to 17 days. 


\subsection{ECONOMIC FEASIBILITY}

In order to determine the economic feasibility of converting a conventional natural gas storage facility in bedded salt to refrigerated natural gas storage, costs additional to conventional storage costs were estimated. Laboratory tests were conducted to determine the thermal conductivity of salt at low temperatures. Using the information from the laboratory testing, thermal finite element simulations were conducted to evaluate the cooling load required to refrigerate the gas. This was followed by developing a preliminary design and performing a cost analysis of the converted facility.

\subsection{DETERMINATION OF SALT THERMAL CONDUCTIVITY AT LOW TEMPERATURES}

Laboratory tests were conducted to determine the thermal conductivity of natural rock salt and its dependence on temperature at the low temperatures expected at a chilled natural gas facility. Knowledge of the thermal conductivity of salt at low temperatures is required to provide an accurate estimate of the cooling loads for refrigerated natural gas storage. The approach used was to perform a series of laboratory-scale thermal tests on a large, cylindrical specimen of natural rock salt obtained from the Michigan Basin salt bed formation.

\subsubsection{Test Procedures and Equipment}

The laboratory study used the technique of imposing a radial heat flow through a cylindrical specimen of salt instrumented with thermocouples and fitted with a central heat source, as shown in Figures 3-1 and 3-2. The heat source was an electrical resistance rod heater placed in a hole drilled along the central axis of the specimen. The rod heater dimensions matched the length and diameter of the central hole to ensure uniform heating over the interior surface of the salt specimen. The amperage and voltage supplied to the resistive heater were controlled and measured during the test to maintain a constant power input to the heater. Thermocouples were inserted in holes drilled parallel to the specimen axis to a depth of half the specimen thickness. The thermocouple holes were located at known radii from the center, and redundant locations were used to allow for thermocouple failures and to check for uniform circumferential heating of the specimen during a test. Thermocouples were also located on the surface of the specimen. Two thermocouples were pasted onto the exterior surface of the specimen at the specimen midheight. Two more thermocouples were pasted on the top and bottom faces of the specimen at a point half way along the radius of the specimen. Another thermocouple was suspended in the air surrounding the specimen. All of the thermocouples were Type T, which are appropriate for the range of temperatures of interest in this study. 


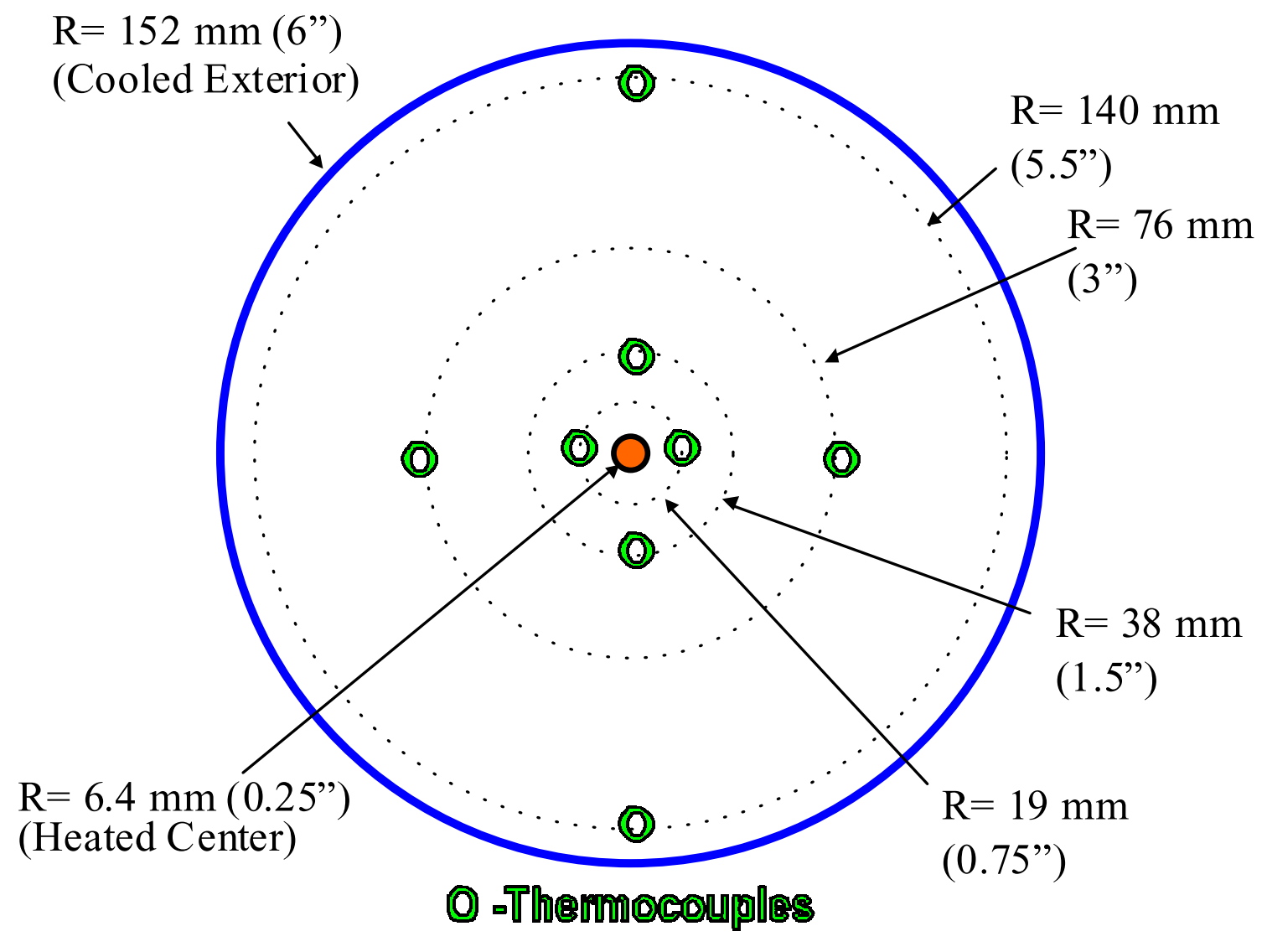

Figure 3-1. Plan View of the Thermocouple Locations in the Salt Specimen. 


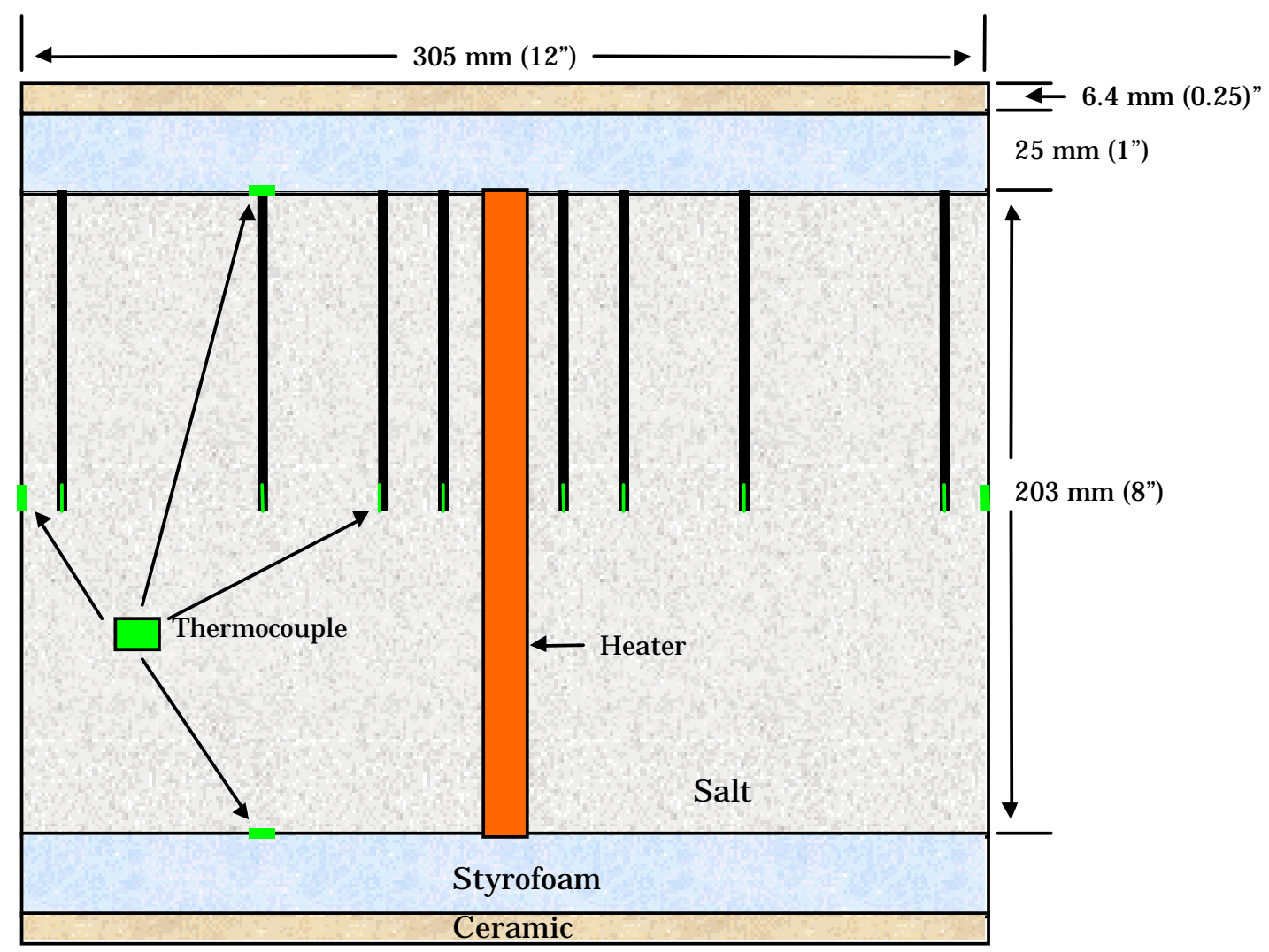

Figure 3-2. Side View of the Thermocouple Locations in the Salt Specimen. 
The instrumented specimen was placed in an insulated environmental chamber. Once inside the chamber, the top and bottom of the specimen were insulated with Styrofoam and ceramic plates to promote radial heat flow during a test. The chamber had ports located in its walls to allow the entry of cabling needed to power the resistance heater and connect the thermocouples to a data acquisition system. The data acquisition system was connected to a personal computer that provided an operator interface for data monitoring and a clock for timing the logging of the measured thermocouple outputs. With the internal heater turned off, a test began by first bringing the specimen to a uniform, initial temperature inside the environmental chamber. The data acquisition was then begun and the heater power was applied. With constant power input to the heater, the temperature through the specimen began to increase, first increasing near the central bore of the specimen and eventually propagating outward to the exterior of the specimen. The temperature-versus-time data for each thermocouple were logged to disk for later data analysis.

The initial testing demonstrated that the environmental chamber cooling system $\left(\mathrm{CO}_{2}\right.$ gas) did not have sufficient capacity to chill the large salt specimen in a reasonable amount of time. For the tests to be performed at or below freezing, dry ice $\left(\mathrm{CO}_{2}\right.$ pellets) was placed inside the chamber to bring the specimen to the desired initial temperature. After the initial temperature was established, the dry ice was removed and the $\mathrm{CO}_{2}$ gas cooling system was relied upon to maintain a constant air temperature. However, the air temperature began to increase very quickly after the removal of the dry ice because there was still significant heat gain through the environmental chamber walls and access ports. As a result, the configuration of the environmental chamber was changed to add additional insulation to the chamber walls and plug the chamber access ports as completely as possible. After eliminating these sources of heat gain, the $\mathrm{CO}_{2}$ gas cooling system could then maintain the cold initial temperatures for an extended period of time. During production testing with the 100-watt internal resistance heater, the $\mathrm{CO}_{2}$ gas cooling system was able to maintain a constant air temperature for about 15 minutes and then the air temperature would begin to increase a few degrees as the heat load began to exceed the cooling system capacity.

\subsubsection{Test Results}

Four production tests were performed on the instrumented sample of salt. The tests are identified as TC1, TC2, TC3, and TC4 in Table 3-1 which lists the conditions for each test. The results of each test are shown graphically in Figures 3-3, 3-4, 3-5, and 3-6 for the tests identified as TC1, TC2, TC3, and TC4, respectively.

Each test result exhibits the same general behavior. When power is applied to the internal resistance heater, the innermost thermocouples respond almost immediately and continue to rise throughout the test until the internal heater is turned off. The internal heater was turned off when the innermost thermocouples indicated a temperature rise of about $40^{\circ} \mathrm{C}\left(72^{\circ} \mathrm{F}\right)$. This limit was established to prevent potential damage to the salt. As expected, the temperature 
increases at larger radii lagged the response seen at smaller radii. The point where the internal heater was turned off is obvious in the plots; the thermocouples exhibit an immediate drop in temperature.

Table 3-1. Thermal Conductivity Test Matrix for Bedded Salt

\begin{tabular}{||c|c|c||}
\hline $\begin{array}{c}\text { Data Set } \\
\text { I.D. }\end{array}$ & $\begin{array}{c}\text { Power Input to } \\
\text { Central Heater } \\
\text { (Watts) }\end{array}$ & $\begin{array}{c}\text { Nominal Initial } \\
\text { Temperature } \\
\text { ('C) }\end{array}$ \\
\hline \hline TC1 & 100 & -20 \\
\hline TC2 & 100 & 0 \\
\hline TC3 & 100 & 20 \\
\hline TC4 & 100 & 45 \\
\hline
\end{tabular}

There are two very important observations that can be made about the results shown in the figures. Both of these observations have a positive impact on the data analysis effort needed to obtain estimates of the thermal conductivity dependence on temperature. The first observation relates to the assumption of symmetric temperatures around the central axis of the specimen. The second observation relates to the assumption of radial heat flow through the specimen during the test.

The first assumption was that the homogeneous salt specimen should exhibit uniform circumferential temperature profiles; that is, for any given radius, the temperature would be the same throughout the specimen. The data indicate that this assumption is valid. There were two diametrically opposed thermocouples located at each of four radii in the specimen. Each pair of thermocouples indicates that the specimen temperatures were uniform at that radius. The exception to this claim is for the two tests performed at initial temperatures above freezing where the $\mathrm{CO}_{2}$ cooling system was not required. This exception does not invalidate the claim, but the exception needs to be explained. The thermocouple pairs at radii of 38 millimeters ( 1.5 inches) and 140 millimeters (5.5 inches) indicate a small difference in temperature while the thermocouple pairs at 19 millimeters (0.75 inch) and 76 millimeters ( 3 inches) indicate no difference in temperature. Referring to Figure 3-1, the thermocouple pairs at 38 millimeters (1.5 inches) and 140 millimeters (5.5 inches) lie along a line parallel to the air flow coming from the fan located at the rear of the environmental chamber, while the thermocouple pairs located at 19 millimeters ( 0.75 inch) and 76 millimeters ( 3 inches) lie along a line perpendicular to the air flow path. The fan forcing the air flow was located inside the environmental chamber and the fan motor generated some heat. This heat source at the rear of the specimen was the cause of the small differences in the thermocouple pairs located parallel to the air flow path. This difference in the thermocouple pairs was not observed for the tests performed at freezing temperatures because the $\mathrm{CO}_{2}$ cooling gas also entered at the rear of the chamber and the cooling action cancelled the fan motor heat source. 


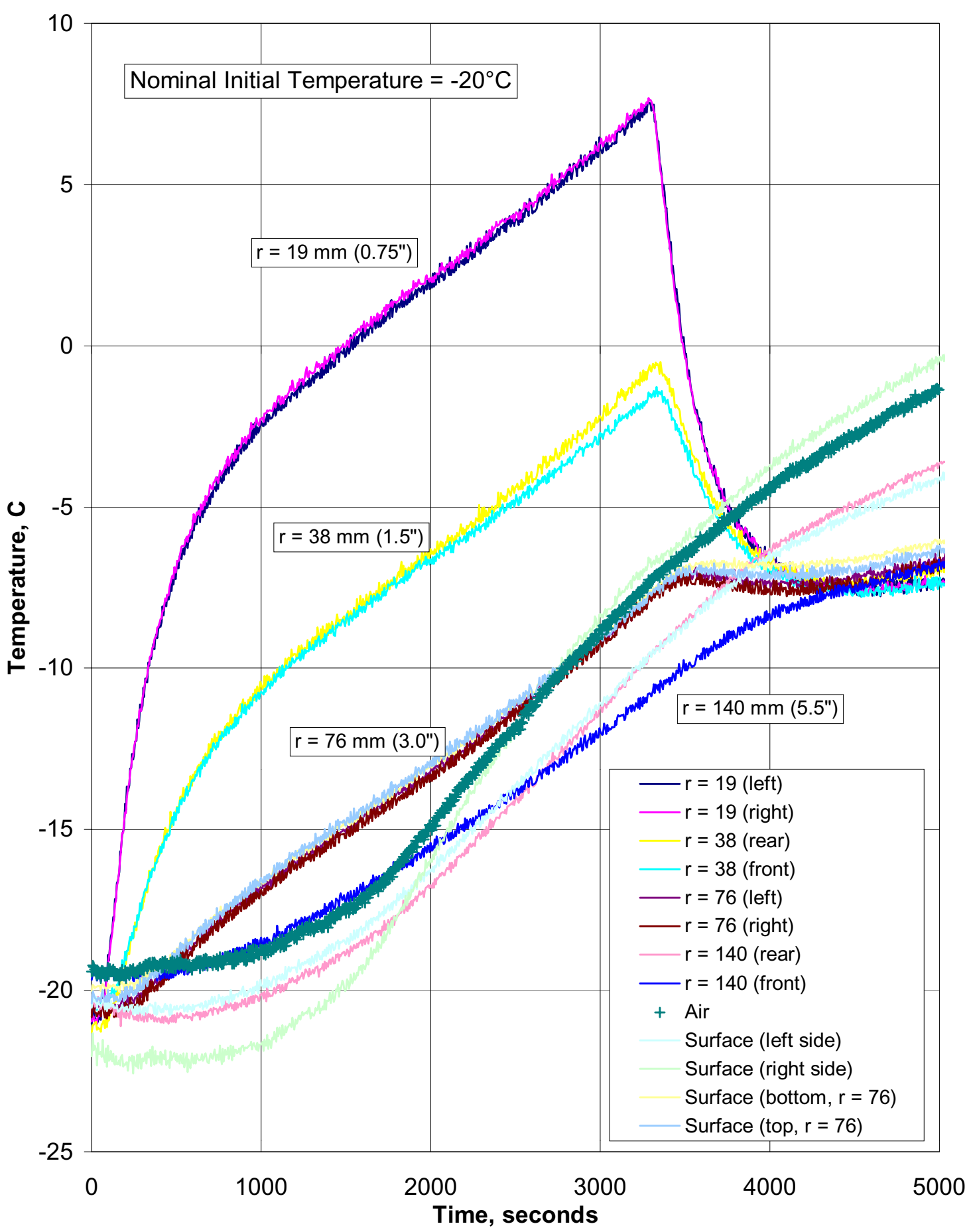

Figure 3-3. Temperature Versus Time With 100-Watt Loading for Test TC1. 


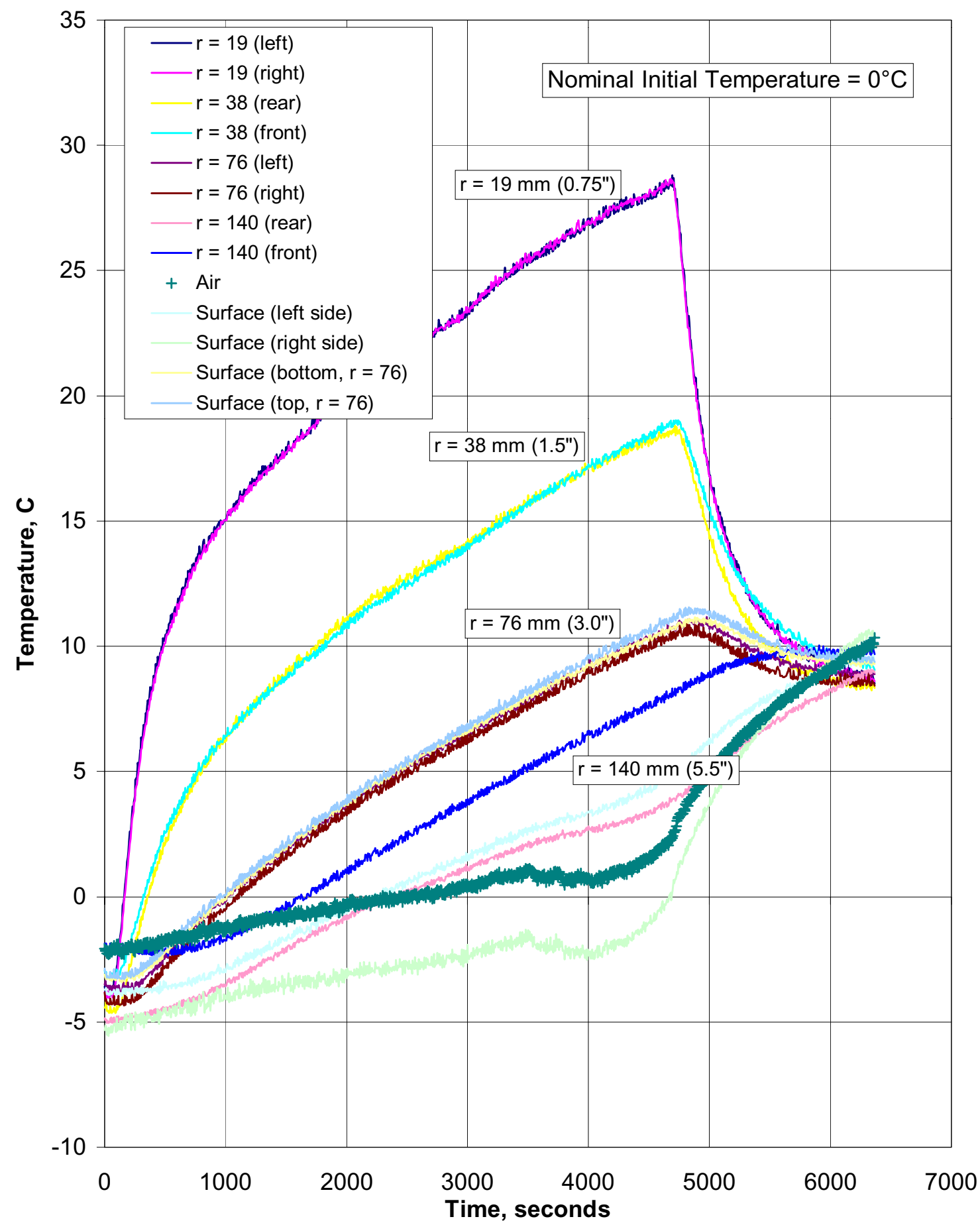

Figure 3-4. Temperature Versus Time With 100-Watt Loading for Test TC2. 


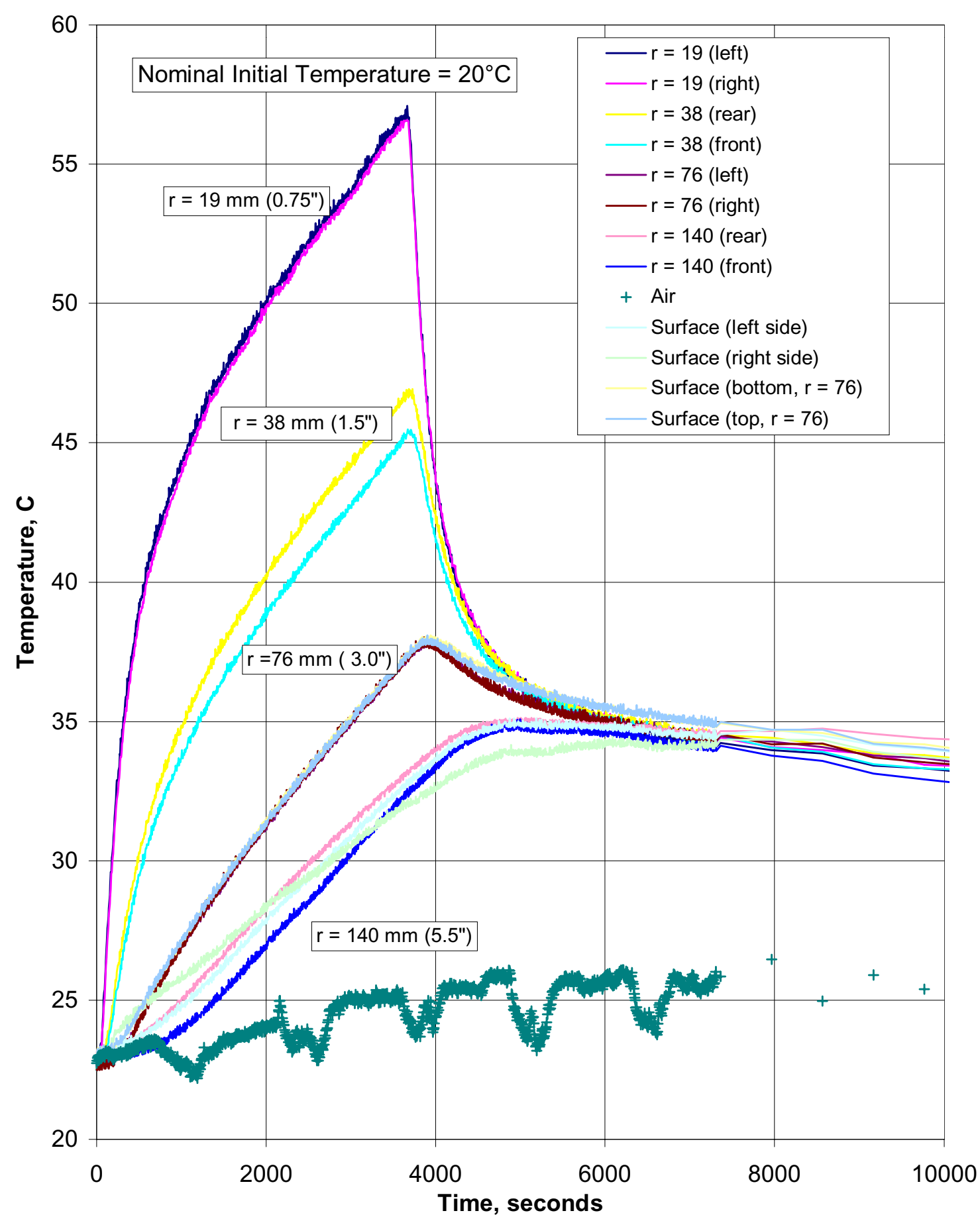

Figure 3-5. Temperature Versus Time With 100-Watt Loading for Test TC3. 


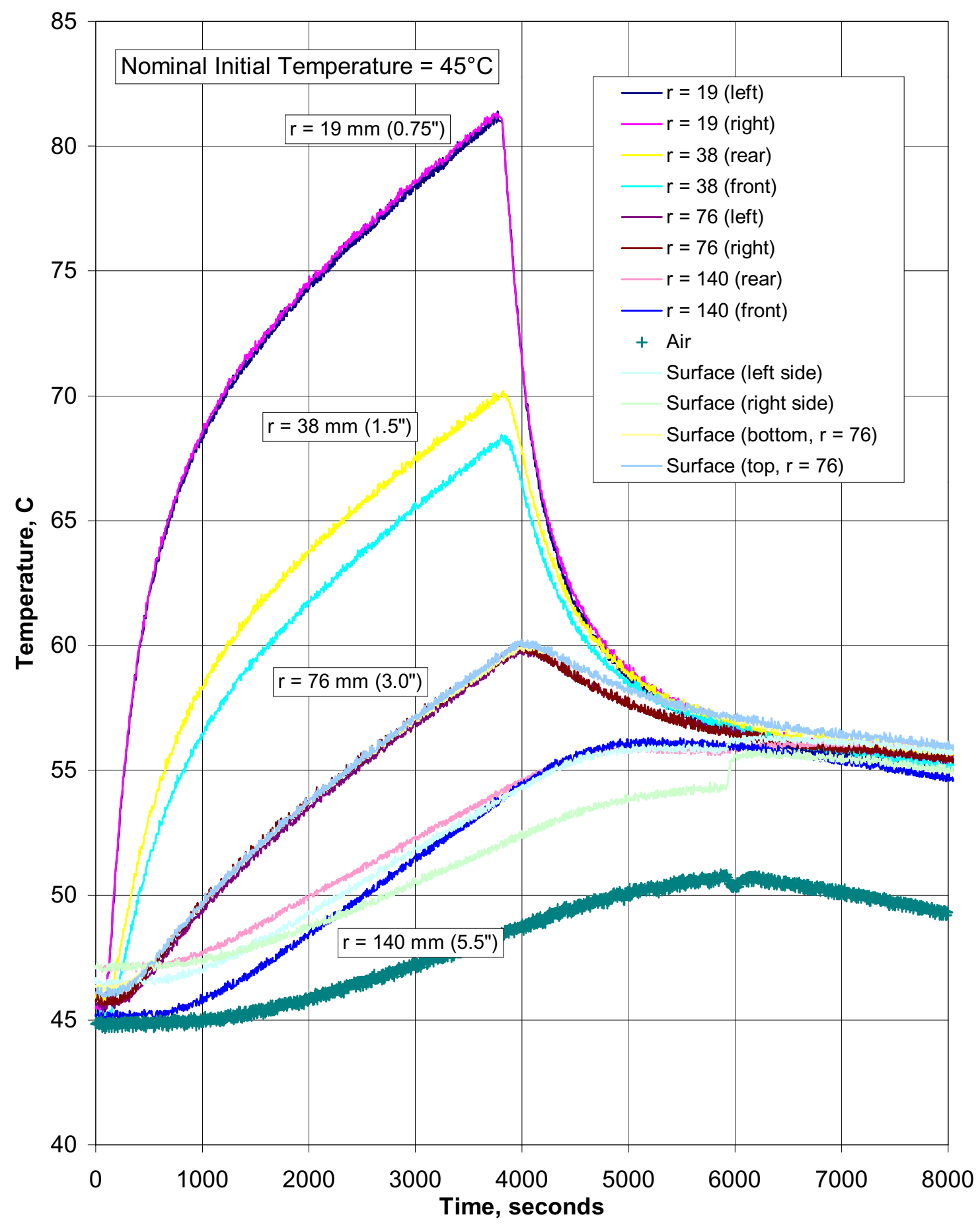

Figure 3-6. Temperature Versus Time With 100-Watt Loading for Test TC4. 
The second assumption was that a radial heat flow condition was maintained; i.e., there was no heat flow parallel to the specimen axis. The data indicate that this assumption is valid. Two thermocouples were placed at the specimen-insulation interfaces above and below the thermocouple located at midheight in the salt at a radius of 76 millimeters ( 3 inches). If any axial heat flow were occurring, these thermocouples would indicate an axial temperature gradient. The fact that these thermocouples all gave the same temperature reading indicated that only radial heat flow was occurring.

\subsubsection{Determination of Thermal Conductivity}

The thermal response of the specimen during each of the tests was simulated using a onedimensional (axisymmetric) numerical model. The temperatures that were predicted by the model at the four radii within the specimen were compared to the temperature measurements made in the four tests. Gevantman [1981] indicates that the thermal conductivity of rock salt over the range of temperatures anticipated in chilled gas storage is a power function of absolute temperature. Consequently, the leading coefficient and the power on temperature were varied in the numerical model until temperatures that best fit the measurements in all four tests at all four radii were predicted. The resultant best-fit relationship between thermal conductivity and temperature is:

$$
\mathrm{K}=\mathrm{a}\left(\frac{\mathrm{T}}{\mathrm{T}_{0}}\right)^{\mathrm{b}}
$$

where:

$$
\begin{aligned}
\mathrm{K}= & \text { thermal conductivity } \\
\mathrm{a}= & 6.678 \mathrm{~W} / \mathrm{m}-\mathrm{K} \\
\mathrm{T}= & \text { absolute temperature } \\
\mathrm{T}_{0}= & \text { absolute temperature at which water freezes } \\
& \text { at } 1 \text { atm pressure (e.g., } 273.15 \mathrm{~K}) \\
\mathrm{b}= & -1.793 .
\end{aligned}
$$

Using the preceding relationship, the root-mean-squared-error between the predicted and measured temperatures is less than $0.5^{\circ} \mathrm{C}\left(0.9^{\circ} \mathrm{F}\right)$. The relationship yields a thermal conductivity of $8.16 \mathrm{~W} / \mathrm{m}-\mathrm{K}\left(4.72 \mathrm{Btu} / \mathrm{hr}-\mathrm{ft}-{ }^{\circ} \mathrm{F}\right)$ at the design temperature for chilled gas storage of $-29^{\circ} \mathrm{C}\left(-20^{\circ} \mathrm{F}\right)$. At a typical ambient geothermal temperature of $43^{\circ} \mathrm{C}\left(110^{\circ} \mathrm{F}\right)$, the thermal conductivity decreases by nearly 40 percent to $5.13 \mathrm{~W} / \mathrm{m}-\mathrm{K}\left(2.97 \mathrm{Btu} / \mathrm{hr}-\mathrm{ft}-{ }^{\circ} \mathrm{F}\right)$. 


\subsection{ESTIMATION OF COOLING LOADS}

Two calculations were made to estimate the cooling load required for refrigerated natural gas storage in solution-mined caverns at the Avoca facility. The first calculation estimates the overall cooling load required to maintain a gas temperature of $-29^{\circ} \mathrm{C}\left(-20^{\circ} \mathrm{F}\right)$. This calculation was made using a finite element simulation of one of the caverns with the heat transfer analysis program SPECTROM-41 [Svalstad, 1989]. The second calculation estimates the heat transfer related to gas compression during injection and gas expansion during withdrawal.

\subsubsection{Finite Element Model}

A two-dimensional finite element model of an Avoca cavern was developed based on the cavern geometry described by Morrill [1996]. The model includes the cross section of a single elongated cavern, and thus, provides estimates of the cooling load on a unit-length basis. The shape of the cross section is the same as that described by Morrill [1996] (see Figures 2-1 and 2-2); however, its size was reduced to account for "necking" of the cavern space between the leaching wells. The size of the cross section was reduced such that a cavern with the reduced cross section and a length of 244 meters (800 feet) results in a working gas volume of about $1.9 \times 10^{7} \mathrm{Nm}^{3}(0.7 \mathrm{Bcf})$, assuming minimum and maximum casing shoe pressures of 5.24 and $19.65 \mathrm{MPa}$ (760 and 2,850 psia), respectively, and a cavern gas temperature of $43^{\circ} \mathrm{C}$ (the estimated average gas temperature before conversion to chilled gas). The modeled cavern cross section has a top width of 34.1 meters (112 feet), a bottom width of 25.6 meters (84 feet), and a height of 17 meters (56 feet). The cavern is modeled between the depths of 1,208.2 and 1225.3 meters (3,964 and 4,020 feet). Based on the planned cavern spacing of 300 meters (1,000 feet) between the long axes, essentially no thermal interaction is expected between caverns. The finite el ement model of the cavern is shown in Figure 3-7. The left boundary of the model represents a plane of symmetry. The model extends about 300 meters (1,000 feet) above and below the cavern and extends 600 meters (2,000 feet) laterally. These extensive boundaries were chosen so that the modeled mine would not be influenced by the boundaries. The finite el ement model contains 8,653 nodes and 2,808 eight-noded elements.

The host stratigraphy was assumed to be interbedded salts and shales and is based on information given by Morrill [1996] and J ohnson and Gonzales [1978]. Table 3-2 shows the thickness of each of the modeled units. The thermal material properties used in the model are shown in Table 3-3. The assumed initial in situ temperature gradient is based on thermal gradients measured in Pennsylvania [Clark, 1966]. A surface temperature of $10^{\circ} \mathrm{C}\left(50^{\circ} \mathrm{F}\right)$ was assumed. The resulting initial in situ temperature as a function of depth is described by the following equation:

$$
\mathrm{T}=10+0.0273 \times \mathrm{D}
$$

where $T$ is in degrees Centigrade and $\mathrm{D}$ is the depth in meters. Based on this equation, the initial in situ temperature at the cavern level is about $43^{\circ} \mathrm{C}\left(110^{\circ} \mathrm{F}\right)$. 


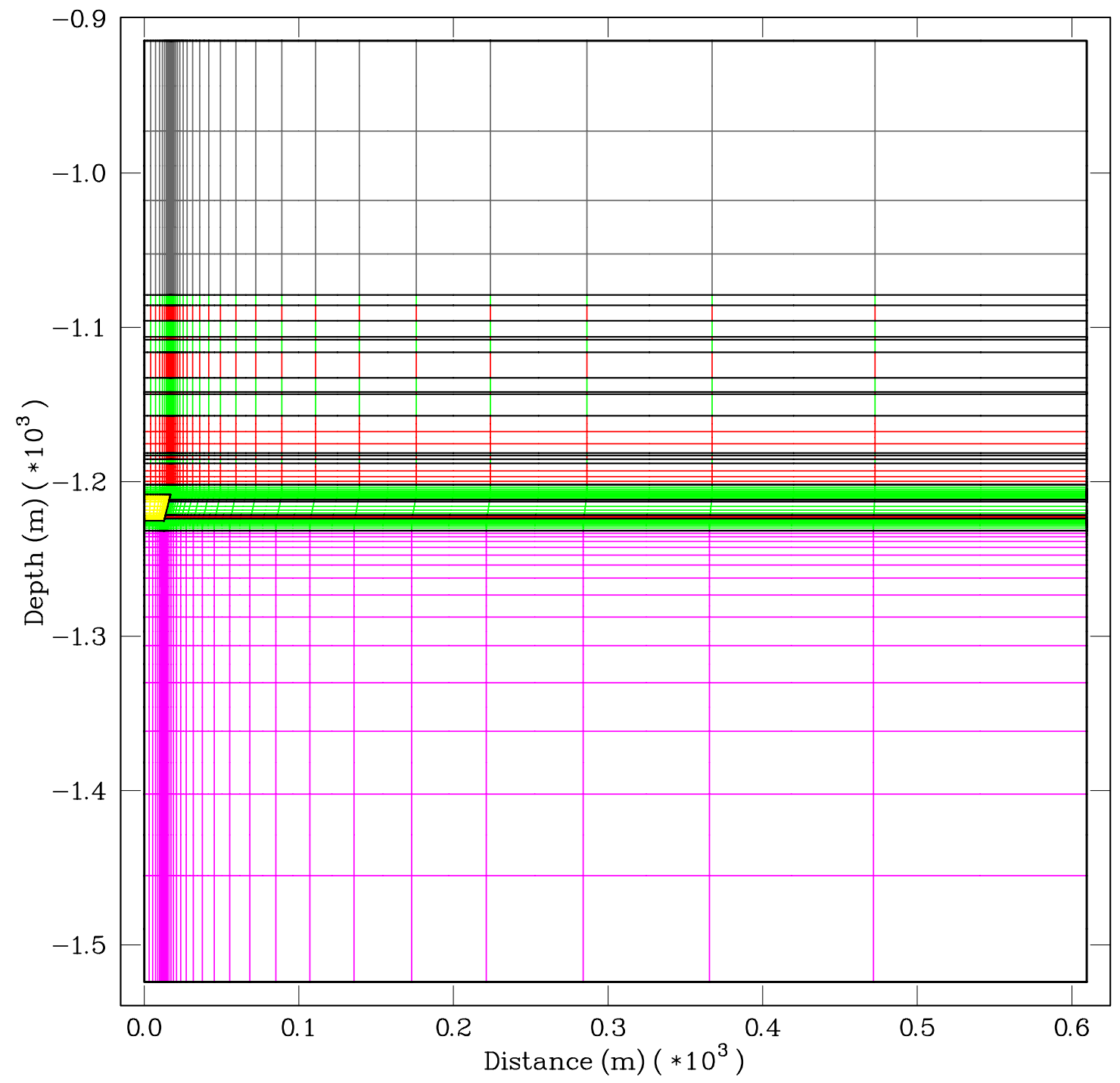

Figure 3-7. Finite Element Mesh for Avoca Cavern. 
Table 3-2. Assumed Stratigraphy

\begin{tabular}{||l|c|c||}
\hline Material & $\begin{array}{c}\text { Depth Interval } \\
(\mathbf{m})\end{array}$ & $\begin{array}{c}\text { Thickness } \\
(\mathbf{m})\end{array}$ \\
\hline \hline Shale & $914.4-1,079.0$ & 164.6 \\
\hline Salt & $1,079.0-1,085.7$ & 6.7 \\
\hline Shale & $1,085.7-1,095.8$ & 10.1 \\
\hline Salt & $1,095.8-1,106.1$ & 10.4 \\
\hline Shale & $1,106.1-1,107.9$ & 1.8 \\
\hline Salt & $1,107.9-1,116.2$ & 8.2 \\
\hline Shale & $1,116.2-1,132.6$ & 16.5 \\
\hline Salt & $1,132.6-1,141.8$ & 9.1 \\
\hline Shale & $1,141.8-1,143.3$ & 1.5 \\
\hline Salt & $1,143.3-1,157.3$ & 14.0 \\
\hline Shale & $1,157.3-1,181.4$ & 24.1 \\
\hline Salt & $1,181.4-1,182.9$ & 1.5 \\
\hline Shale & $1,182.9-1,185.4$ & 2.4 \\
\hline Salt & $1,185.4-1,188.1$ & 2.7 \\
\hline Shale & $1,188.1-1,201.8$ & 13.7 \\
\hline Salt & $1,201.8-1,211.6$ & 9.8 \\
\hline Shale & $1,211.6-1,212.8$ & 1.2 \\
\hline Salt & $1,212.8-1,221.6$ & 8.8 \\
\hline Shale & $1,221.6-1,223.8$ & 2.1 \\
\hline Salt & $1,223.8-1,231.7$ & 7.9 \\
\hline Shale & $1,231.7-1,524.0$ & 292.3 \\
\hline \hline
\end{tabular}

\subsubsection{Overall Cooling Load}

The overall cooling load for refrigerated storage was estimated based on a storage temperature of $-29^{\circ} \mathrm{C}\left(-20^{\circ} \mathrm{F}\right)$. Because of the large difference between the temperature of the stored natural gas and that of the surrounding rock, a large amount of heat will be transferred from the surrounding rock to the stored gas. Through time, the rock surrounding the caverns will cool and less heat will be transferred to the gas. External cooling will have to be provided 
to counteract the heat transferred from the surrounding rock to maintain a constant gas temperature in the caverns.

Table 3-3. Thermal Properties for Salt and Shale

\begin{tabular}{|c|c|c|c|}
\hline Material & Property & Value & Source \\
\hline \multirow[t]{3}{*}{ Salt } & Thermal Conductivity & $\begin{array}{c}6.678\left(\frac{T}{273.15}\right)^{-1.793} \\
W / m-K\end{array}$ & $\begin{array}{l}\text { Current Laboratory Testing } \\
\text { (see Section 3.1.3) }\end{array}$ \\
\hline & Specific Heat & $841 \mathrm{~J} / \mathrm{kg}-\mathrm{K}$ & Dahlstrom [1988] \\
\hline & Density & $2162.5 \mathrm{~kg} / \mathrm{m}^{3}$ & Typical Value \\
\hline \multirow{3}{*}{ Shale } & Thermal Conductivity & $1.76 \mathrm{~W} / \mathrm{m}-\mathrm{K}$ & Osnes et al. [1978] \\
\hline & Specific Heat & $837 \mathrm{~J} / \mathrm{kg}-\mathrm{K}$ & Osnes et al. [1978] \\
\hline & Density & $2402 \mathrm{~kg} / \mathrm{m}^{3}$ & Osnes et al. [1978] \\
\hline
\end{tabular}

To estimate the cooling load required to maintain the gas temperature at $-29^{\circ} \mathrm{C}\left(-20^{\circ} \mathrm{F}\right)$, a finite el ement simulation was performed in which the nodes at the cavern surface were fixed at $-29^{\circ} \mathrm{C}\left(-20^{\circ} \mathrm{F}\right)$ and the heat required to maintain this fixed temperature boundary condition was tracked. The cooling load was tracked over a total simulation time of 10 years. Figure 3-8 shows the estimated cooling load as a function of time (adjusted to show the cooling load requirements for the whole facility). The cooling load versus time is nearly linear on the log-log plot, indicating that the cooling load initially drops very quickly when the temperature gradients around the cavern are large, but drops much slower as these temperature gradients decrease. At the end of the first year, the cooling load is about 4.1 MW (14 MMBtu/hour), and after 10 years, the cooling load is reduced to about 1.75 MW (6 MMBtu/hour). Figure 3-9 shows the temperature gradients surrounding the modeled cavern at various times during the simulation.

\subsubsection{Thermal Effects of Gas Injection and Gas Withdrawal}

During gas injection, mechanical energy is converted to thermal energy as the gas is compressed. The opposite occurs during gas withdrawal. This phenomenon, referred to as the J oule-Thompson effect, results in significant heat gains during gas injections and heat losses during gas withdrawals. The total thermal energy generated or consumed during gas injection or withdrawal based on ideal gas behavior is described by:

$$
\dot{q}=\operatorname{RTV}_{\mathrm{c}}\left(\frac{\partial \rho}{\partial \mathrm{t}}+\overrightarrow{\mathrm{v}} \bullet \nabla \rho\right)
$$




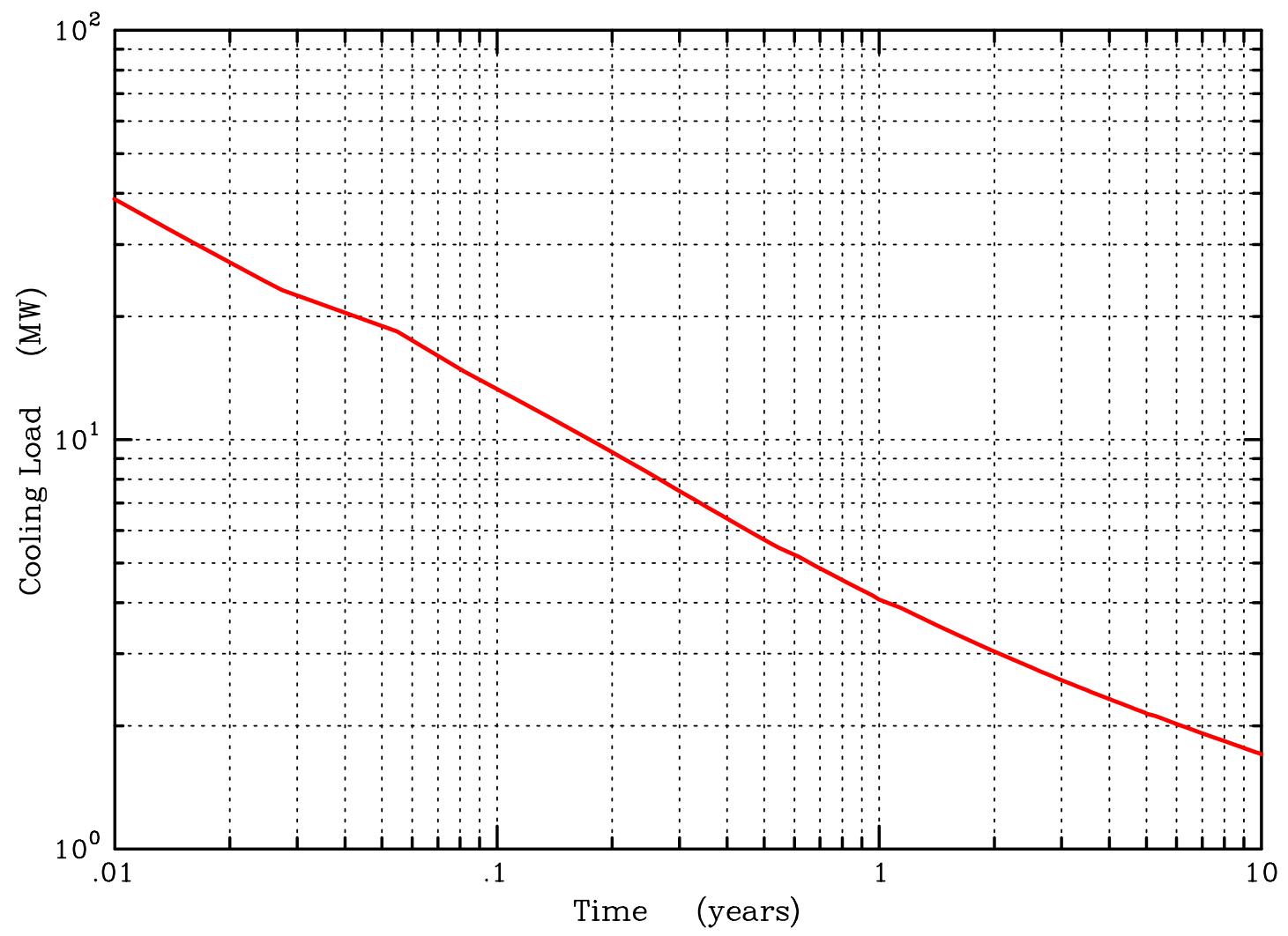

Figure 3-8. Cooling Load Required to Maintain Storage Caverns at $-29^{\circ} \mathrm{C}$. 
RSI-621-01-048

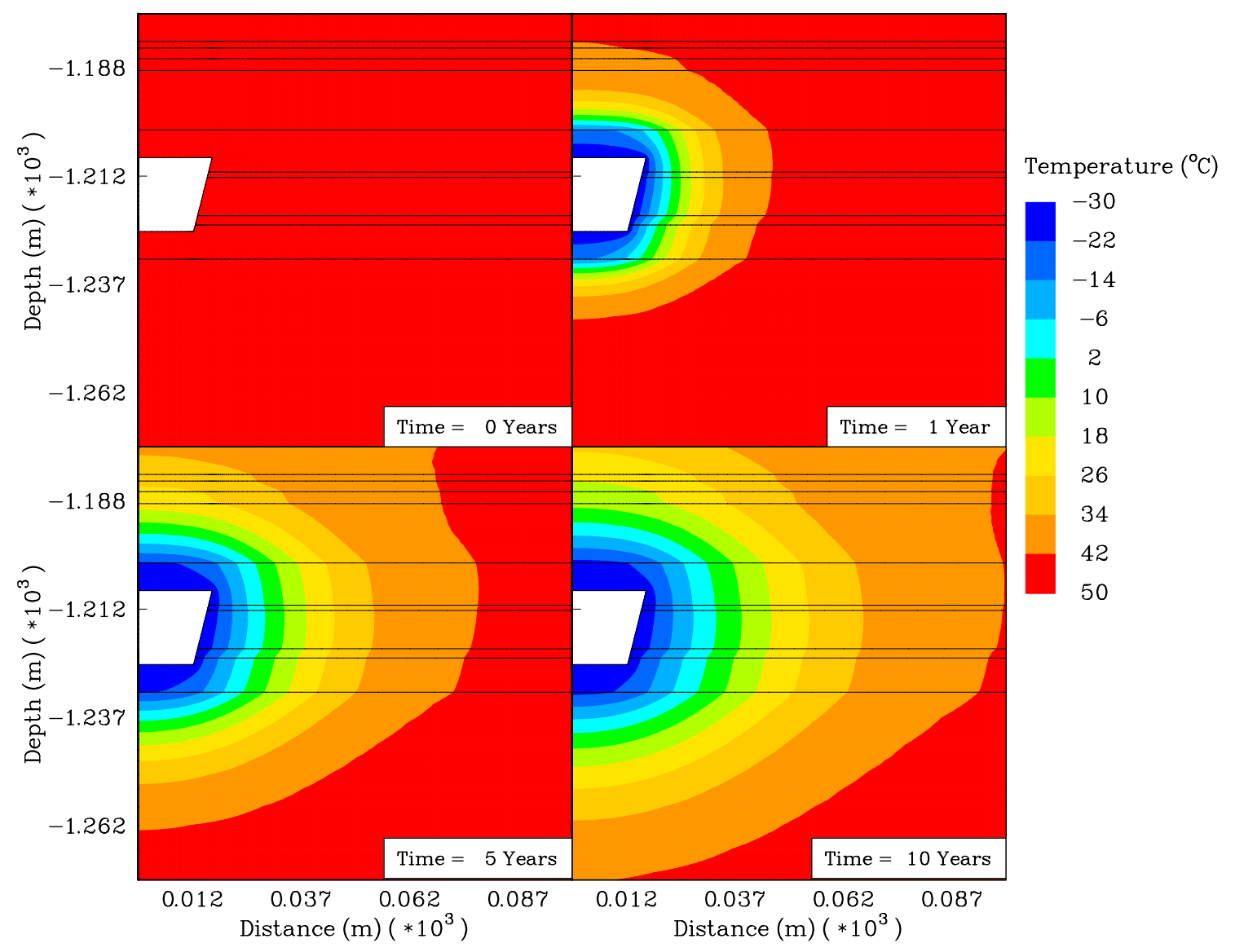

Figure 3-9. Temperature Contours Around Cavern at Various Times. 
where:

$$
\begin{aligned}
\mathrm{R} & =\text { gas constant }(\mathrm{kJ} / \mathrm{kg}-\mathrm{K}) \\
\mathrm{T} & =\text { temperature }(\mathrm{K}) \\
\mathrm{V}_{\mathrm{c}} & =\text { cavern volume }\left(\mathrm{m}^{3}\right) \\
\rho & =\text { gas density }\left(\mathrm{kg} / \mathrm{m}^{3}\right) \\
\overrightarrow{\mathrm{V}} & =\text { gas vel ocity vector. }
\end{aligned}
$$

In this analysis, the gas velocities and the gas density gradients within the caverns are assumed to be small, and thus, the second term of Equation 3-3 is ignored. To account for the nonideal behavior of the gas, the gas constant was calculated as:

$$
\mathrm{R}=\frac{\mathrm{Z} \overline{\mathrm{R}}}{\mathrm{M}_{\mathrm{w}}}
$$

where:

$$
\begin{aligned}
Z & =\text { compressibility factor of the gas } \\
\bar{R} & =\text { universal constant }(8.314 \mathrm{~kJ} / \mathrm{kmole}-\mathrm{R}) \\
\mathrm{M}_{\mathrm{w}} & =\text { molecular weight of the gas. }
\end{aligned}
$$

The compressibility factor, Z, was calculated using an empirical relationship developed by Coker [1993]. The gas was assumed to be pure methane $\left(M_{w}=16.04\right)$. The resulting equation used to estimate the heat generated or consumed during injection or withdrawal is given by:

$$
\dot{\mathrm{q}}=\frac{Z \overline{\mathrm{R}} \mathrm{T} \dot{\mathrm{m}}}{\mathrm{M}_{\mathrm{w}}}
$$

The mass flow rate for a gas injection rate of $5.9 \times 10^{6} \mathrm{Nm}^{3} /$ day $(220 \mathrm{MM} \mathrm{cfd})$ is about 182,370 $\mathrm{kg} /$ hour (402,050 lbm/hour). During gas injection from minimum gas pressure (5.24 MPa or $760 \mathrm{psi}$ ) to maximum gas pressure (19.65 $\mathrm{MPa}$ or 2,850 psi), the average rate of heat added to the cavern is $4.1 \mathrm{MW}$ (14.0 MMBtu/hour). The mass flow rate for a gas withdrawal at a rate of $1.18 \times 10^{7} \mathrm{Nm}^{3} /$ day (440 MM cfd) is about $364,730 \mathrm{~kg} /$ hour $(-804,100 \mathrm{lbm} /$ hour $)$. During withdrawal from maximum to minimum gas pressure, an average rate of heat removed from the cavern is $8.1 \mathrm{MW}$ (27.6 MMBtu/hour). The temperature of the cavern was assumed to be maintained at $-29^{\circ} \mathrm{C}\left(-20^{\circ} \mathrm{F}\right)$. The heating and cool ing rates are average because the compressibility of the gas changes as the pressure in the cavern changes. Of the total heat consumed, a portion will be taken from the rock surrounding the cavern and a portion will be taken from the gas. Although the heat gains during injection are generally offset by heat losses during withdrawal, they will need to be counteracted to maintain a constant cavern temperature. 


\subsection{PRELIMINARY DESIGN AND COST ANALYSIS}

Conversion of a conventional gas storage facility to a refrigerated storage facility will require additional equipment and gas processing and will have additional costs. The purpose of this section is to provide a preliminary design showing the required additional equipment and its cost and also to estimate the additional costs of operating the facility. For this study, it was assumed that the original design maximum injection rate of $5.9 \times 10^{6} \mathrm{Nm}^{3} /$ day (220 M M cfd) and maximum withdrawal rate of $1.18 \times 10^{7} \mathrm{Nm}^{3} /$ day (440 MM cfd) are sufficient. This increases the minimum pressure to maximum pressure injection time from 20 days to 34 days and the maximum pressure to minimum pressure withdrawal time from 10 days to 17 days.

\subsubsection{Preliminary Design}

Efficient storage of gas in underground caverns requires process equipment which properly conditions the gas for storage (see Process Flow Diagram 174-MD-001 and Drawings 174MD002, 174MD003, 174MD004, 174MD005, 174MD006, and 174MD007 in Appendix B). The gas to be stored will likely be drawn from a large natural gas transmission line (trunk-line) at a pressure which is too low for efficient storage in an underground cavern. The trunk-line pressure may vary from 2.5 to $4.0 \mathrm{MPa}$ (400 to $600 \mathrm{psi}$ ) during the heating season to as high as 9.0 MPa (1,300 psi) during the summer months. The planned storage caverns at Avoca are designed for a minimum pressure of $5.24 \mathrm{MPa}(760 \mathrm{psi}$ ) and a maximum pressure of $19.65 \mathrm{MPa}$ $(2,850 \mathrm{psi})$ at the casing shoe. These pressures are based on a casing seat depth of 1,158 meters (3,800 feet) with minimum and maximum pressure gradients of 0.0045 and $0.0170 \mathrm{MPa} / \mathrm{meter}$ (0.20 and $0.75 \mathrm{psi} / \mathrm{foot})$, respectively.

During periods of gas injection into the cavern, the trunk-line pressure will likely be at a pressure that is closer to the 9.0 MPa (1,300 psi) maximum than the 2.5 to $4.0 \mathrm{MPa}$ (400 to $600 \mathrm{psi}$ ) minimum pressure. Nevertheless, the gas will have to be compressed in order to fill the cavern. The gas compression may be achieved by at least one, and likely two or more, gas compressors operating in parallel. The compressors may be driven by electric motors, gas turbines, or piston engines. In the case of the design presented in this report, two gas turbinedriven, centrifugal compressors are assumed.

The following sections describe the gas processing required for refrigerated storage and also describe the equipment assumed to be already in place for conventional storage and the additional equipment required for refrigerated storage.

\subsubsection{Measurement}

The process begins by drawing pipeline-quality natural gas from one or more natural gas transmission lines, which are in close proximity to the Avoca facility. The gas is first measured with custody transfer-type orifice plate meters, which are completely automated and can transmit measurement data via telephone, microwave system, and satellite. The meter skid 
consists of four 0.305 -meter (12-inch) tubes along with a climate-controlled instrument building. The skid is self-contained and requires a minimal amount of human intervention. Gas flow to the meter skid is controlled by a switching valve skid, which directs gas flow, depending on whether gas is being injected into or withdrawn from the cavern.

\subsubsection{Compression}

Since the incoming gas is expected to be at pressures as low as $4.0 \mathrm{MPa}(600 \mathrm{psi})$, the gas must be compressed in order to be stored in the cavern at $19.65 \mathrm{MPa}(2,850 \mathrm{psi})$. In this study, it is assumed that the facility is equipped with two Solar Turbines (Caterpillar) C160R centrifugal compressors, each driven by Mars 90 gas turbines, providing a total power capability of over $18.5 \mathrm{MW}(25,000$ horsepower (HP)). The maximum compressor power requirements occur near the end of the injection cycle when the cavern pressure is the highest. The maximum power requirement during injection is $17.2 \mathrm{MW}(23,100 \mathrm{HP})$ and is based on a flow rate of $5.9 \times 10^{6} \mathrm{Nm}^{3} /$ day (220 MM cfd), a trunk-line supply pressure of $4.0 \mathrm{MPa}$ (600 psi), and a cavern pressure $19.65 \mathrm{MPa}(2,850 \mathrm{psi})$.

These compressors may occasionally be used during cavern withdrawal whenever the cavern pressure is lower than the delivery pressure at one or more transmission pipeline connections. A maximum flow rate of $1.18 \times 10^{7} \mathrm{Nm}^{3} /$ day (440 MMcfd) is assumed during gas withdrawal from the cavern. At this flow rate, the horsepower requirement would be substantially less than the $18.5 \mathrm{MW}(25,000 \mathrm{HP})$ combined capability of the compressors.

Each compressor/turbine unit is fully automated and is fueled with pipelinequality natural gas (the same gas as that being compressed). The units are housed in a sound-deadened, insulated building.

Before entering each of the two compressors, the incoming gas passes through two vertical separators, which remove free liquids from the gas. The compressors are designed to only compress gas and are not designed to handle any liquids.

The gas stream temperature increases from $90^{\circ}$ to $120^{\circ} \mathrm{C}\left(200^{\circ}\right.$ to $\left.250^{\circ} \mathrm{F}\right)$ upon being compressed, and therefore, must be cooled by fin-fan air coolers. At the higher pressures, liquids, such as water and heavy hydrocarbons, may condense. These liquids can harm the molecular sieve material used for drying the gas stream, prior to being chilled; therefore, two vertical separators are placed downstream of the compressor aftercooler.

\subsubsection{Dehydration}

The gas taken from transmission pipelines is conditioned for typical pipeline operating conditions; however, the gas is not likely to be sufficiently conditioned for cold storage operations. In general, pipelinequality natural gas contains too much water for the expected storage 
temperature of $-29^{\circ} \mathrm{C}\left(-20^{\circ} \mathrm{F}\right)$ or lower. Too high of a water content in the gas may result in the formation of methane hydrates, a hybrid crystalline structure of water and methane molecules. The methane hydrates are stable at high pressures and low temperatures (e.g., at pressures greater than $5.5 \mathrm{MPa}(800 \mathrm{psi})$, methane hydrates are stable at temperatures bel ow $7^{\circ} \mathrm{C}\left(45^{\circ} \mathrm{F}\right)$ ).

Prevention of methane hydrate formation is achieved by removing a quantity of water sufficient for the anticipated storage temperature. The proposed method for water removal prior to storage in the mine is by physical absorption of the water using molecular sieve desiccant. Molecular sieve is an engineered aluminum oxide (alumina) pellet, which efficiently attracts and holds on to water molecules. Water-laden gas passes through a pressure vessel containing a bed of molecular sieve pellets. The gas emerges with almost no water and can be refrigerated without the chance of forming hydrates.

The maximum water content of "pipelinequality" natural gas is $112 \mathrm{~kg}$ per million $\mathrm{Nm}^{3}$ (7 pounds/MMcf) of gas. The water content must be reduced to less than $16 \mathrm{~kg}$ per million $\mathrm{Nm}^{3}$ (1 pound/MMcf) before the gas can be refrigerated. This reduction of water content is easily achieved using molecular sieve dehydration. The molecular sieve dehydrator consists of two identical, skid-mounted pressure vessels, which are vertically oriented. Two vessels (i.e., beds) are used because while one bed is absorbing water, the second bed is being regenerated. When the first bed is completely water laden, as determined by a hygrometer, it is automatically switched off line and regenerated. The second bed is switched on line, allowing for continuous water absorption.

Bed regeneration is carried out by taking a side stream of dehydrated gas and heating it to $290^{\circ} \mathrm{C}\left(550^{\circ} \mathrm{F}\right)$ in a small, direct-fired heater. Since each of the two beds must be regenerated with a stream of heated natural gas $\left(290^{\circ} \mathrm{C}\right)$, the pressure vessels containing the molecular sieve material (beds) are covered with high-temperature insulation. The hot gas heats the molecular sieve material, resulting in water being driven out of the desiccant and carried away by the hot gas stream. Once the hot gas exits a bed, it is cooled by a small air cooler (not shown), resulting in water condensation. The condensed water drops out in a small separator (see Drawing 174-MD-005 in Appendix B) and the gas is routed to the suction of the inlet compressors.

\subsubsection{Refrigeration}

Once the gas is sufficiently dehydrated, it must be cooled for the purpose of achieving greater storage efficiency when compared to conventional, ambient temperature storage. The gas will be chilled to approximately $-29^{\circ} \mathrm{C}\left(-20^{\circ} \mathrm{F}\right)$ before entering the cavern. The chiller will use refrigerant-grade propane as a refrigerant. The propane refrigerant is capable of chilling the gas to as low as $-37^{\circ} \mathrm{C}\left(-35^{\circ} \mathrm{F}\right)$. If a $-40^{\circ} \mathrm{C}\left(-40^{\circ} \mathrm{F}\right)$ storage temperature is desired, a different type of refrigeration system and refrigerant (propylene) must be used. In addition, 
consideration will have to be made for the metallurgy of the equipment handling the lower temperature.

The refrigeration system may be powered by electric motors or gas turbines. Gas turbine drivers were chosen for this design. The refrigeration system is a compression-expansion-type system, consisting of a three-stage evaporative cooling system. Each evaporator or "chiller" is a kettle-type, shell-and-tube heat exchanger, with the gas stream passing through tubes immersed in boiling liquid propane in the shell of each heat exchanger. Each chiller operates at a different pressure: high, medium and low pressures. The high-pressure chiller is the warmest of the three chillers, while the low-pressure chiller is the coldest. Cooling the incoming gas in three steps results in greater energy efficiency when compared with a singlestage (one low-pressure chiller) refrigeration system.

The boiled propane is compressed by a three-stage, gas turbine-driven centrifugal compressor. It is then condensed in a fin-fan (air) cooler before being reduced in pressure in each of the three evaporators. A total of $13.0 \mathrm{MW}$ (44.5 MMBtu/hour) of refrigeration will be required (three 4.4-MW (1,250-ton) units are specified), assuming a $5.9 \times 10^{6} \mathrm{Nm}^{3} /$ day (220 MMcfd) gas flow rate, a $38^{\circ} \mathrm{C}\left(100^{\circ} \mathrm{F}\right)$ incoming gas temperature (compressor discharge), and $\mathrm{a}-29^{\circ} \mathrm{C}\left(-20^{\circ} \mathrm{F}\right)$ storage temperature.

After being chilled, the incoming gas stream will enter the left cavern through a 273millimeter (10 3/4-inch) cased wellbore (only a portion of the $5.9 \times 10^{6} \mathrm{Nm}^{3} /$ day (220 MMcfd) flow rate is injected through one wellbore since several pairs of caverns will be used). The chilled gas will completely fill the left cavern, then move to the right-hand cavern through the interconnecting tunnel. The cold gas will begin filling the right-hand cavern, displacing the warmer gas upward and out of the cavern through a second 273-millimeter (10 3/4-inch) cased wellbore. The "displaced" warmer gas then is recirculated through the refrigeration heat exchangers and then subsequently injected into the left cavern. The recirculation of cold gas is continued until the desired storage temperature $\left(-29^{\circ} \mathrm{C}\right)$ is achieved. Over time, a certain thickness of formation surrounding the cavern is chilled and the amount of refrigeration required for maintaining the low cavern temperature is reduced, as described in Section 3.2.

After the first year of storage operations, the cooling load required to maintain the cavern at $-29^{\circ} \mathrm{C}\left(-20^{\circ} \mathrm{F}\right)$ is estimated to be about 4.1 MW (14 M MBtu/hour). The cooling rate will decline with time, and after 10 years, the estimated cooling load is reduced to about $1.75 \mathrm{MW}$ (6 MMBtu/hour). The cavern will require additional refrigeration during injection due to the J oule-Thompson effect of generating heat during gas compression. The cavern will also experience beneficial cooling during gas withdrawal periods due to the expansion of the gas upon withdrawal. During injection and static operations, maintenance cooling will be provided by circulation through the refrigeration system. 
Gas circulation is achieved through the use of a low-pressure boost centrifugal compressor, located on one of the three refrigeration skids. The recirculation compressor will be powered by the same turbine powering the main refrigeration compressor. Once the cavern is full, gas will be withdrawn via either one of the two cavern wellbores, compressed by the recirculation compressor, chilled, and then reinjected into the cavern through the other well bore.

\subsubsection{Gas Heating}

When the gas is withdrawn, it may require heating. A $15.6^{\circ} \mathrm{C}\left(60^{\circ} \mathrm{F}\right)$ gas temperature is ideal since this is an industry-standard temperature used for measurement as well as a typical pipeline operating temperature.

Heating of the gas upon withdrawal is achieved using a direct-fired, forced-draft convection heater. The heat input to warm $1.18 \times 10^{7} \mathrm{~N} \mathrm{~m}^{3} /$ day $(440 \mathrm{M} \mathrm{M} \mathrm{cfd})$ from $-29^{\circ} \mathrm{C}$ to $15.6^{\circ} \mathrm{C}\left(-20^{\circ} \mathrm{F}\right.$ to $60^{\circ} \mathrm{F}$ ) and to counteract the heat loss due to the J oule-Thompson effect of expanding the gas requires using a $45.5 \mathrm{MW}$ (155 MMBtu/hour) (gross heat input) heater. After the gas is heated, it is either metered and transferred to the trunk-line, or it is first recompressed then metered. Since recompression heats the gas, the amount of added heat required from the heater is reduced or not required at all. Recompression depends on the cavern pressure and the trunkline pressure, as well as gas flow rate $\left(1.18 \times 10^{7} \mathrm{Nm}^{3} /\right.$ day $(440 \mathrm{MMcfd})$ is the design withdrawal flow rate). In the case of the Avoca storage facility, recompression is expected to occur infrequently.

\subsubsection{Emergency Shutdown System}

Emergency shutdown will be manually activated at strategically located Emergency Shutdown System (ESD) activation stations. One ESD valve is located on the inlet/discharge pipeline at the facility fence line and one ESD valve per well (two wells per cavern pair), located on each wellhead.

\subsubsection{Facility Layout}

The facility plot will consist of an area somewhat larger than the border formed from the projection of the outer dimension of the cavern. The area required for the surface facility is 4 to 7 acres. The layout Drawing 147-GP-001 is an example layout, taking advantage of the ample land area required for the cavern. Since natural gas and refrigerant propane are being handled by mechanical equipment, leakage of these hydrocarbons can occur. Wider spacing between equipment areas may allow for greater safety.

The spacing and location of equipment will be determined on the basis of code requirements and the direction of the prevailing wind. The code requirements specifically address equipment spacing; e.g., combustion sources, such as the regeneration gas heater or flare vent stack, must be 45 meters ( 150 feet) or more from an area where the potential for hydrocarbon leakage exists. 


\subsubsection{Cost Analysis}

As described above, conversion of the facility from conventional storage to refrigerated storage requires additional equipment and additional gas processing. Table 3-4 shows the design and construction cost of the equipment to equip the existing natural gas storage facility with the equipment necessary for refrigerated storage at a temperature of $-29^{\circ} \mathrm{C}\left(-20^{\circ} \mathrm{F}\right)$. The estimated capital cost of this equipment and its installation is $\$ 13,310,000$ or $\$ 160$ per thousand $\mathrm{Nm}^{3}$ ( $\$ 4.29$ per $\mathrm{Mcf}$ ) of additional working gas capacity. The major additional equipment includes the refrigeration system to chill the gas, the dehydration system to remove water from the gas, and the heating system required to reheat the gas back to trunk-line temperatures. This preliminary design assumes that the original design maximum injection and withdrawal rates are acceptable. Increasing the flow rates would result in additional equipment and processing costs.

Table 3-4. Additional Equipment and Construction Cost Summary

\begin{tabular}{|c|c|}
\hline Item & Cost (\$) \\
\hline Refrigeration System (3 units) & $4,500,000^{(a)}$ \\
\hline Forced-Draft Heater & $1,200,000$ \\
\hline Molecular Sieve Dehydration & $3,500,000^{(a)}$ \\
\hline Additional SCADA Equipment & 100,000 \\
\hline Equipment Nessel/Piping F oundations & 150,000 \\
\hline Piping/Valves/Fittings & 500,000 \\
\hline Electrical Hardware & 150,000 \\
\hline Engineering/Design & 400,000 \\
\hline Additional Facility Construction and Commissioning & 500,000 \\
\hline Subtotal & $11,000,000$ \\
\hline Contingency on all costs @10 percent & $1,100,000$ \\
\hline Subtotal & $12,100,000$ \\
\hline Contractors' profit at 10 percent on surface facilities & $1,210,000$ \\
\hline Total Incremental Cost & $13,310,000$ \\
\hline
\end{tabular}

(a) Based on recent discussions with vendors, these estimates are believed to be more accurate than those reported for the mined hard-rock facility [PB-KBB, Inc., 1998].

The additional operational costs for refrigerated storage were estimated based on the additional energy costs required to process the gas. Additional labor and equipment maintenance costs were not considered. The estimated additional processing costs include a maintenance refrigeration cost and additional refrigeration, dehydration, and heating cost associated with the throughput of gas. Table 3-5 shows the estimated additional gas processing costs to operate the facility (see Table 3-6 for equivalent estimates using industry standard 
units). At a present energy cost of about $\$ 13.65 / \mathrm{MW}-\mathrm{hr}(\$ 4 / \mathrm{MMbtu})$, the estimated additional costs are about $\$ 2.05$ per thousand $\mathrm{Nm}^{3}$ (\$0.055 per $\mathrm{Mcf}$ ) throughput. Table 3-7 shows the estimated yearly maintenance cooling costs. At a present energy cost of about $\$ 13.65 / \mathrm{MW}-\mathrm{hr}$ (\$4/MMBtu) the maintenance refrigeration will cost about $\$ 316,000$ after the first year and decrease to $\$ 132,000$ after 10 years as the rock surrounding the cavern cools. In terms of dollars per incremental increase in working gas capacity, these costs are $\$ 3.80$ per thousand $\mathrm{Nm}^{3}$ (\$0.102 per Mcf) after the first year and $\$ 1.60$ per thousand $\mathrm{Nm}^{3}$ ( $\$ 0.043$ per Mcf) after 10 years. The total additional annual operating cost for refrigerated storage can be estimated by adding the maintenance refrigeration cost and the gas processing cost. For example, assuming an annual throughput of $4 \times 10^{8} \mathrm{Nm}^{3}$ (two complete cycles of the total working gas) during the second year, the additional annual cost for that year, assuming an energy cost of $\$ 13.65 / \mathrm{MW}-\mathrm{hr}$ (\$4/MMBtu), is calculated as:

SI Units:

Additional Annual Cost $=\$ 316,000+4.0 \times 10^{5} 10^{3} \mathrm{Nm}^{3} \times \$ 2.05 / 10^{3} \mathrm{~N} \mathrm{~m}^{3}=\$ 1,136,000$

The total additional annual cost per thousand $\mathrm{Nm}^{3}$ throughput for this example is $\$ 2.84$.

U.S. Industry Units:

Additional Annual Cost $=\$ 316,000+15,000,000 \mathrm{Mcf} \times \$ 0.055 / \mathrm{Mcf}=\$ 1,141,000$

The total additional annual cost per Mcf throughput for this example is $\$ 0.076$.

Table 3-5. Additional Processing Cost Summary (SI Units)

\begin{tabular}{|c|c|c|c|c|}
\hline \multirow[t]{2}{*}{ Item } & \multirow[t]{2}{*}{$\begin{array}{l}\text { Energy } \\
\text { Requirements } \\
\text { (MW) }\end{array}$} & \multicolumn{3}{|c|}{$\begin{array}{l}\text { Estimated Additional Processing Cost } \\
\qquad\left(\$ / 10^{3} \mathrm{Nm}^{3}\right)^{(\mathrm{a})} \\
\text { Energy Cost }(\$ / \mathrm{MW}-\mathrm{hr})\end{array}$} \\
\hline & & $\$ 10.24$ & $\$ 13.65$ & $\$ 17.06$ \\
\hline $\begin{array}{l}\text { Refrigeration } \\
{\text { (Injection })^{(b)}}\end{array}$ & 4.54 & 0.19 & 0.25 & 0.32 \\
\hline 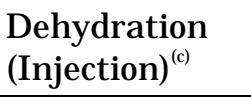 & 14.65 & 0.41 & 0.54 & 0.68 \\
\hline $\begin{array}{l}\text { Heating } \\
{\text { (Withdrawal })^{(\mathrm{d})}}\end{array}$ & 45.43 & 0.95 & 1.26 & 1.58 \\
\hline Total & & 1.55 & 2.05 & 2.58 \\
\hline
\end{tabular}

(a) Assumes a gas injection rate of $5.9 \times 10^{6} \mathrm{Nm}^{3} /$ day and a gas withdrawal rate of $1.18 \times$ $10^{7} \mathrm{Nm}^{3} /$ day.

(b) Refrigeration system runs 24 hours per day during injection periods. Refrigeration system is assumed to have a coefficient of performance of 3 .

(c) Dehydration system operates 16 hours per day during gas injection periods.

(d) Heating system runs 24 hours per day during gas withdrawal periods. 
Table 3-6. Additional Processing Cost Summary (U.S. Industry Units)

\begin{tabular}{|c|c|c|c|c|}
\hline \multirow[t]{2}{*}{ Item } & \multirow{2}{*}{$\begin{array}{l}\text { Energy } \\
\text { Requirements } \\
\text { (MMBtu/hr) }\end{array}$} & \multicolumn{3}{|c|}{$\begin{array}{c}\text { Estimated Additional Processing Cost } \\
\text { (\$/Mcf) } \\
\text { Energy Cost }(\$ / \mathrm{MMBtu})\end{array}$} \\
\hline & & $\$ 3$ & $\$ 4$ & $\$ 5$ \\
\hline 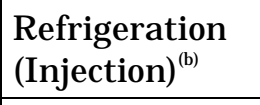 & 15.5 & 0.005 & 0.007 & 0.008 \\
\hline 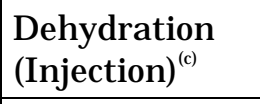 & 50 & 0.011 & 0.015 & 0.018 \\
\hline $\begin{array}{l}\text { Heating } \\
(\text { Withdrawal) })^{(\mathrm{d})}\end{array}$ & 155 & 0.025 & 0.034 & 0.042 \\
\hline Total & & 0.041 & 0.055 & 0.069 \\
\hline
\end{tabular}

(a) Assumes a gas injection rate of $220 \mathrm{MMcfd}$ and a gas withdrawal rate of $440 \mathrm{MMcfd}$.

(b) Refrigeration system runs 24 hours per day during injection periods. Refrigeration system is assumed to have a coefficient of performance of 3 .

(c) Dehydration system operates 16 hours per day during gas injection periods.

(d) Heating system runs 24 hours per day during gas withdrawal periods.

Table 3-7. Maintenance R efrigeration Cost Summary

\begin{tabular}{|c|c|c|c|c|}
\hline \multirow{2}{*}{ Time } & \multirow{2}{*}{$\begin{array}{c}\text { Energy } \\
\text { Requirements } \\
\text { MW } \\
\text { (MMBtu/hr) }^{(\mathbf{a})}\end{array}$} & \multicolumn{3}{|c|}{$\begin{array}{c}\text { Yearly Maintenance Refrigeration Cost } \\
\text { Energy Cost - MW-hr (\$/MMBtu) }\end{array}$} \\
\hline & & $\$ 10.24(\$ 3)$ & $\$ 13.65$ (\$4) & $\$ 17.06(\$ 5)$ \\
\hline After 1 Y ear & $2.6(9.0)$ & $\$ 237,000$ & $\$ 316,000$ & $\$ 395,000$ \\
\hline After 5 Y ears & $1.4(4.7)$ & $\$ 125,000$ & $\$ 166,000$ & $\$ 208,000$ \\
\hline After 10 Years & $1.1(3.8)$ & $\$ 99,000$ & $\$ 132,000$ & $\$ 165,000$ \\
\hline
\end{tabular}

(a) Assumes maintenance refrigeration system runs continuously. Refrigeration system is assumed to have a coefficient of performance of 3 . The fuel consumption rate required for gas circulation is assumed to be 32 percent of the cooling load. 


\subsection{TECHNICAL FEASIBILITY}

To determine the technical feasibility of converting the Avoca facility to a refrigerated gas storage facility, the structural stability of the caverns during refrigerated storage was evaluated. To complete this evaluation, laboratory testing was performed to determine the mechanical properties of salt at low temperatures. This was followed by numerical finite element modeling using these properties to evaluate cavern stability during chilled gas storage.

\subsection{LABORATORY TESTING}

\subsubsection{Scope}

In the previous chapter, a description was given of a laboratory study that produced data needed to assess the economi c feasibility of increasing the working gas capacity in a bedded salt storage facility by chilling the gas to $-29^{\circ} \mathrm{C}\left(-20^{\circ} \mathrm{F}\right)$. In this chapter, a second laboratory study is described that was executed to assess the effects of chilled temperatures on the thermomechanical analyses needed to evaluate the technical feasibility of increasing working gas capacity by chilling the stored gas. Mechanical properties tests were performed on 100-millimeter-diameter (3.94-inch-diameter) cylinders at temperatures as low as $-30^{\circ} \mathrm{C}\left(-22^{\circ} \mathrm{F}\right)$ to determine how strength and deformation properties changed with a decrease in temperature. The mechanical tests included: (1) constant strain rate, triaxial compression tests to evaluate strength and elastic moduli, (2) constant mean stress tests to evaluate the dilatancy limit, and (3) constant stress creep tests to evaluate the time-dependent deformation rates at low temperature. Laboratory procedures and equipment are described in this chapter, along with the test results that illustrate how the mechanical properties of salt are affected by reductions in salt temperature.

\subsubsection{Specimens}

All of the specimens used in this laboratory study were right-circular cylinders of bedded salt. The specimens were prepared from core samples obtained from bedded salt formations in the northeastern United States.

A number of salt specimens were prepared for use in determining the mechanical properties of the chilled salt. These specimens were 100 millimeters (3.94 inches) in diameter with lengths of 200 millimeters ( 7.87 inches) $(L: D=2)$. The ends of the specimens were ground flat and parallel to assure uniform axial stresses were applied during testing. The core samples were recovered from a depth of about 1,280 meters (4,200 feet) in Bale Well No. 1 near Cayuta, New York, in 1993 and were stored in sealed containers at RESPEC until needed for testing. The Engineering Mining Experiment Station (EMES) at the South Dakota School of Mines and 
Technology in Rapid City, South Dakota, performed mineralogical and X-ray diffraction analyses on samples recovered from the depth range of $1,273.1$ to $1,278.9$ meters $(4,177$ to 4,196 feet). The results indicated that halite represented about 99 percent (by weight) of the constituents, with the remaining 1 percent being anhydrite. Additionally, four homogenized samples of the salt were subjected to a chemical analysis to determine their dominant chemical content. The average results were (by weight percent):

- Calcium (Ca)

- Sodium ( $\mathrm{Na})$

- Chlorine $(\mathrm{Cl})$

- Sulphate $\left(\mathrm{SO}_{4}\right)$

- Potassium (K)

- Magnesium (Mg)

- Water Insolubles
0.34 percent

30.2 percent

60.6 percent

0.73 percent

not detected

not detected

2.53 percent.

\subsubsection{Equipment and Procedures}

The mechanical properties testing consisted of using different load paths that were performed at refrigerated temperatures. The load paths can be separated into two types. The first type requires that the applied stresses change over time (quasi-static triaxial compression), and the second type requires that the applied stresses remain constant over time (creep). Both types of tests are described here.

\subsubsection{Quasi-Static Triaxial Compression Testing}

These load paths were applied using the UTS2 rock mechanics test frame. The UTS2 is a computer-controlled, servohydraulic test system comprising a pressure vessel and an MTS 312.41 load frame, as shown in Figure 4-1. A hydraulic actuator located in the base of the load frame is capable of applying an axial force of 110,000 pounds $(500 \mathrm{KN})$. A load cell bolted to the moveable crosshead provides a measure of axial force. A pressure transducer located in the line between the intensifier and the pressure vessel measures the confining pressure applied to the surface of the specimen. A control console houses the signal conditioning for the transducers, as well as the feedback and valve driver modules that service the hydraulics. The console interfaces with a microprocessor to provide data acquisition and programmable control.

Typical specimens tested in the UTS2 are cylinders with a 100-millimeter-diameter (3.94inch-diameter) and a length-to-diameter ratio of 2 . Axial and radial strain can be measured in each test with direct-contact extensometers, as illustrated in Figure 4-1. The axial extensometer, an MTS 632.90C-04 strain-gage-type, consists of two sensing arms that are diametrically opposed when the extensometer is mounted on the specimen. The mounted extensometer has an initial gage length of 100 millimeters (3.94 inches) and is centered on the 


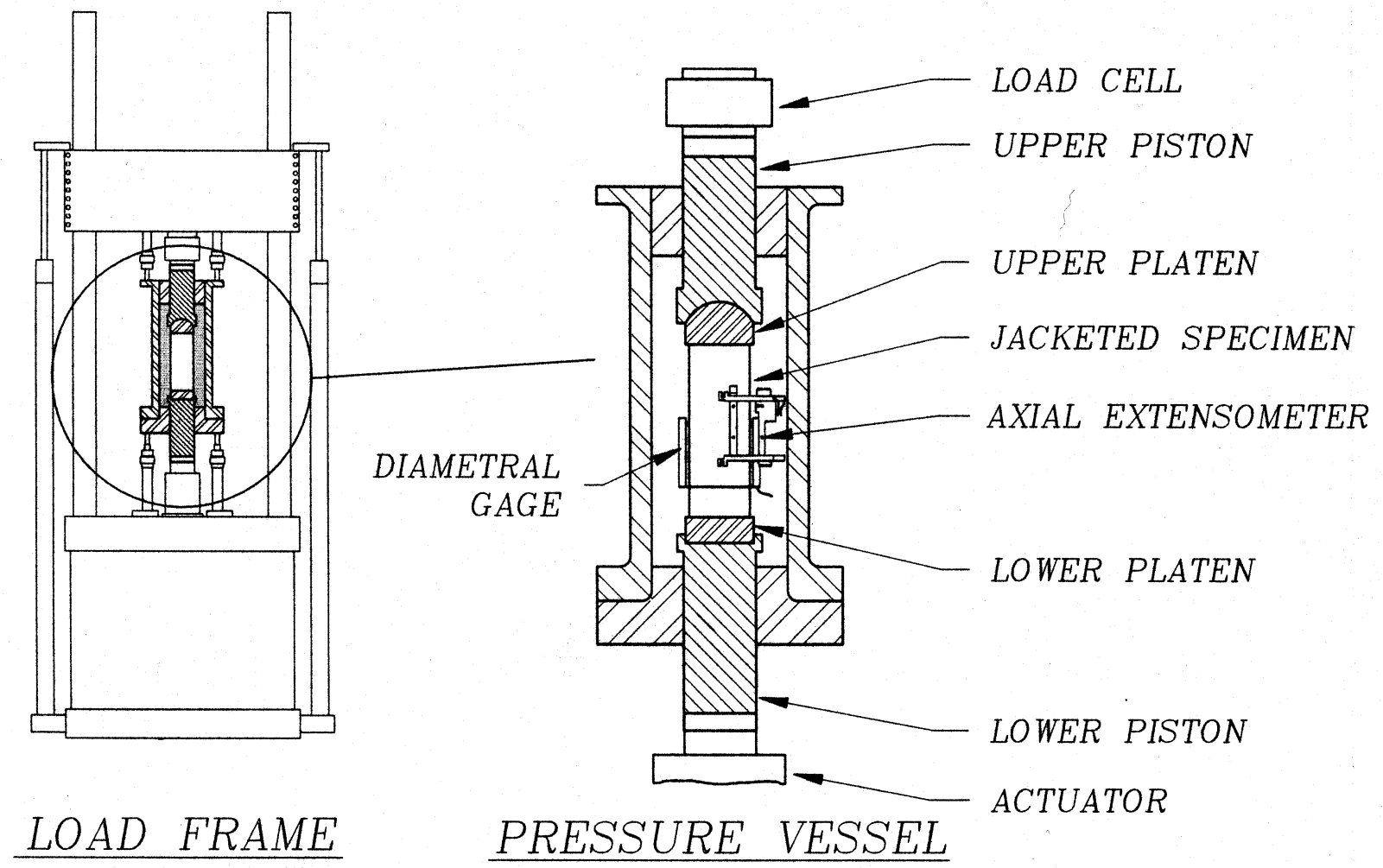

Figure 4-1. Schematic of UTS2 Test System. 
specimen midheight. The radial extensometer is a strain-gaged annular metal disk that senses the radial movement of the two vertical mounting posts. To minimize jacket interference, the two mounting posts contact the specimen through ports cut in the protective jacket that are sealed with metal shims.

Quasi-static tests were initiated by first loading a specimen to a hydrostatic stress state at a pressurization rate of $0.02 \mathrm{MPa} / \mathrm{s}(2.9 \mathrm{psi} / \mathrm{s})$ and room temperature of $20^{\circ} \mathrm{C}\left(68^{\circ} \mathrm{F}\right)$. The specimens were then cooled to $-30^{\circ} \mathrm{C}\left(-22^{\circ} \mathrm{F}\right)$ while maintaining the hydrostatic stress state. The cooling was achieved by circulating chilled fluid (supplied by a NESLAB ULT-80 chiller) through tubular heat exchangers wrapped around the pressure vessel and covered with adequate insulation to prevent excessive heat gain from the room. Ceramic insulators were placed in the load train above and below the vessel to prevent axial heat flow. After equilibration at $-30^{\circ} \mathrm{C}\left(-22^{\circ} \mathrm{F}\right)$, the test truly began with the application of an axial stress difference (the difference between total axial stress and the confining pressure).

There were two types of quasi-static tests performed: one known as a constant strain rate test and the other known as a constant mean stress test. For the constant strain rate tests, an axial stress difference was applied by increasing axial load to maintain an axial strain rate of $1 \times 10^{-4} \mathrm{~s}^{-1}$ while maintaining the confining pressure constant at the hydrostatic level. When the axial strain reached 1 percent, an unload/reload cycle was performed to generate data for estimating values of the elastic moduli. The axial loading was then resumed and continued until the axial strain transducer reached its limit. For the constant mean stress tests, the axial stress difference was applied by increasing the axial stress at twice the rate the confining pressure was decreased to maintain a constant mean stress equal to the hydrostatic level. The loading was continued until the confining pressure reached zero.

\subsubsection{Constant Stress Creep Testing}

The constant stress creep tests were performed on a pair of test frames equipped with pressure vessels suited for maintaining static stress states. A typical creep test system is shown in Figure 4-2. Creep tests are initiated by applying confining pressure to all exterior surfaces of a jacketed specimen and then cooling the jacketed specimen to the prescribed test temperature. The cooling is performed in the same manner as previously outlined for the UTS2

test system. After the temperature has stabilized, an axial stress difference is quickly applied to the specimen by increasing the axial load while maintaining the confining pressure constant. The confining pressure and axial stress difference are then maintained at their specified levels for the duration of the test. Creep tests are typically continued for weeks or months, so servo-controlled test systems (like the UTS2 described previously) are not practical. Instead, nitrogen-charged accumulators are connected to the system to aid in maintaining a constant axial stress on the specimen. The system is computer controlled and uses the dilatometer and the accumulators to maintain a constant stress state. This ability is important because the axial force must be steadily increased to maintain a constant axial stress as the specimen cross-sectional area increases with time. 


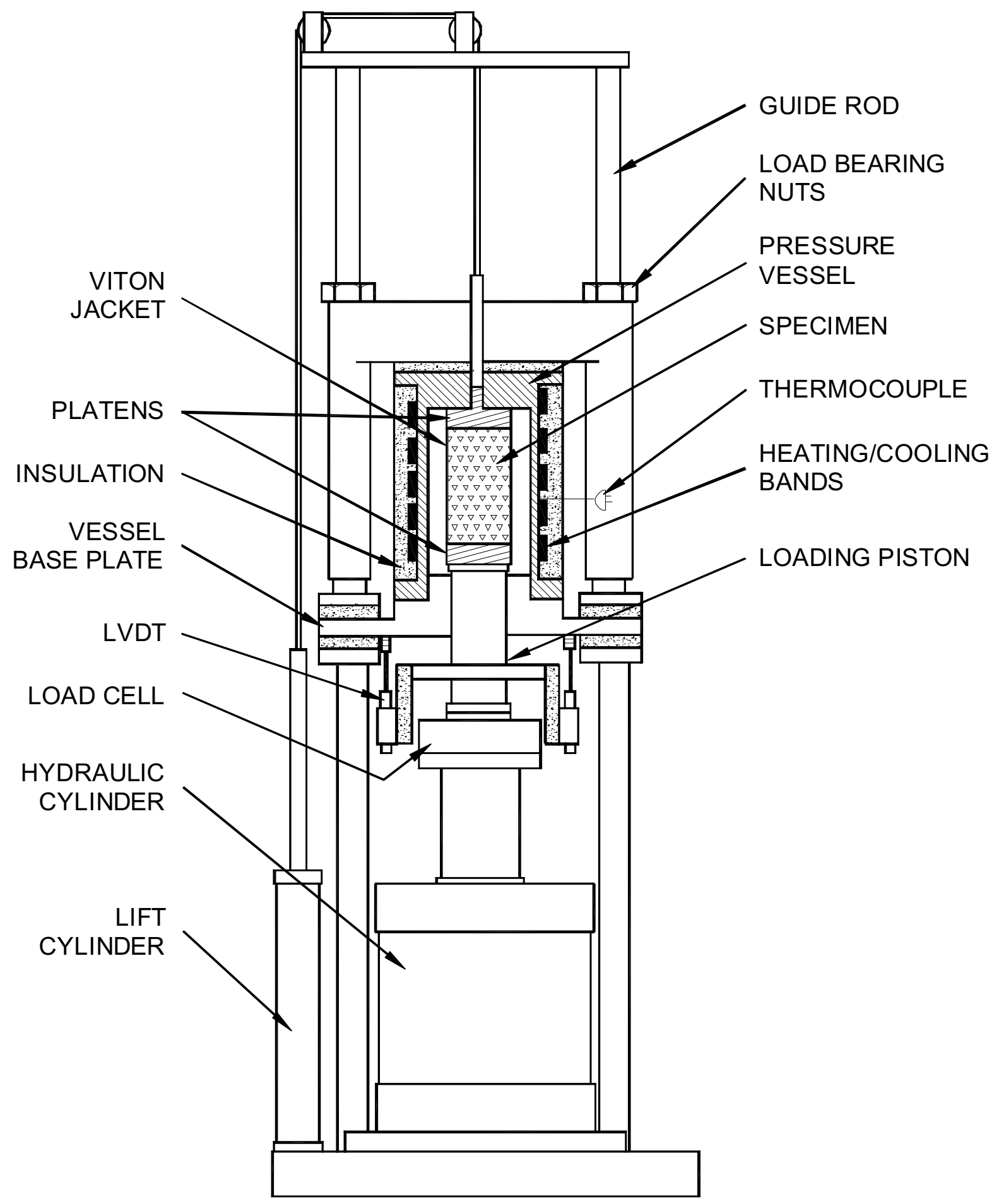

Figure 4-2. Schematic of Creep Test System. 
During a creep test, axial force, confining pressure, axial displacement, radial displacement, and temperature are recorded. Axial stress is calculated from the axial force measurement and the current cross-sectional area of the specimen. Radial stress is simply the measured value of the confining pressure. Axial and radial true (logarithmic) strains can be calculated from the axial and radial displacements and the specimen dimensions. Axial displacement measurements are provided by the LVDTs that track movement of the axial force actuator ram. The radial displacement of the specimen is inferred from the dilatometric measurement after accounting for the axial strain in the specimen. A thermocouple mounted in the pressure vessel wall provides temperature data.

A typical creep test exhibits a high rate of straining when the axial stress difference is first applied. This high strain rate slows quickly and approaches a steady-state value as the specimen continues to deform. The creep test is continued until a reasonable estimate of the steady-state strain rate is available with typical test durations being about 1 or 2 months.

\subsubsection{Refrigerated Temperature Considerations}

The test systems used in this laboratory study are generally used for testing at temperatures greater than or equal to room temperature. This work had the unusual requirement of testing at refrigerated temperatures, so additional test system verifications were performed to ensure proper operation. An aluminum specimen was used in the UTS2 test system to conduct a series of constant strain rate tests at different temperatures over the range of $20^{\circ} \mathrm{C}$ to $-30^{\circ} \mathrm{C}\left(68^{\circ} \mathrm{F}\right.$ to $-22^{\circ} \mathrm{F}$ ). These tests verified the ability of the recirculating chiller to bring the test specimen to a constant temperature within a reasonable amount of time. The typical system temperature response that plots temperature versus time is shown in Figure 4-3. The cooling system was reasonably efficient because the thermal gradient was small from the chiller bath to the specimen, less than about $5^{\circ} \mathrm{C}\left(9^{\circ} \mathrm{F}\right)$. The specimen temperature was taken as the average of two thermocouples placed in the oil inside the pressure vessel at locations near the top and bottom of the specimen. As seen in Figure 4-3, the axial thermal gradient in the specimen is very small, less than $1^{\circ} \mathrm{C}\left(1.8^{\circ} \mathrm{F}\right)$. A smoothed line drawn through the oil temperature data indicates the typical system response. If a specimen was cooled (or heated) very rapidly, differential temperature changes in the specimen could damage a crystalline material-like salt, but Figure 4-3 shows that the average cooling rate of the specimen was approximately $0.06^{\circ} \mathrm{C} /$ minute $\left(0.108^{\circ} \mathrm{F} /\right.$ minute), which was considered very safe.

The shakedown tests on aluminum also allowed an investigation of the possible effects of cold temperatures on the displacement transducers that were mounted directly on the specimen. In each of the tests on aluminum, Young's modulus was calculated from the stressstrain data. A total of 12 such tests was performed over the range of temperatures from $20^{\circ} \mathrm{C}$ to $-30^{\circ} \mathrm{C}\left(68^{\circ} \mathrm{F}\right.$ to $\left.-22^{\circ} \mathrm{F}\right)$. The results indicated that while there was some variability in the data, there was no trend that could be correlated to changes in temperature. Thus the elastic moduli that were determined in the tests on salt may be considered reliable. 
RSI-999-01-004

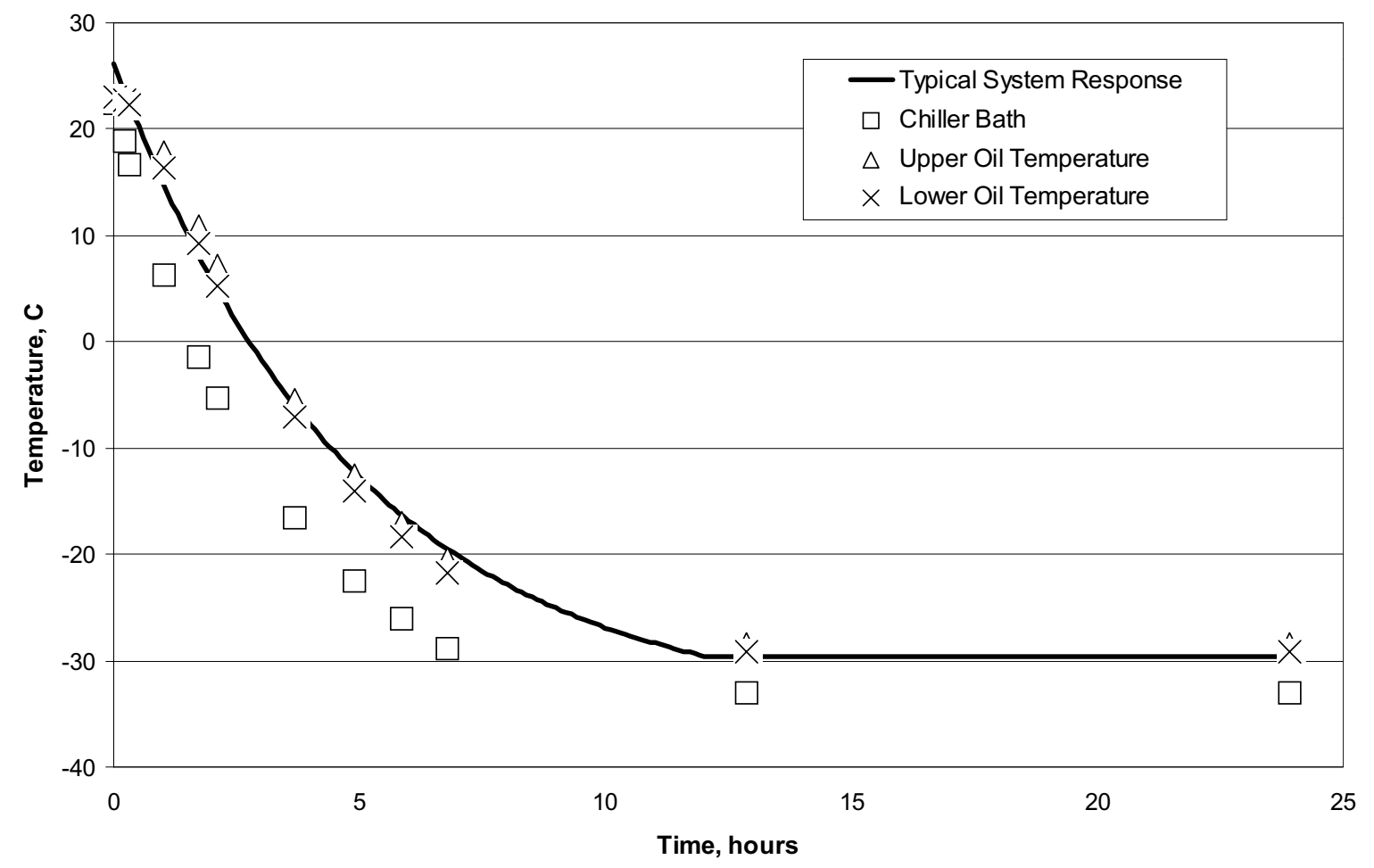

Figure 4-3. Typical System Temperature Response for the UTS2 Test System. 


\subsubsection{Results}

The laboratory results have been separated into three sections in this chapter. The first section presents the results of the constant strain rate tests, followed by the results of the constant mean stress tests in the second section. The third section is dedicated to the results of the creep tests.

\subsubsection{Constant Strain Rate Results}

Three constant strain rate tests were performed at a temperature of $-30^{\circ} \mathrm{C}\left(-22^{\circ} \mathrm{F}\right)$. They were performed at confining pressures of $3.45,1.38$, and $0.69 \mathrm{MPa}(500,200$, and $100 \mathrm{psi})$. In all three tests, an unload/reload cycle was performed to generate data for estimating values of the elastic moduli. The axial loading was then resumed and continued until the axial strain transducer reached its limit of about 7.5 percent strain. The test results are shown in Figures 4-4, 4-5, and 4-6 that plot axial stress difference versus axial and radial strain. Also given in the figures are the elastic moduli calculated from the unload/reload cycles performed at 1 percent axial strain.

A comparison of the constant strain rate tests performed at $-30^{\circ} \mathrm{C}\left(-22^{\circ} \mathrm{F}\right)$ and room temperature is shown in Figure 4-7 by plotting the stress-versus-axial strain traces obtained from each test. The data obtained at $-30^{\circ} \mathrm{C}\left(-22^{\circ} \mathrm{F}\right)$ are the results of the three tests performed in the current project. The room temperature data were obtained from previous work on the same salt performed in 1994. The confining pressure conditions that were used in the refrigerated testing correspond to the pressure conditions used previously in the room temperature testing. The chilled test performed at the intermediate confining pressure of 1.38 MPa (200 psi) is being discounted because a posttest examination indicated that the specimen had an unusual failure plane that was at a very low angle to the horizontal specimen axis. As seen in the figure, the stress increases more quickly at refrigerated temperatures as the specimen strains, but the elastic response displayed during the unload/reload cycle at 1 percent strain appears similar at both temperatures. The conclusion is that viscoplastic (creep) behavior becomes less prominent as the temperature decreases. At the lower confining pressure, the strength at a temperature of $-30^{\circ} \mathrm{C}\left(-22^{\circ} \mathrm{F}\right)$ was about 10 percent higher than the strength seen at $20^{\circ} \mathrm{C}\left(68^{\circ} \mathrm{F}\right)$. A similar statement cannot be made at the higher confining pressures because the $20^{\circ} \mathrm{C}\left(-22^{\circ} \mathrm{F}\right)$ tests were terminated prior to failure. However, the overall impression is that the strength of the salt at refrigerated temperatures is expected to be at least as great as the strength at room temperature. The strength and elastic properties measured at room temperature and refrigerated temperatures are summarized in Table 4-1. The strength reported in Table 4-1 is the maximum axial stress difference applied to the specimen. 


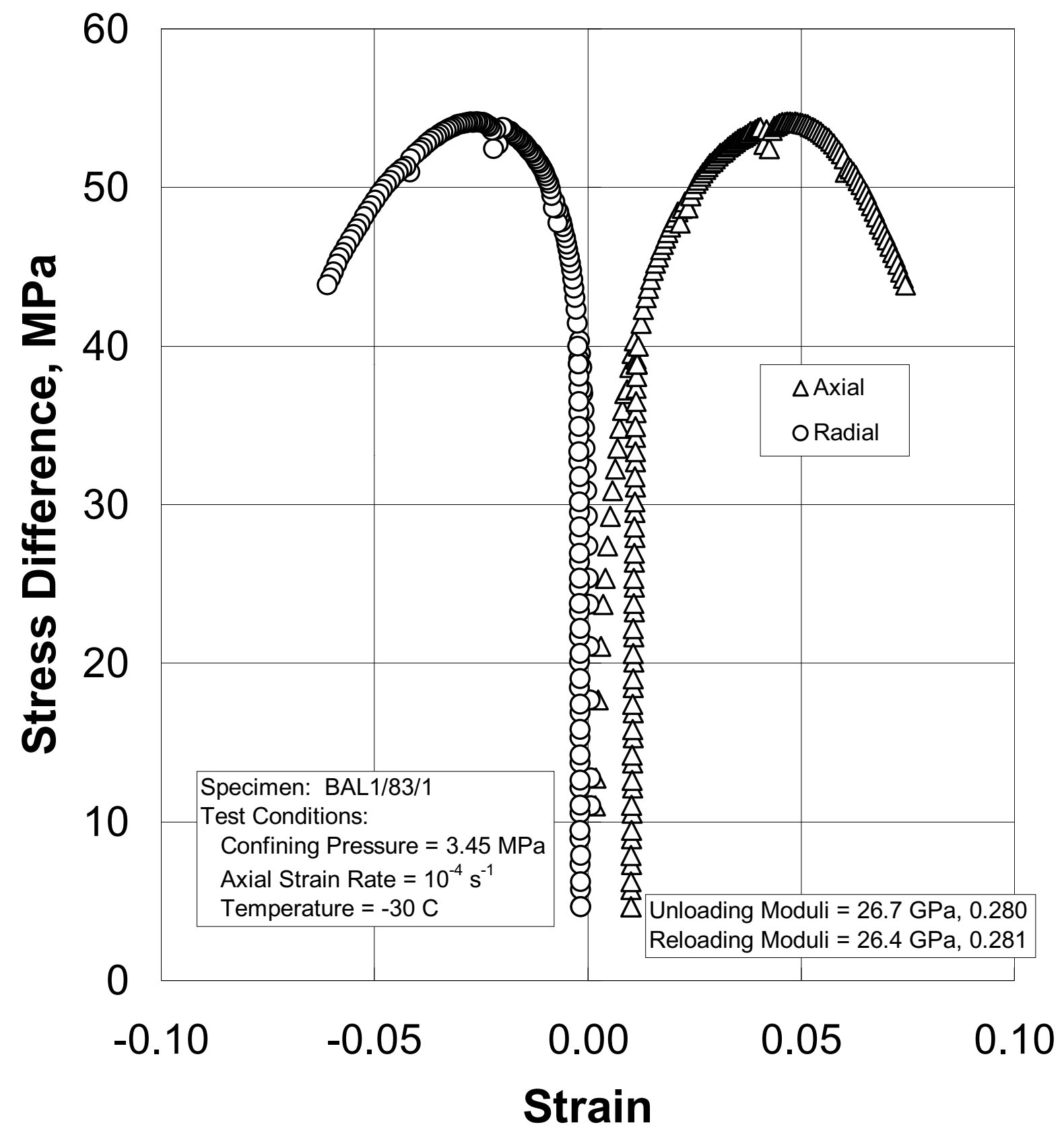

Figure 4-4. Stress-Strain Results for a Constant Strain Rate Test on Salt Specimen BAL 1/83/1. 


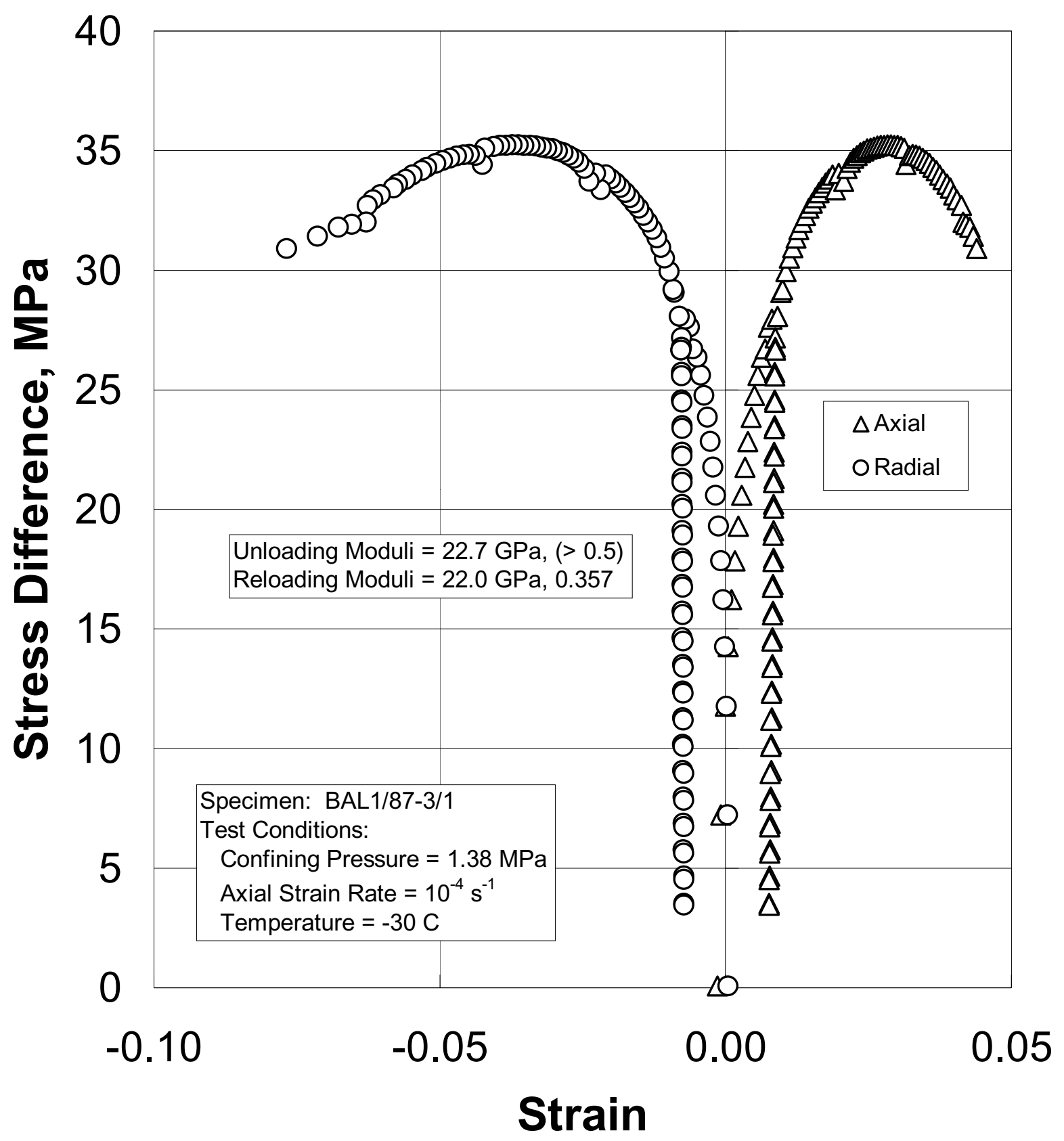

Figure 4-5. Axial Stress Difference as a Function of Strain for a Constant Strain Rate Test on Specimen BAL 1/87-3/1. 


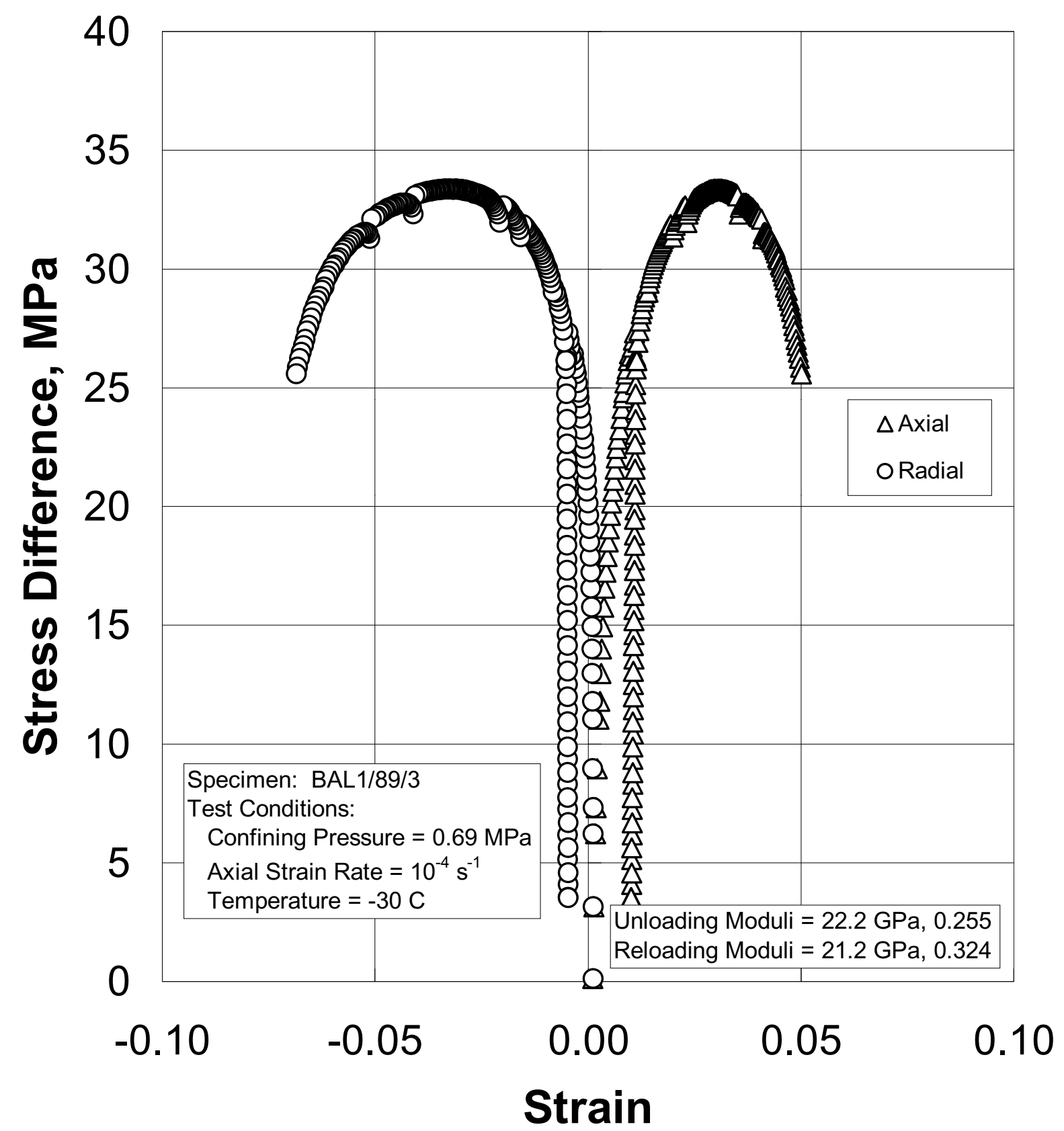

Figure 4-6. Axial Stress Difference as a Function of Strain for a Constant Strain Rate Test on Specimen BAL 1/89/3. 


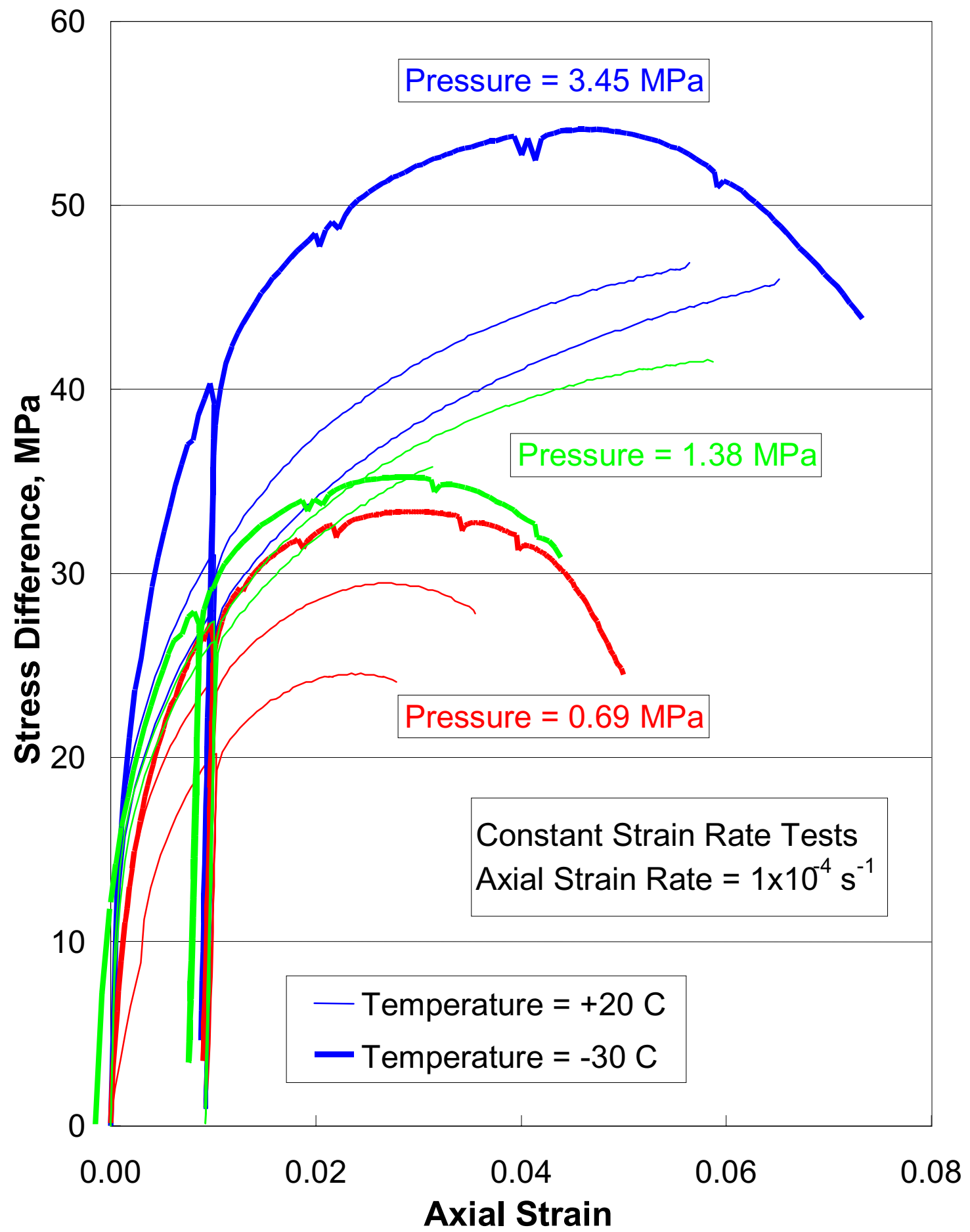

Figure 4-7. Comparison of Constant Strain Rate Results at Two Temperatures. 
Table 4-1. Summary of Constant Strain Rate Test Results

\begin{tabular}{|c|c|c|c|c|c|c|}
\hline \multirow[b]{2}{*}{$\begin{array}{c}\mathbf{P} \\
(\mathrm{MPa})\end{array}$} & \multicolumn{3}{|c|}{$\mathrm{T}=20^{\circ} \mathrm{C}$} & \multicolumn{3}{|c|}{$\mathrm{T}=-30^{\circ} \mathrm{C}$} \\
\hline & $\begin{array}{l}\text { Strength } \\
\qquad \sigma_{\max }\end{array}$ & $\begin{array}{c}\text { Young's } \\
\text { Modulus, E } \\
\text { (GPa) }\end{array}$ & $\begin{array}{c}\text { Poisson's } \\
\text { Ratio } \\
\text { v }\end{array}$ & $\begin{array}{l}\text { Strength } \\
\Delta \sigma_{\max }\end{array}$ & $\begin{array}{c}\text { Young's } \\
\text { Modulus, E } \\
\text { (GPa) }\end{array}$ & $\begin{array}{c}\text { Poisson's } \\
\text { Ratio } \\
\text { v }\end{array}$ \\
\hline \multirow{2}{*}{0.69} & 24.6 & 22.0 & $>0.5$ & \multirow{2}{*}{33.4} & \multirow{2}{*}{21.7} & \multirow{2}{*}{0.29} \\
\hline & 23.9 & 23.9 & 0.50 & & & \\
\hline \multirow{2}{*}{1.38} & $>41.6$ & 26.4 & 0.49 & \multirow{2}{*}{$35.2^{(a)}$} & \multirow{2}{*}{22.1} & \multirow{2}{*}{0.36} \\
\hline & $>35.8$ & 27.2 & 0.36 & & & \\
\hline \multirow{2}{*}{3.45} & $>48.4$ & 29.3 & 0.30 & \multirow{2}{*}{54.1} & \multirow{2}{*}{26.6} & \multirow{2}{*}{0.28} \\
\hline & $>46.9$ & 27.2 & 0.34 & & & \\
\hline
\end{tabular}

(a) Anomalous failure mode.

\subsubsection{Constant Mean Stress Results}

Three constant mean stress tests were performed at a temperature of $-30^{\circ} \mathrm{C}\left(-22^{\circ} \mathrm{F}\right)$. The tests were performed at mean stresses of $6.9,10.3$, and $13.8 \mathrm{MPa}(1,000,1,500$, and 2,000 psi). In each test, the stress difference was recorded at the onset of dilation (volumetric strain caused by microfracturing) to estimate a dilation limit criterion for the salt at $-30^{\circ} \mathrm{C}\left(-22^{\circ} \mathrm{F}\right)$.

The individual constant mean stress test results are shown in Figures 4-8, 4-9, and 4-10 that plot axial stress difference versus axial and radial strain. The axial stress difference at the onset of dilation is shown in each figure. As expected, the dilation stress increased as mean stress increased. The quasi-static test results were pooled to evaluate the effect of temperature on the dilation criterion. The dilation points for these tests were plotted and fitted in stress space as shown in Figure 4-11, which also plots the dilation criterion that was previously established at $20^{\circ} \mathrm{C}\left(68^{\circ} \mathrm{F}\right)$. The dilation criteria values are higher than the values determined for many other salt sites [Van Sambeek et al., 1993; Ratigan et al., 1991], but as seen in the figure, the comparison of dilation criterions fitted at both chilled and room temperatures indicates that the salt dilation is not significantly affected as the temperature is decreased from $20^{\circ} \mathrm{C}$ to $-30^{\circ} \mathrm{C}\left(68^{\circ} \mathrm{F}\right.$ to $\left.-22^{\circ} \mathrm{F}\right)$.

\subsubsection{Creep Test Results}

Five constant stress creep tests were performed. Three tests were performed at a temperature of $0^{\circ} \mathrm{C}\left(32^{\circ} \mathrm{F}\right)$ and two tests were performed at a temperature of $-20^{\circ} \mathrm{C}\left(-4^{\circ} \mathrm{F}\right)$. All tests were performed at a confining pressure of $27.6 \mathrm{MPa}(4,000 \mathrm{psi})$. The three tests at $0^{\circ} \mathrm{C}$ $\left(32^{\circ} \mathrm{F}\right)$ were subjected to axial stress differences of $6.9,10.7$, and $20.7 \mathrm{MPa}(1,000,1,550$, and $3,000 \mathrm{psi})$; respectively, while the two tests at $-20^{\circ} \mathrm{C}\left(-4^{\circ} \mathrm{F}\right)$ were subjected to axial stress differences of 10.7 MPa and 20.7 MPa (1,550 and 3,000 psi). In all tests, the zero origin 


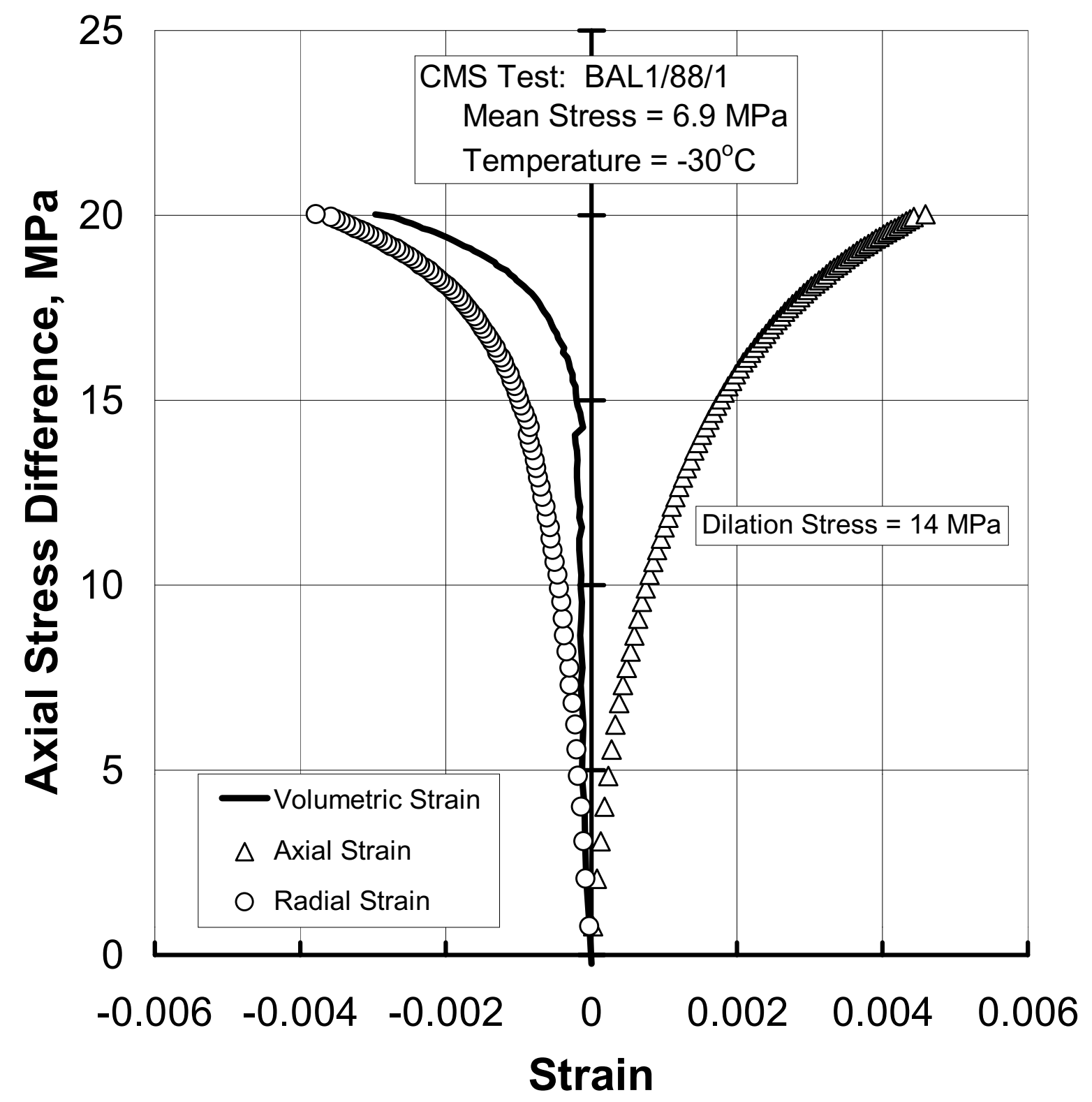

Figure 4-8. Constant Mean Stress Test at 6.9 MPa on Specimen BAL 1/88/1. 


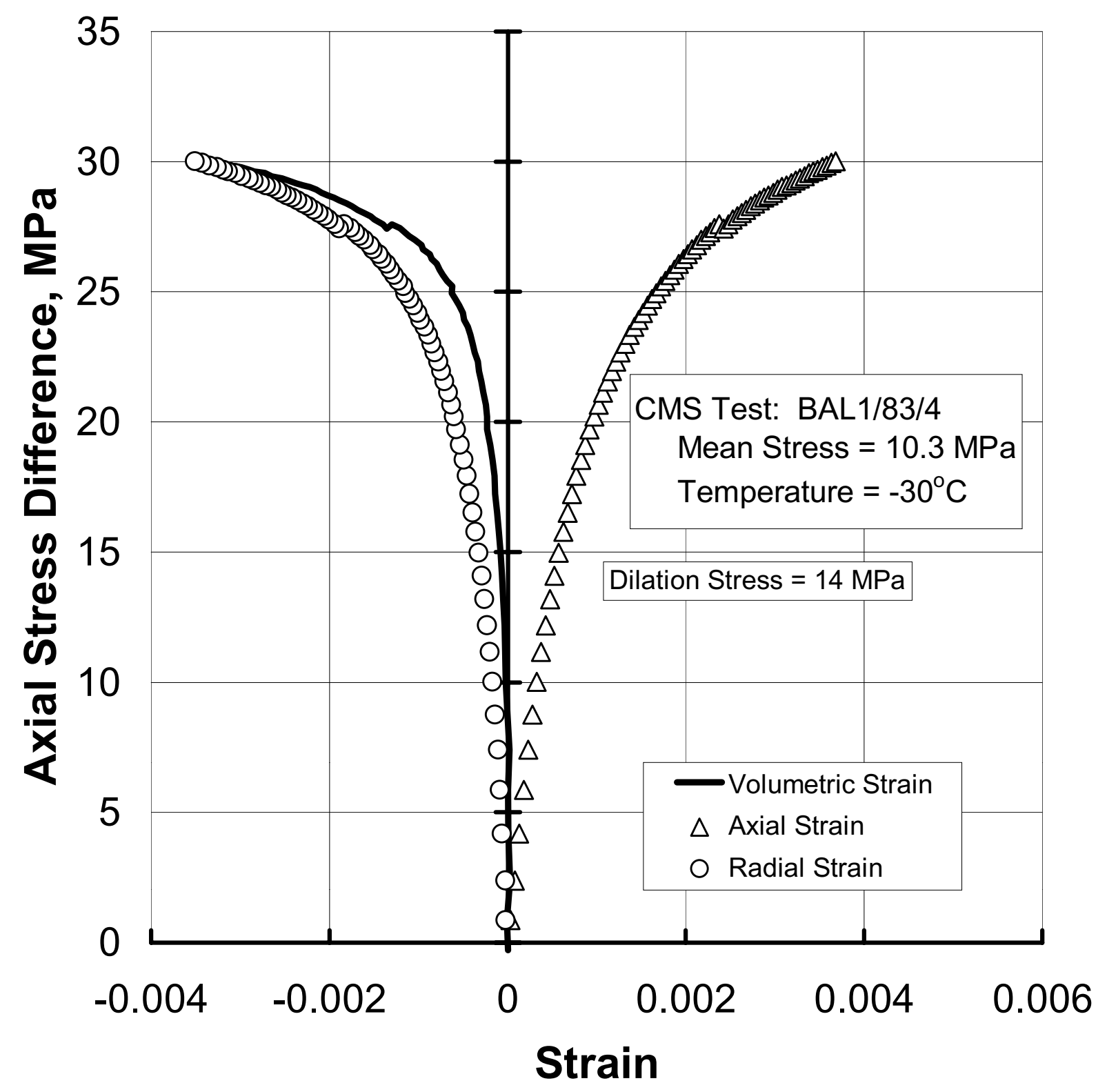

Figure 4-9. Constant Mean Stress Test at 10.3 MPa on Specimen BAL 1/83/4. 


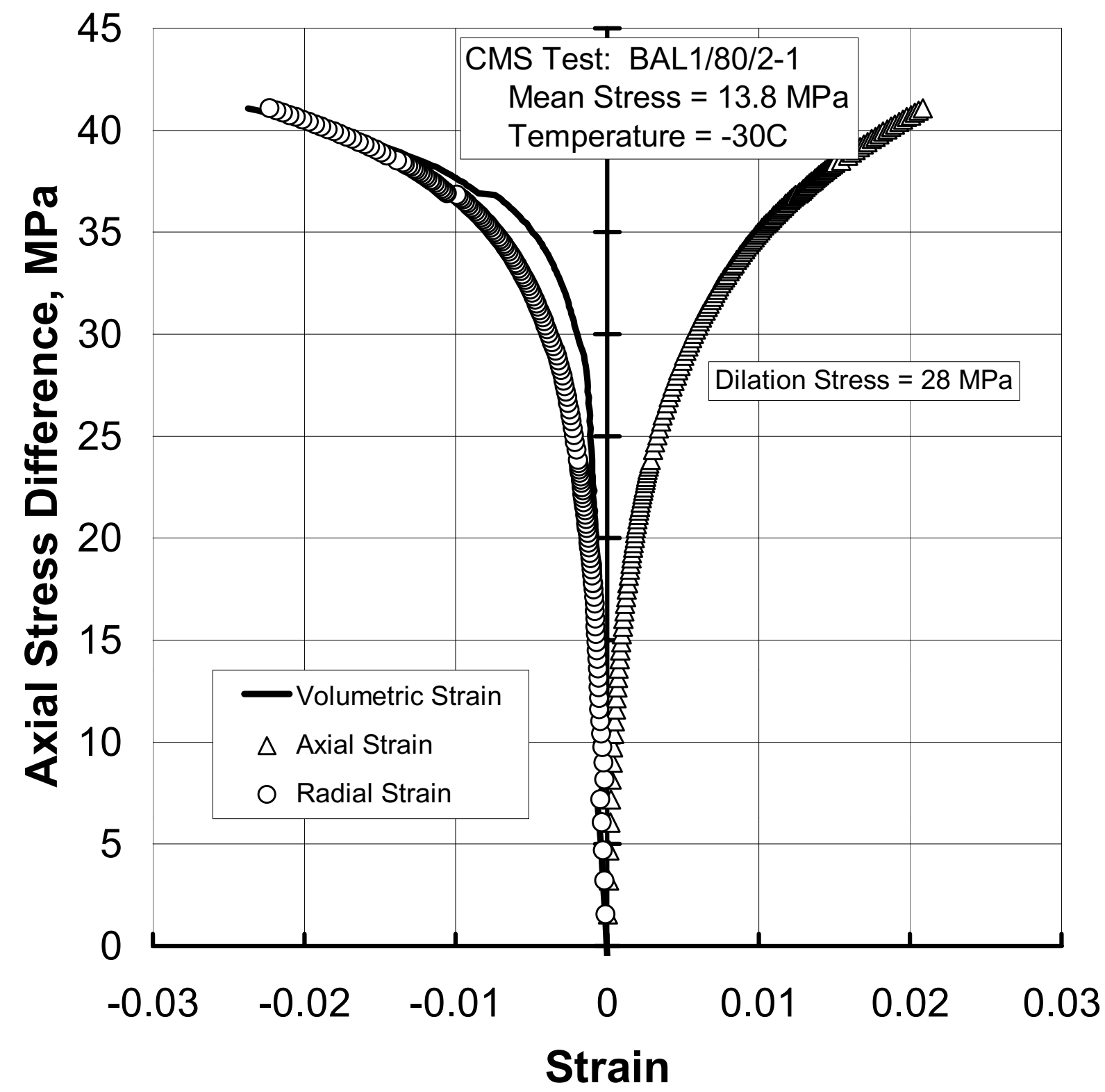

Figure 4-10. Constant Mean Stress Test at 13.8 MPa on Specimen BAL1/80/2-1. 


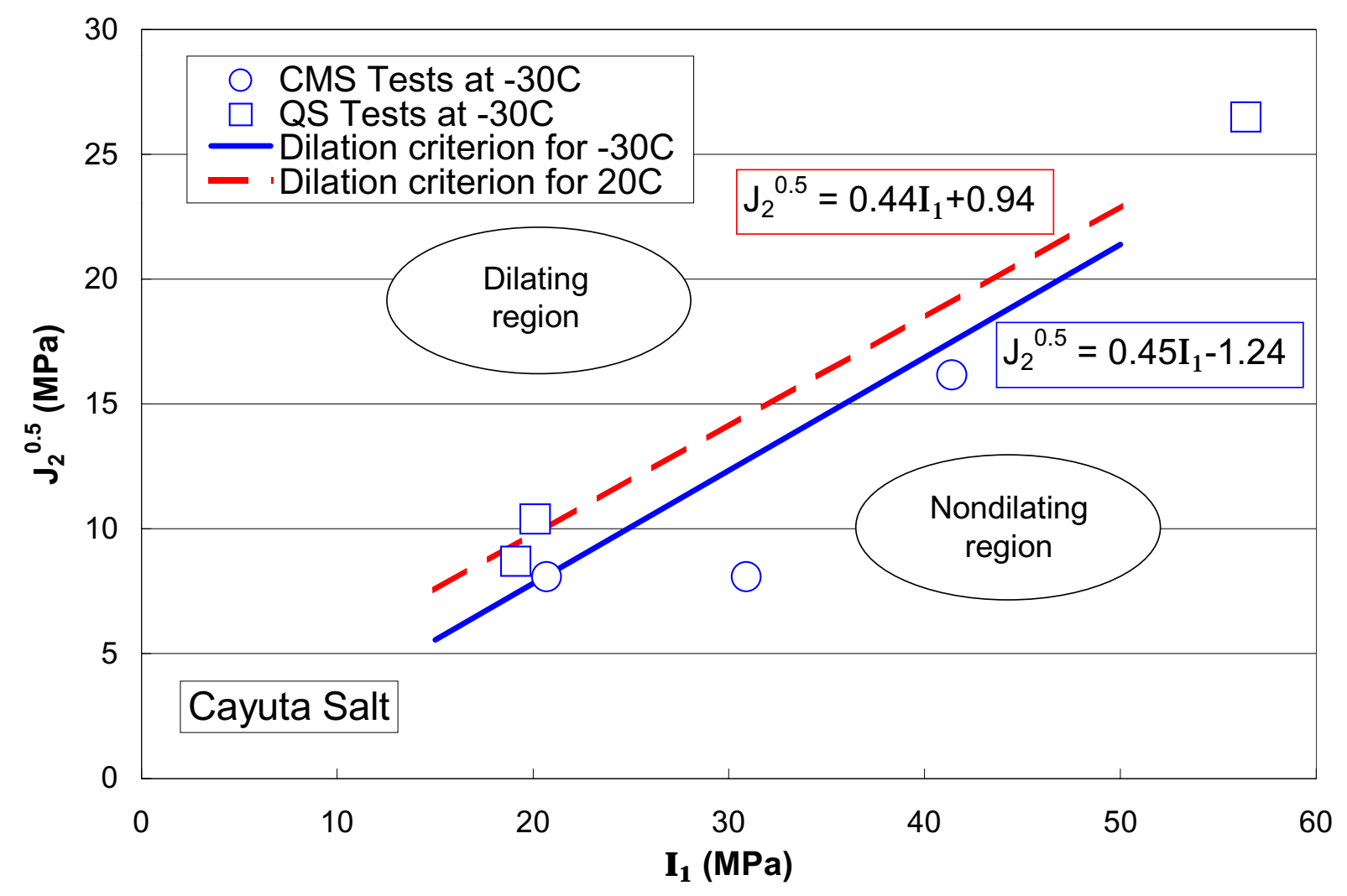

Figure 4-11. Dilation Criterions at $-30^{\circ} \mathrm{C}$ and $20^{\circ} \mathrm{C}$. 
for time and strain was established at the point where the specimen was under hydrostatic stress just before the axial stress difference was applied. The axial stress difference was applied very quickly in these tests with the stress differences being applied in less than 30 seconds. During stress application, both elastic and plastic strains accumulated in the specimen, and the rapid loading was an attempt to reduce the amount of creep strain induced prior to the onset of constant stress conditions. Following the stress application, the axial stress difference was held constant so the elastic strain remained constant while the plastic strain continued to accumulate with time (creep).

The results of the creep tests are shown in Figures 4-12 and 4-13 that plot total axial strain (elastic + plastic) versus time for temperatures of $0^{\circ} \mathrm{C}$ and $-20^{\circ} \mathrm{C}\left(32^{\circ} \mathrm{F}\right.$ and $\left.-4^{\circ} \mathrm{F}\right)$, respectively. The dilatometric technique that was used for measuring the radial strain had inadequate resolution at such small strain levels, so only the axial strains are reported. Also shown in each figure is the stress difference used for each test and the axial strain rate that was calculated from the data near the end of each test. These terminal strain rates are the best estimates of the steady-state strain rates that would be observed if the tests were continued for very long periods of time. For example, while four of the tests were terminated after about 1 month, the test performed at the low stress difference of $10.3 \mathrm{MPa}(1,500 \mathrm{psi})$ was continued for another month to obtain a better estimate of the steady-state strain rate.

With only five test results available, estimation of constitutive parameters in a creep law would be highly preliminary. However, the results obtained at different temperatures can be compared, as shown in Figure 4-14 that plots axial creep strain as a function of time for three creep tests performed under the same stress conditions, but at temperatures of $40^{\circ} \mathrm{C}, 0^{\circ} \mathrm{C}$, and $-20^{\circ} \mathrm{C}\left(104^{\circ} \mathrm{F}, 32^{\circ} \mathrm{F}\right.$, and $\left.-4^{\circ} \mathrm{F}\right)$. As can be seen in the figure, the specimen strain is much smaller at the lower temperatures. The differences in the strain accumulation are attributable to differences in plastic strain rate, with plastic strain rates being lower at the lower temperatures.

\subsubsection{Discussion of Laboratory Results}

The change in mechanical properties was investigated by performing both quasi-static loading tests and creep tests at refrigerated temperatures. The quasi-static tests comprised two types of triaxial compression tests: (1) constant strain rate tests where the confining pressure was held constant and (2) constant mean stress tests where the confining pressure was reduced at half the rate the axial stress was increased so that the mean stress on the specimen remained constant.

The constant strain rate tests demonstrated that the elastic moduli of the salt were relatively unaffected by the change in temperature. The average elastic moduli of Cayuta salt determined at $-30^{\circ} \mathrm{C}\left(-22^{\circ} \mathrm{F}\right)$ were $\mathrm{E}=24.2 \mathrm{GPa}\left(3.51 \times 10^{6} \mathrm{psi}\right)$ and $v=0.29$, which compared favorably with typical room temperature elastics values of $\mathrm{E}=25.6 \mathrm{GPa}\left(3.71 \times 10^{6} \mathrm{psi}\right)$ and 


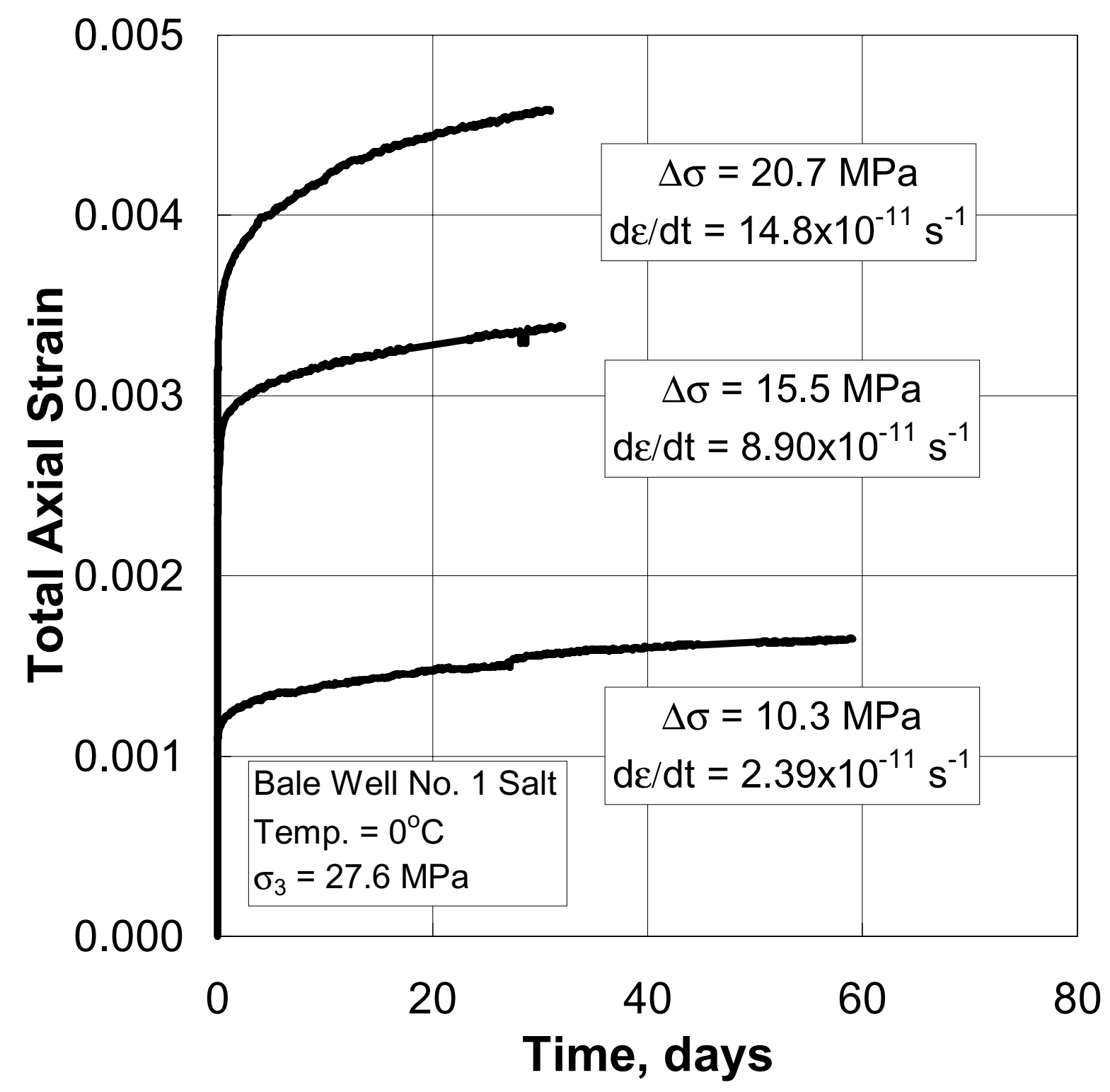

Figure 4-12. Total Axial Strain as a Function of Time for Creep Tests at $0^{\circ} \mathrm{C}$. 


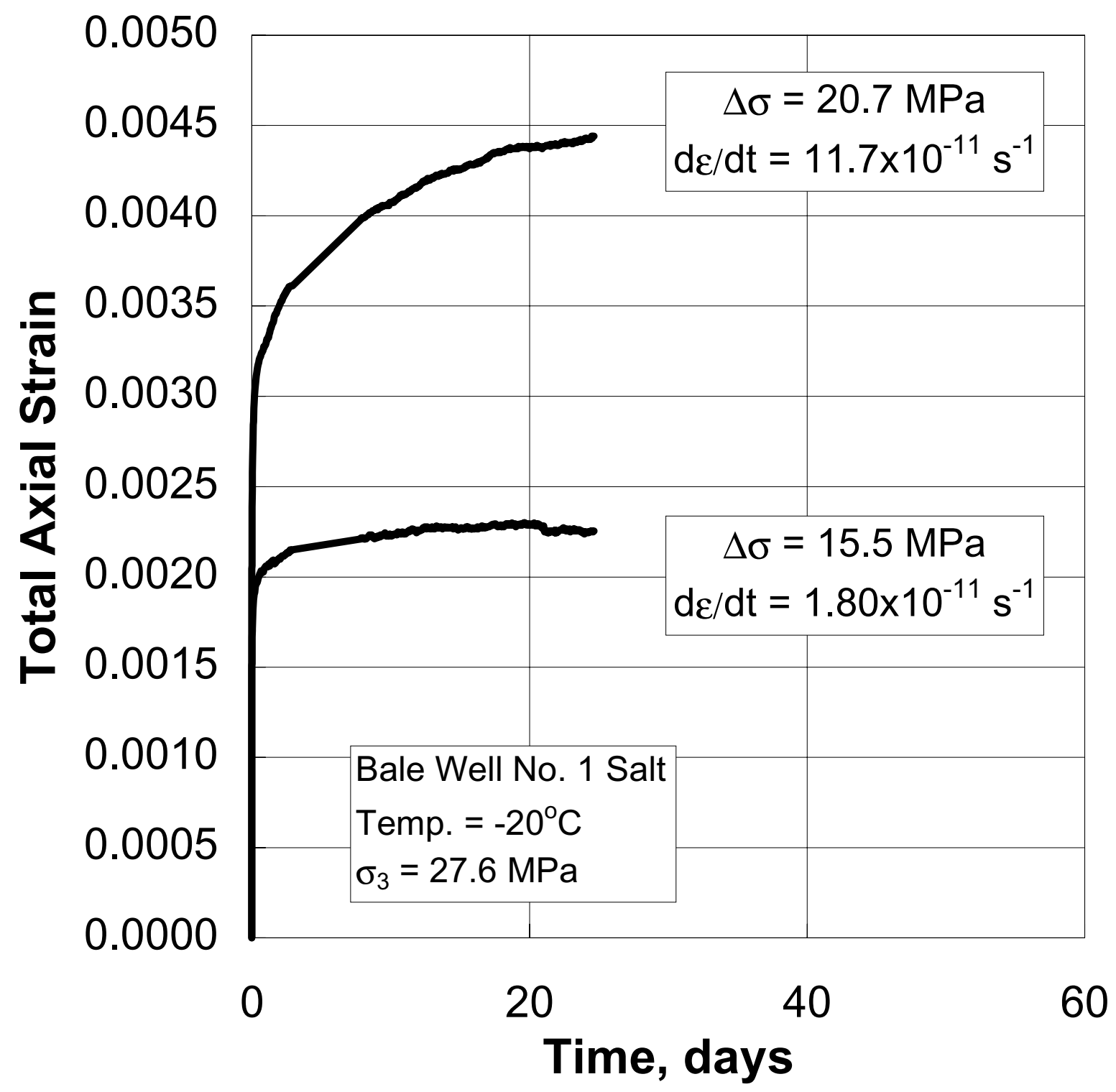

Figure 4-13. Total Axial Strain as a Function of Time for Creep Tests at $-20^{\circ} \mathrm{C}$. 


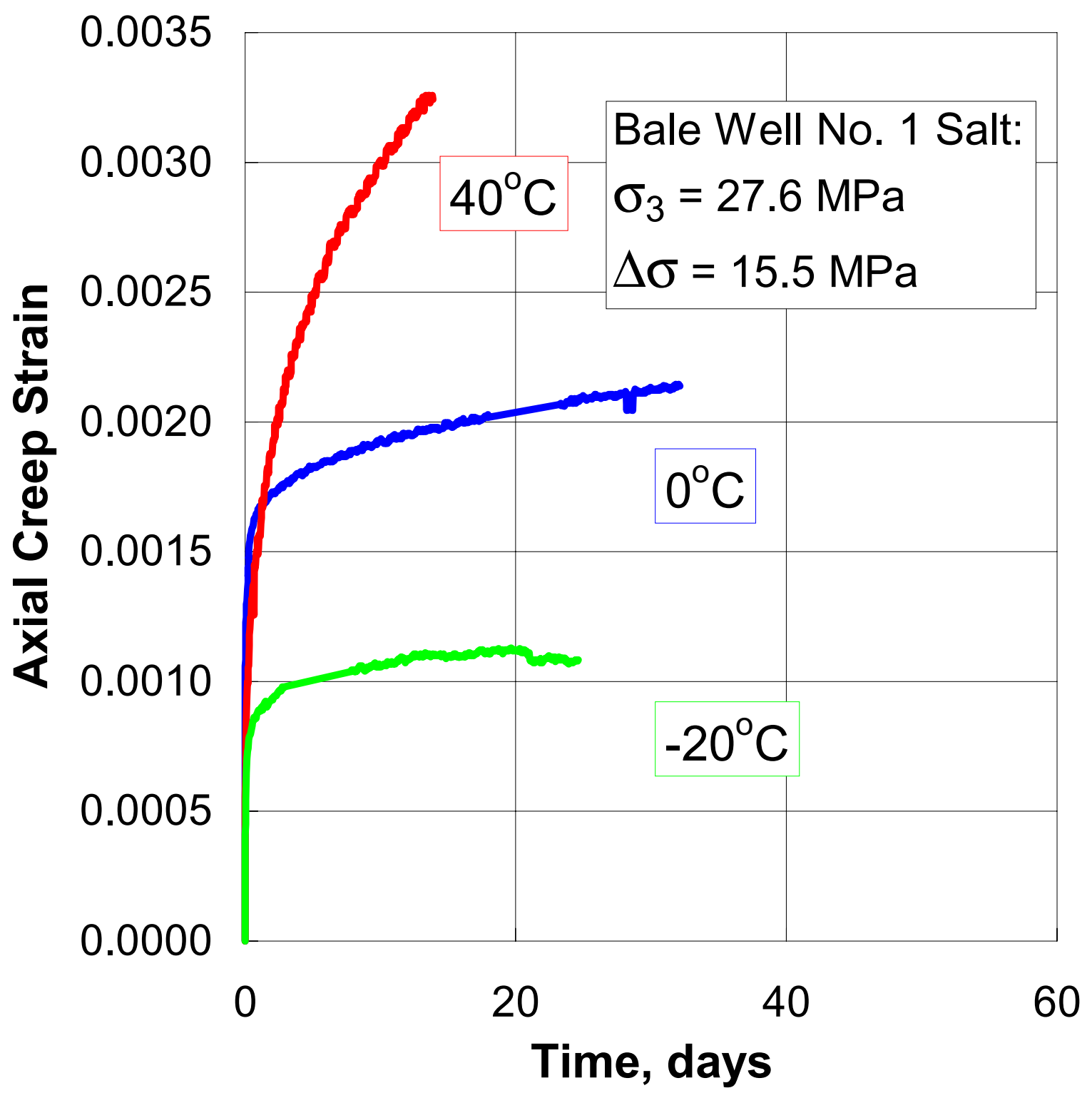

Figure 4-14. Comparison of Creep Response at Different Temperatures. 
$v=0.32$. In addition, the constant strain rate tests indicated that the ultimate strength of the chilled salt is expected to match the strength of room temperature specimens, although the strain at failure is expected to be much lower because the colder temperature inhibits the plastic behavior.

The results of the constant mean stress tests were analogous to the constant strain rate results because they indicated little difference in dilational behavior as the temperature was reduced. Previous estimates of the dilation criterion for Cayuta salt were determined at room temperature and indicated that dilation would not occur so long as $\sqrt{J_{2}}$ was less than $0.44 I_{1}$ (i.e., $\left.\sqrt{J_{2}}<0.44 \mathrm{I}_{1}\right)$. The tests performed at a temperature of $-30^{\circ} \mathrm{C}\left(-22^{\circ} \mathrm{F}\right)$ indicated that the criterion would be nearly the same at 0.45 . Both of these values are higher than the value of 0.27 observed for many other types of salt.

Three creep tests were performed at a temperature of $0^{\circ} \mathrm{C}\left(32^{\circ} \mathrm{F}\right)$ and two creep tests were performed at a temperature of $-20^{\circ} \mathrm{C}\left(-4^{\circ} \mathrm{F}\right)$ with all five using a confining pressure of $27.6 \mathrm{MPa}$ (4,000 psi). Different stress differences were applied within each temperature regime, and as expected, the specimens subjected to higher axial stress differences exhibited more axial strain, meaning that the strain rate in the specimen is a nonlinear function of the stress difference. The creep responses were also compared at different temperatures using the same stress difference and again, as expected, the warmer specimens exhibited more strain than did the chilled specimens.

The chilled creep tests that have been completed are an insufficient database to precisely determine parameters in a constitutive model for salt at refrigerated gas temperatures, but they were useful in evaluating the numerical predictions. As described elsewhere in this chapter, the creep responses observed at refrigerated temperatures in the laboratory study were predicted by an existing constitutive model to evaluate the model's adequacy for establishing design limits for salt caverns that will be used to store chilled natural gas.

\subsection{EVALUATION OF CAVERN STABILITY}

Cavern stability during refrigerated natural gas storage was evaluated for the proposed Avoca facility using thermomechanical finite element simulations. The following two sections describe the technical approach used in the modeling and the results of the analysis.

\subsubsection{Technical Approach}

The technical approach used to evaluate cavern stability was to model the conversion from conventional to refrigerated storage using the finite element method. Material properties for the salt and nonsalt rocks were determined from the current and previous laboratory testing. Cavern stability was then evaluated by comparing stress states predicted in the simulations to 
criterion devel oped from laboratory testing of the salt and nonsalt rocks. Below is a description for each of the different elements of the technical approach.

\subsubsection{Finite Element Program}

The finite element program, SPECTROM-32 [Callahan et al., 1989], was used to evaluate cavern stability for the chilled gas storage facility. SPECTROM-32 is a thermomechanical finite element program developed by RESPEC for the solution of rock mechanics problems. It was designed specifically for the simulation of underground openings and structures. SPECTROM-32 not only has the capability to model the elastic-plastic response that is commonly associated with brittle rock types, but it also has the capability to simulate the viscoplastic behavior that is observed in rock salt. The features and capabilities of SPECTROM-32 required specifically for this analysis include:

- Option for modeling two-dimensional and axisymmetric geometries

- Kinematic and traction boundary conditions

- Munson-Dawson multimechanism constitutive model for viscoplastic behavior of salt

- Capability to represent arbitrary in situ stress and temperature fields.

\subsubsection{Material Properties}

The properties used to model the salt and shale in the finite element modeling and to evaluate the structural stability of the cavern are based mostly from previous testing of Bale Well No. 1 at in situ temperature (Appendix A) and from current testing of salt at low temperatures (Section 4.1). The sections bel ow summarize the properties used.

\subsection{Elastic Properties}

The values of Young's modulus (E) and Poison's ratio (v) used to model the salt and shale in the cavern model were based on testing of core from Bale Well No. 1. Those used for salt are weighted average values of testing conducted at both ambient and subambient temperatures. These average values are $25.2 \mathrm{GPa}\left(3.65 \times 10^{6} \mathrm{psi}\right)$ and 0.35 for Young's modulus and Poisson's ratio, respectively. The values used for the shale are based on testing conducted at room temperature and are $34.7 \mathrm{GPa}\left(5.04 \times 10^{6} \mathrm{psi}\right)$ and 0.19 for Young's modulus and Poisson's ratio, respectively.

The coefficient of linear thermal expansion $(\alpha)$ for salt decreases somewhat as temperature decreases. A value of $3.83 \times 10^{-5} \mathrm{~K}^{-1}\left(2.13 \times 10^{-5} \mathrm{R}^{-1}\right)$ was used to model the salt in this study and is calculated from a temperature-dependent equation given by Senseny et al. [1992] at a temperature of $7^{\circ} \mathrm{C}$ (the average of in situ and chilled gas temperatures). A value of $7.87 \times$ $10^{-6} \mathrm{~K}^{-1}\left(4.37 \times 10^{-6} \mathrm{R}^{-1}\right)$ was used to model the coefficient of linear thermal expansion $(\alpha)$ for 
shale in the model and is based on testing of various shales at temperatures ranging from $0^{\circ} \mathrm{C}$ to $200^{\circ} \mathrm{C}$ [Croff et al., 1985].

\subsection{Creep Properties for Salt}

Considerable research has been performed to determine a satisfactory constitutive law that characterizes the viscoplastic (creep) behavior of rock salt. The Munson-Dawson multimechanism constitutive model has been found to perform reasonably well in fitting data from laboratory constant-stress tests and in predicting the response of laboratory, field, and benchscale tests performed on salt from the Waste Isolation Pilot Plant (WIPP) site in New Mexico [Munson et al., 1989]. Two differential rate equations comprise the Munson-Dawson model: (1) the strain-rate equations, which give the viscoplastic strain rate (Equation 4-1) and (2) the evolutionary equation, which gives the rate of change of an internal variable (Equation 4-2). The three-dimensional form of the Munson-Dawson model is given below.

$$
\begin{gathered}
\dot{\varepsilon}_{\mathrm{ij}}^{\mathrm{vp}}=\frac{\partial \sigma_{\mathrm{e}}}{\partial \sigma_{\mathrm{ij}}} \dot{\varepsilon}_{\mathrm{s}} \\
\dot{\zeta}=(F-1) \dot{\varepsilon}_{\mathrm{s}}
\end{gathered}
$$

where:

$$
\begin{gathered}
\dot{\varepsilon}_{\mathrm{s}}=\sum_{\mathrm{i}=1}^{3} \dot{\varepsilon}_{\mathrm{s}_{\mathrm{i}}} \\
\dot{\varepsilon}_{\mathrm{s}_{\mathrm{i}}}=\text { steady-state strain rate for mechanism i } \\
\dot{\varepsilon}_{\mathrm{s}_{1}}=\mathrm{A}_{1} \exp \left(-\mathrm{Q}_{1} / \mathrm{RT}\right)\left(\sigma_{\mathrm{e}} / \mu\right)^{\mathrm{n}_{1}} \\
\dot{\varepsilon}_{\mathrm{s}_{2}}=\mathrm{A}_{2} \exp \left(-\mathrm{Q}_{2} / \mathrm{RT}\right)\left(\sigma_{\mathrm{e}} / \mu\right)^{\mathrm{n}_{2}} \\
\dot{\varepsilon}_{\mathrm{s}_{3}}=\left[\mathrm{B}_{1} \exp \left(-\mathrm{Q}_{1} / \mathrm{RT}\right)+\mathrm{B}_{2} \exp \left(-\mathrm{Q}_{2} / \mathrm{RT}\right)\right] \cdot \sinh \left[\mathrm{q}\left(\sigma_{\mathrm{e}}-\sigma_{\mathrm{o}}\right) / \mu\right] \mathrm{H}\left(\sigma_{\mathrm{e}}-\sigma_{\mathrm{o}}\right)
\end{gathered}
$$




$$
\begin{gathered}
F= \begin{cases}\exp \left[\Delta\left(1-\frac{\varsigma}{\varepsilon_{\mathrm{t}}^{*}}\right)^{2}\right] & \text { for } \varsigma<\varepsilon_{\mathrm{t}}^{*} \\
1 & \text { for } \varsigma=\varepsilon_{\mathrm{t}}^{*} \\
\exp \left[-\delta\left(1-\frac{\varsigma}{\varepsilon_{\mathrm{t}}^{*}}\right)^{2}\right] & \text { for } \varsigma>\varepsilon_{\mathrm{t}}^{*}\end{cases} \\
\varepsilon_{\mathrm{t}}^{*}=\mathrm{K}_{\mathrm{o}} \exp (c T)\left(\sigma_{\mathrm{e}} / \mu\right)^{\mathrm{m}} \\
\Delta=\alpha+\beta \log \left(\sigma_{\mathrm{e}} / \mu\right)
\end{gathered}
$$

and

$$
\begin{aligned}
\dot{\varepsilon}_{\mathrm{ij}}^{\mathrm{vp}} & =\text { viscoplastic strain-rate tensor } \\
\sigma_{\mathrm{e}} & =\sqrt{3 \mathrm{~J}_{2}} \text { (effective stress) } \\
\mathrm{J}_{2} & =\frac{1}{2} \mathrm{~s}_{\mathrm{ij}} \mathrm{s}_{\mathrm{ij}} \\
\mathrm{s}_{\mathrm{ij}} & =\sigma_{\mathrm{ij}}-\delta_{\mathrm{ij}} \sigma_{\mathrm{m}} \text { (deviatoric stress tensor) } \\
\sigma_{\mathrm{m}} & =\frac{1}{3} \sigma_{\mathrm{kk}} \text { (mean stress) } \\
\sigma_{\mathrm{ij}} & =\text { stress tensor } \\
\delta_{\mathrm{ij}} & =\text { Kronecker delta } \\
\varsigma & =\text { internal variable } \\
\mathrm{T} & =\text { absolute temperature } \\
\mathrm{H}(\mathrm{x}) & =\text { Heaviside function } \\
\mu & =9,618 \mathrm{MPa} \text { (a constant) } \\
\mathrm{Q}_{1} / \mathrm{R} & =12,629 \mathrm{~K} \text { (a constant) } \\
\mathrm{n}_{1} & =5.5 \text { (a constant) } \\
\mathrm{A}_{1}, \mathrm{~A}_{2}, \mathrm{~B}_{1}, \mathrm{~B}_{2}, \mathrm{Q}_{2}, \mathrm{n}_{2} & =
\end{aligned}
$$$$
q, \sigma_{0}, \delta, K_{0}, c, m, \alpha, \beta=\text { experimentally determined parameters. }
$$

As indicated by Equation 4-3, the steady-state creep rate $\left(\dot{\varepsilon}_{\mathrm{s}}\right)$ based on the Munson-Dawson model is composed of three terms. Each term is associated with a different creep mechanism. The first and third mechanisms $\left(\dot{\varepsilon}_{s_{1}}\right.$ and $\left.\dot{\varepsilon}_{s_{3}}\right)$ are dislocation climb and dislocation glide, respectively, and the second mechanism $\left(\dot{\varepsilon}_{s_{2}}\right)$ is referred to as the undefined mechanism. The relative contribution of each mechanism to the steady-state creep rate strongly depends on the effective stress and temperature. 
When pressure conditions in a storage cavern are changed, the transient nature of the Munson-Dawson model can be an important factor in the response of the cavern. According to Equation 4-1, the steady-state creep rate is multiplied by a transient factor $(F)$ to obtain the viscoplastic strain rate. The value of the transient factor depends on whether the internal variable $(\varsigma)$ is less than, equal to, or greater than the transient strain limit $\left(\varepsilon_{t}^{*}\right)$, which is a function of the effective stress and temperature. When $\varsigma<\varepsilon_{t}^{*}$, the viscoplastic strain rate is greater than the steady-state creep rate $(F>1)$. This is the work-hardening branch of the Munson-Dawson model. The work-hardening branch is commonly associated with an increase in loading, such as when the cavern pressure is decreased. When $\varsigma>\varepsilon_{t}^{*}$, the viscoplastic strain rate is less than the steady-state creep rate $(F<1)$. This is the recovery branch of the MunsonDawson law. This branch is commonly associated with a decrease in loading, such as when the cavern pressure is increased. Through the evolutionary equation, the value of the internal variable is always approaching the transient strain limit. In turn, the viscoplastic strain rate is al ways approaching the steady-state creep rate (i.e., $F$ approaches unity as $\varsigma$ approaches $\varepsilon_{t}^{*}$ ).

The Munson-Dawson model has 14 parameters that must be determined experimentally or estimated empirically. The parameter values used to represent the salt at the Avoca facility were determined by fitting the model to the data obtained from eight triaxial compression creep tests performed on salt from Bale Well No. 1 using a nonlinear, least-squares procedure. Five of the tests were performed at subambient conditions, as described in Section 4.1.4.3. The remaining three tests were performed at an elevated temperature of $40^{\circ} \mathrm{C}$ (see Appendix A). These parameter values were subsequently used in the SPECTROM-32 finite element analysis to model the viscoplastic behavior of the salt surrounding the chilled gas storage cavern.

Determining a set of parameter values for the Munson-Dawson model that represents the salt over the stress and temperature range of interest for the chilled gas storage proved to be very difficult. These difficulties include:

- The Munson-Dawson model was developed for investigating nuclear waste disposal in salt where temperatures are typically above $20^{\circ} \mathrm{C}\left(68^{\circ} \mathrm{F}\right)$. The model does not accommodate the very sharp transition from transient creep to steady-state creep observed in the low temperature creep tests.

- The number of laboratory tests obtained for Bale Well No. 1 salt is limited and has no redundancy, so specimen-to-specimen variability is unknown. This is illustrated by two of the creep tests conducted at a stress difference of $20.7 \mathrm{MPa}(3,000 \mathrm{psi})$. The test at $0^{\circ} \mathrm{C}$ $\left(32^{\circ} \mathrm{F}\right)$ had a higher creep rate than the test at $-20^{\circ} \mathrm{C}\left(-4^{\circ} \mathrm{F}\right)$.

Several attempts were made to determine the parameters used to model the Avoca site. The final fit was arrived at through the following methodology: 
1. The test conducted at a stress difference of $20.7 \mathrm{MPa}(3,000 \mathrm{psi})$ and a temperature of $0^{\circ} \mathrm{C}\left(32^{\circ} \mathrm{F}\right)$ was excluded from the fit.

2. Individual fits were made to each of the other seven creep tests to determine the steadystate strain rate $\left(\dot{\varepsilon}_{\mathrm{ss}}\right)$, the transient strain limit $\left(\varepsilon_{\mathrm{t}}^{*}\right)$, and the hardening parameter $(\Delta)$. Note that $F$ remains on the strain-hardening branch (upper branch of Equation 4-8) during a creep test.

3. The parameters $A_{1}, A_{2}, B_{1}, B_{2}, Q_{1} / R, Q_{2} / R, n_{2}$, and $q$ were then determined by fitting the steady-state strain rates $\left(\dot{\varepsilon}_{s s}\right)$ determined from each of the tests to Equation 4-3. The stress cut-off $\left(\sigma_{0}\right)$ for the third mechanism was left at the WIPP value of $20.57 \mathrm{MPa}$ $(2,983$ psi).

4. The parameters $\mathrm{K}_{0}, \mathrm{c}$, and $\mathrm{m}$ were determined by fitting the transient strain limit values determined from the individual test fits to Equation 4-9.

5. The parameters $\alpha$ and $\beta$ were determined by fitting the hardening parameter $(\Delta)$ values determined from the individual test fits to Equation 4-10.

6. Because the fits to the transient parameters in Steps 4 and 5 were not very good (especially the fit to the hardening parameter), an attempt was made to improve the overall fits to the test data by making a global fit to the creep tests. In this fit, the steady-state parameters determined in Step 3 were fixed and the transient parameters determined in Steps 4 and 5 were all owed to change.

The resulting Munson-Dawson parameter values used for Bale Well No. 1 salt are shown in Table 4-2. A comparison of the creep test data and the numerical fits is shown in Figures 4-15, 4-16, and 4-17. In general, the modeled steady-state creep rates are equal to or exceed the tested values. The tests at low temperature have a much sharper transition between transient and steady-state creep than the tests conducted at $40^{\circ} \mathrm{C}\left(104^{\circ} \mathrm{F}\right)$ and proved to be very difficult to replicate with the Munson-Dawson model.

\subsubsection{In Situ Conditions}

Because the creep rate of salt is dependent on temperature and stress, it is important to model temperatures and stresses which are representative of those in the vicinity of the Avoca caverns. The following two sections describe the in situ temperature and stress distributions assumed in this analysis.

\subsection{Temperature Profile}

The initial in situ temperature distribution used is the same as that used for the thermal analysis (see Section 3.2.1) where temperature as a function of depth is described by the following equation:

$$
T=10+0.0273 \times D
$$


where $T$ is the temperature in degrees Centigrade and $D$ is the depth in meters. During chilled gas storage simulations, a temperature database that is output from thermal finite element simulations is read into the structural finite element simulations to supply the temperature distribution as a function of time.

Table 4-2. Estimates of the Munson-Dawson Creep Parameters for Bale Well No. 1 Salt

\begin{tabular}{||c|c|c||}
\hline Parameters & Units & Value \\
\hline \hline $\mathrm{A}_{1}$ & $\mathrm{~d}^{-1}$ & $1.37\left(10^{27}\right)$ \\
\hline $\mathrm{A}_{2}$ & $\mathrm{~d}^{-1}$ & $1.58\left(10^{18}\right)$ \\
\hline $\mathrm{B}_{1}$ & $\mathrm{~d}^{-1}$ & $9.93\left(10^{10}\right)$ \\
\hline $\mathrm{B}_{2}$ & $\mathrm{~d}^{-1}$ & $4.95\left(10^{2}\right)$ \\
\hline $\mathrm{K}_{0}$ & - & $1.79\left(10^{6}\right)$ \\
\hline $\mathrm{m}$ & - & $2.65(10)$ \\
\hline$\alpha$ & - & $-2.49\left(10^{1}\right)$ \\
\hline$\beta$ & - & $-1.16\left(10^{1}\right)$ \\
\hline $\mathrm{q}$ & - & $4.50\left(10^{3}\right)$ \\
\hline $\mathrm{Q}_{1} / \mathrm{R}$ & $\mathrm{K}$ & $1.26\left(10^{4}\right)$ \\
\hline $\mathrm{Q}_{2} / \mathrm{R}$ & $\mathrm{K}$ & $6.22\left(10^{4}\right)$ \\
\hline $\mathrm{N}_{2}$ & - & $4.76(10)$ \\
\hline$\sigma_{0}$ & $\mathrm{MPa}$ & $2.06\left(10^{1}\right)$ \\
\hline $\mathrm{C}$ & $\mathrm{K}$ & $-7.27\left(10^{-3}\right)$ \\
\hline$\delta$ & - & 0.58 \\
\hline
\end{tabular}

\subsection{Stress Distribution}

The in situ stress state at the Avoca facility is known to be anisotropic. The initial in situ stress state used in the cavern stability analysis is based on stress test measurements in Bale Well No. 1 (see Appendix A). For this analysis, the maximum horizontal stress is 1.81 times the vertical stress and the minimum horizontal stress is 0.9 times the vertical stress. The vertical in situ stress distribution prior to the excavation of caverns was assumed to be:

$$
\sigma_{z}=0.02269(z-1,162.2)+30.76
$$

where $\sigma_{\mathrm{z}}$ is the vertical stress in MPa and $\mathrm{z}$ is the depth in meters. 


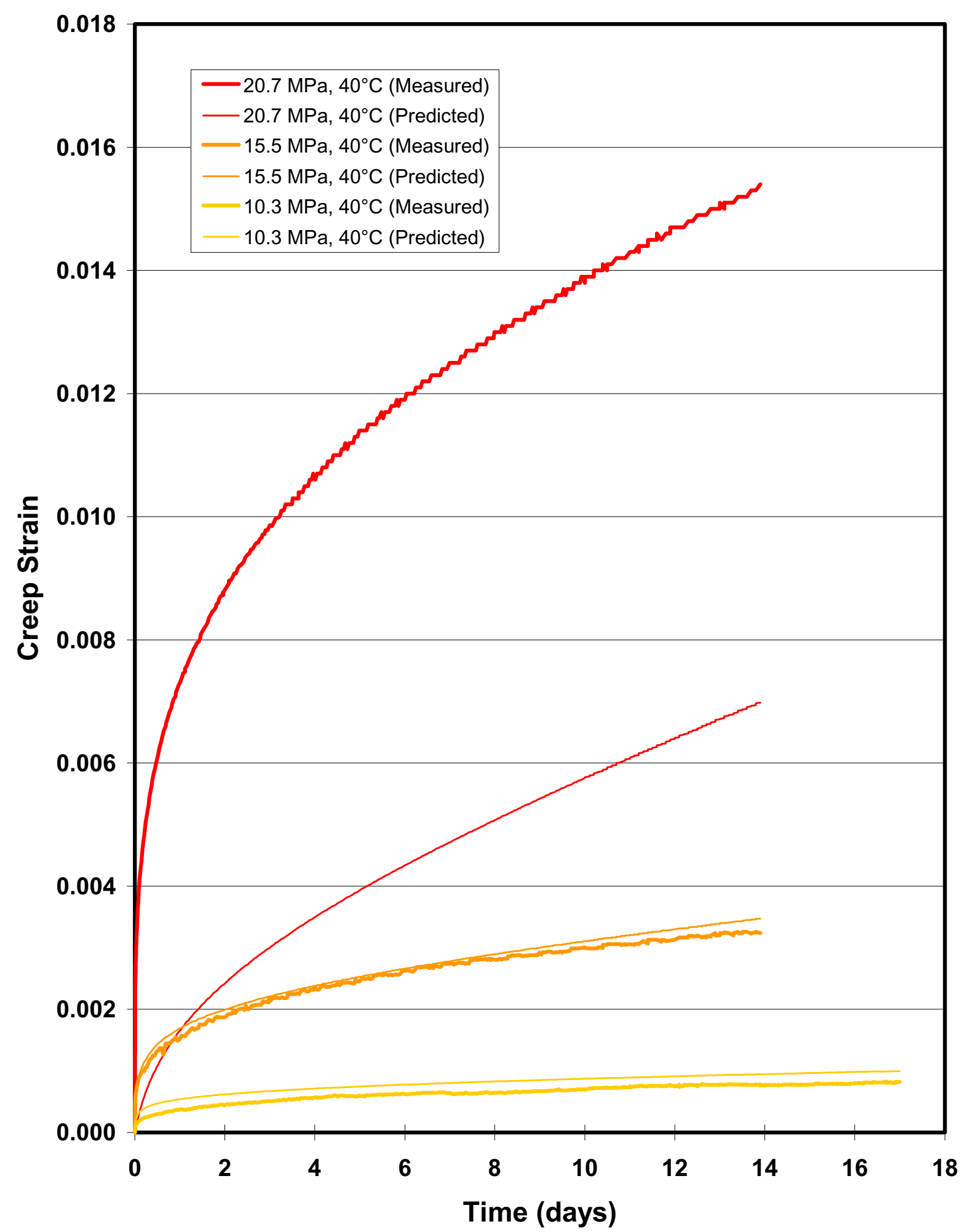

Figure 4-15. Measured and Predicted Creep Strain for Creep Tests Conducted at $40^{\circ} \mathrm{C}$. 


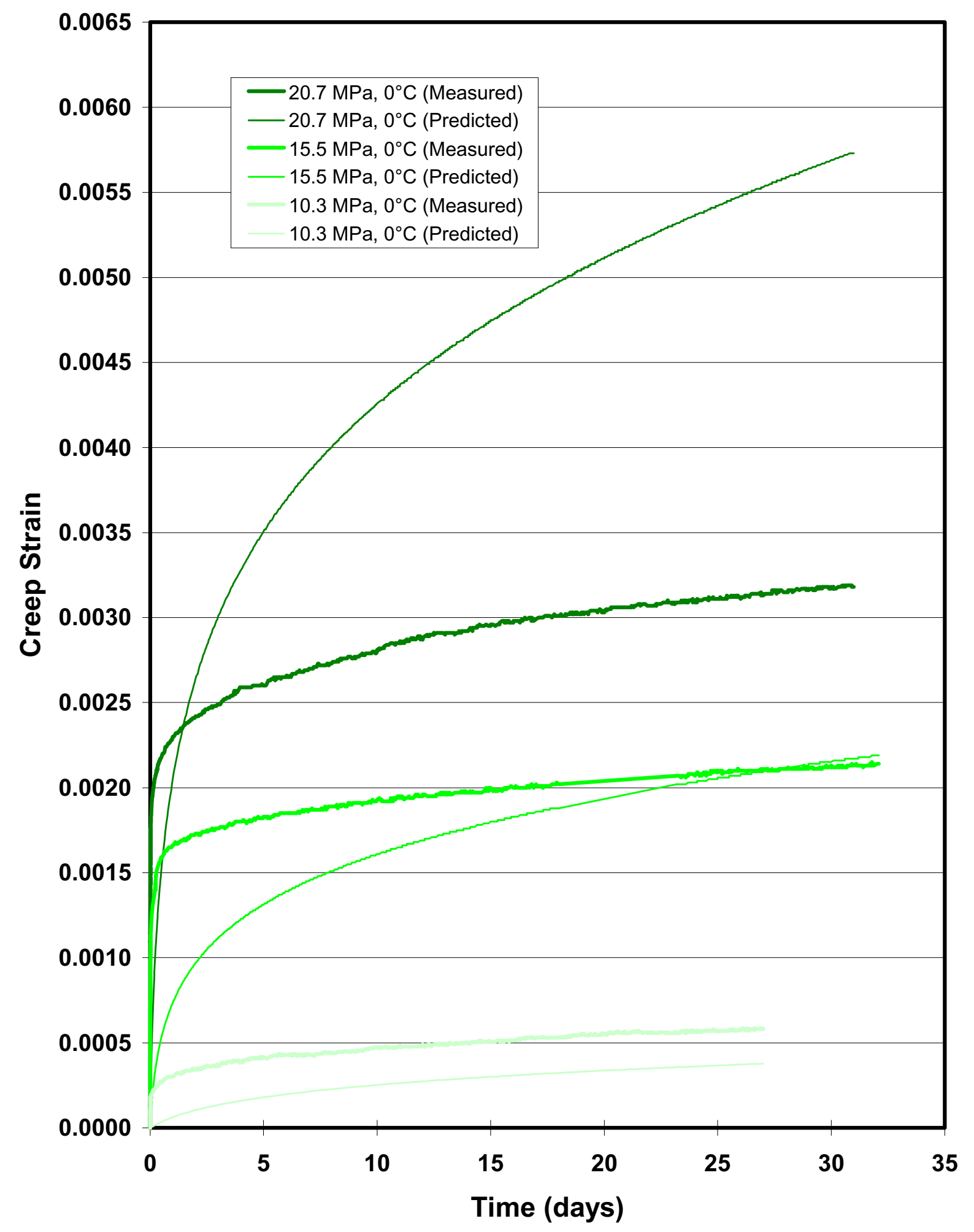

Figure 4-16. Measured and Predicted Creep Strain for Creep Tests Conducted at $0^{\circ} \mathrm{C}$. 


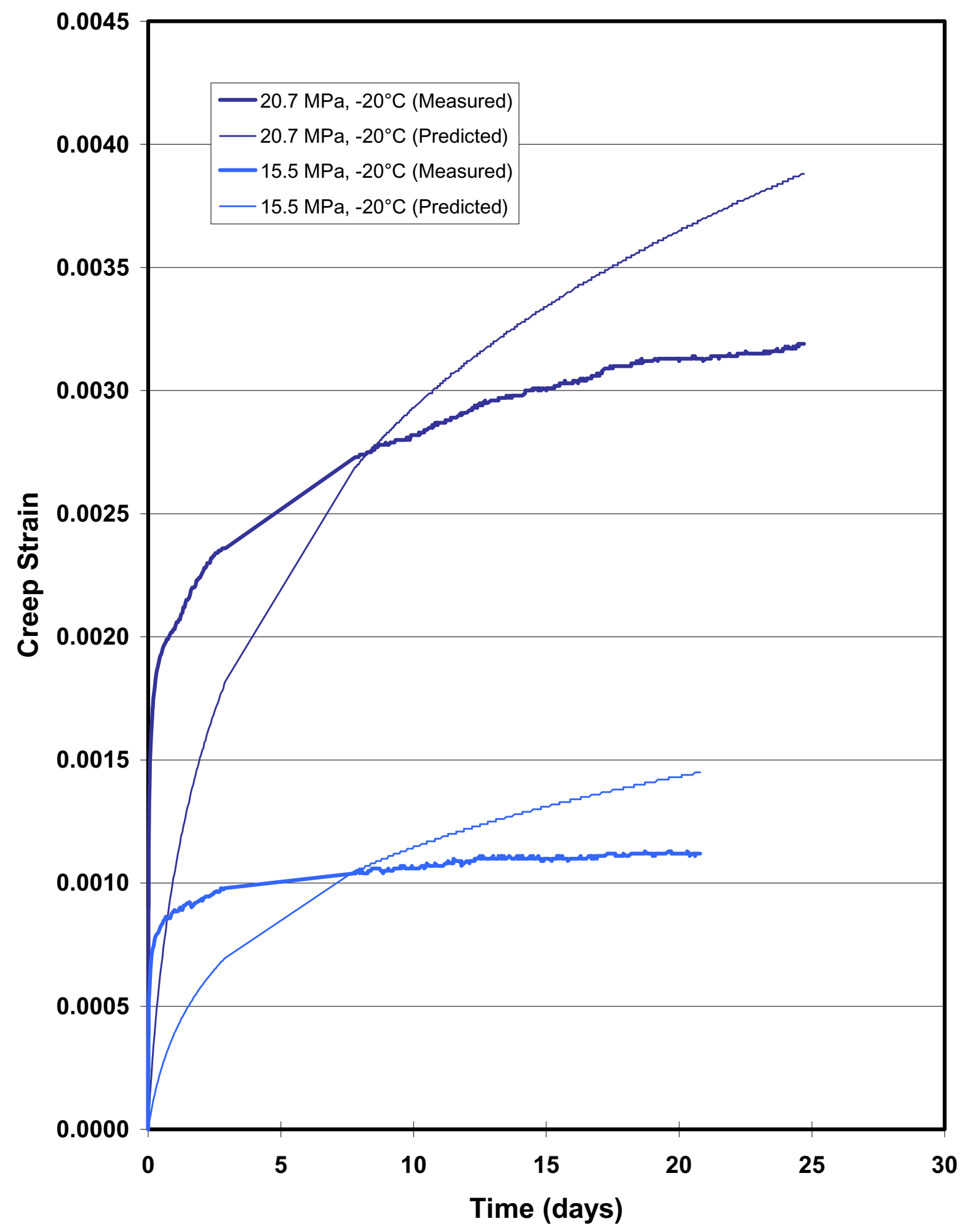

Figure 4-17. Measured and Predicted Creep Strain for Creep Tests Conducted at $-20^{\circ} \mathrm{C}$. 


\subsubsection{Properties of Well Fluids}

The mechanical response of a gas storage cavern depends not only on the material properties of the salt surrounding the cavern, but also on the material properties of the fluids inside the cavern. It is assumed that the cavern was filled with saturated brine after solutioning was complete and before the cavern was dewatered. The cavern was subsequently filled with compressed natural gas. In the simulations of the cavern, these fluids are represented by their pressures applied as normal tractions to the surfaces of the cavern. An equation-of-state relating the fluid's pressure to its density and temperature was assumed for each fluid. The fluids were assumed to be essentially stagnant, so at a given depth, the vertical pressure gradient was assumed to be equal to the fluid's density at that depth. In the following two subsections, the assumed equations-of-state and the resultant vertical pressure gradients are presented for natural gas and for saturated brine.

\subsection{Natural Gas Characteristics}

The gas pressure, $\mathrm{P}$, in a well can be described as:

$$
P=P_{0}+\int_{0}^{z} \rho g d z
$$

where:

$$
\begin{aligned}
P_{0} & =\text { the wellhead pressure } \\
\rho & =\text { the density of the gas } \\
g & =\text { the gravitational acceleration } \\
z & =\text { the depth bel ow well head. }
\end{aligned}
$$

The density of natural gas is dependent on pressure and temperature, both of which change with depth. A compressibility equation for natural gas described by Coker [1993] was used to calculate the density as a function of pressure and temperature. Equation 4-13 was integrated numerically to determine the pressure-versus-depth data to determine a linear pressure gradient for the gas at the various pressures simulated.

\subsection{Brine Characteristics}

Because of the very small compressibility of brine, approximately $2.8 \times 10^{-4} / \mathrm{MPa}$, the increase in brine density associated with the hydrostatic pressure increases over the height of the cavern is negligible. Consequently, the brine density was assumed to remain a constant $1,200 \mathrm{~kg} / \mathrm{m}^{3}$ (75 pounds per cubic foot), resulting in a vertical pressure gradient of $0.0118 \mathrm{MPa} / \mathrm{m}(0.52 \mathrm{psi} / \mathrm{foot})$.

\subsection{Finite Element Model of Avoca Cavern}

The finite element model used to evaluate cavern stability is the same as that used to determine cooling loads described in Section 3.3.1 and shown in Figure 3-7. The cavern was 
modeled in plane strain. The side and bottom boundaries of the model are restricted from normal displacement. The area immediately outside of the cavern is very finely subdivided to provide accurate representation of the high-stress and temperature gradients that are anticipated near the cavern.

\subsubsection{Criteria for Evaluating Technical Feasibility}

The stresses predicted with the finite element models of the Avoca cavern were used to evaluate cavern performance in terms of stability of the cavern roof and walls. The criterion for the salt is (1) no salt dilation in the salt surrounding the cavern and (2) no development of tensile regions. The criterion for the shale in the roof is that it maintains a factor of safety of at least 2 with respect to the shear failure.

Factors of safety are used to quantify the likelihood of dilation occurring in the salt and of shear failure in the shale. Failure limits based on salt and shale testing from Bale Well No. 1 were used to calculate the factors of safety for these materials. Based on earlier testing of Bale Well No. 1 shale (see Appendix A), the factor of safety with respect to shear failure in the shale is defined as:

$$
\text { factor of safety }=\frac{0.50 \mathrm{I}_{1}+4.63 \mathrm{MPa}}{\sqrt{\mathrm{J}_{2}}}
$$

Based on current testing of salt at low temperatures (see Section 4.1.4.2), the factor of safety with respect to dilation in the salt is defined as:

$$
\text { factor of safety }=\frac{0.45 \mathrm{I}_{1}-1.24 \mathrm{MPa}}{\sqrt{\mathrm{J}_{2}}}
$$

A factor of safety of 1.0 is the limit stress state for shear failure or dilation to occur. The likelihood of shear failure or dilation increases with decreasing factor-of-safety values.

\subsubsection{Modeling Results}

The Avoca cavern model was run through two stages of operations. First, the model was used to simulate leaching, dewatering, and filling the cavern with natural gas at $43^{\circ} \mathrm{C}\left(110^{\circ} \mathrm{F}\right)$. This was followed by simulations to where the gas is cooled to $-29^{\circ} \mathrm{C}\left(-20^{\circ} \mathrm{F}\right)$. Based on the Avoca design [Morrill, 1996], the cavern is modeled with the maximum horizontal in situ stress parallel to the long axis of the cavern. No simulations were made of gas cycles because the salt failed before the cavern could be cooled to a temperature of $-29^{\circ} \mathrm{C}\left(-20^{\circ} \mathrm{F}\right)$. The results of the simulations are described below. 


\subsubsection{Leaching and Dewatering}

The purpose of simulating the leaching and dewatering of the cavern is to obtain the stress distribution prior to converting the facility to refrigerated storage. Temperature perturbations to the in situ temperature distribution were neglected during the leaching and dewatering simulation. At the start of the simulation, the cavern was instantly excavated and a normal traction equal to the brine pressure head was applied inside the cavern. The cavern was then allowed to creep for a time of 200 days, which is the estimated time required to leach the cavern. This is followed by simulation of a 30-day dewatering period in which the gas is injected at maximum gas pressure (19.65 MPa or 2,850 psi at the casing shoe). At the end of the simulation, the cavern is full of natural gas at maximum gas pressure and a temperature of $43^{\circ} \mathrm{C}\left(110^{\circ} \mathrm{F}\right)$.

The cavern is stable at the end of dewatering. Stresses around the cavern are all compressive, the factors of safety with respect to dilation in the salt around the cavern are greater than 5, and the factors of safety in the shale above the roof of the cavern are greater than 2.

\subsubsection{Conversion to Refrigerated Storage}

After dewatering the cavern, simulations were performed to cool the gas from $43^{\circ} \mathrm{C}\left(110^{\circ} \mathrm{F}\right)$ down to $-29^{\circ} \mathrm{C}\left(-20^{\circ} \mathrm{F}\right)$. These simulations are continuations of the leaching and dewatering simulation, and thus, the stress distribution at the beginning of the simulations is the same as the stress distribution at the end of the leaching and dewatering simulation. Two cooling scenarios were evaluated: (1) the gas temperature in the cavern was cooled at a constant rate over a period of 30 days and (2) the gas was cooled at a constant rate over a period of 1 year. The pressure was assumed to remain constant during the simulations.

Figure 4-18 shows contours of the least-compressive or most tensile principal stress (tension is positive) around the cavern at various times for the model with a 30-day cooling period. Note that the contours shown for time zero (time $=0$ days) are the conditions at the end of dewatering before any cooling has started. At time zero, the least-compressive stresses in the model are generally normal to the cavern periphery and equal in magnitude to the gas pressure in the cavern. However, upon cooling the gas in the cavern, the rock around the cavern also begins to cool and contracts. This results in the formation of tensile stresses in directions perpendicular to the cavern wall. The stresses normal to the cavern wall remain compressive and equal to the gas pressure.

Figure 4-19 shows temperature contours around the cavern at various times during the 30-day cooling period. Because it is assumed that the gas pressure is maintained at maximum pressure, the stresses normal to the surface of the cavern remain compressive and equal to the gas pressure. However, the stresses in the other two directions become less and less compressive, and as a result, the effective stress in the salt around the cavern (see Figure 4-20) 
RSI-621-01-052

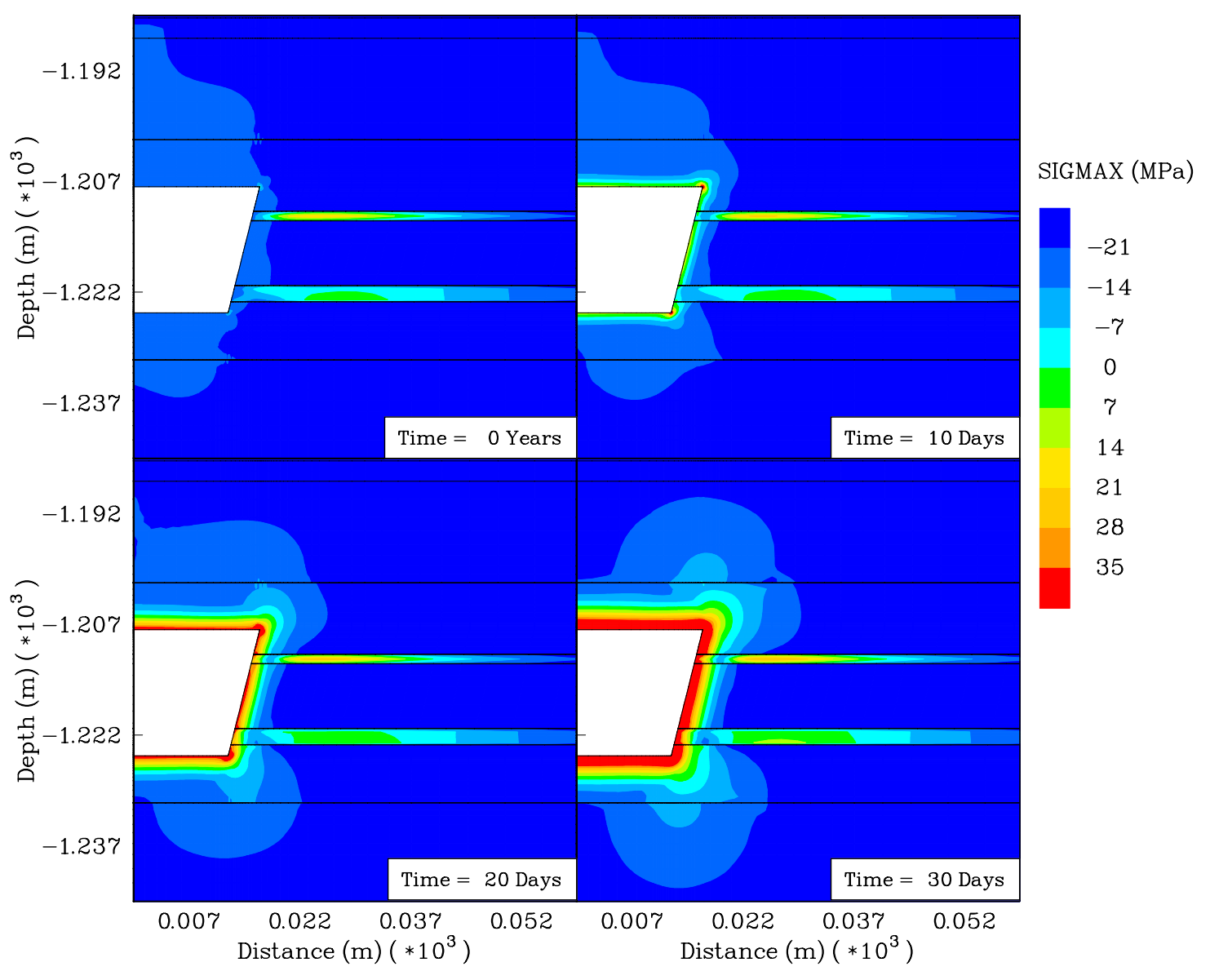

Figure 4-18. Contours of Least-Compressive Principal Stress for a 30-Day Conversion to Refrigerated Storage. 
RSI-621-01-053

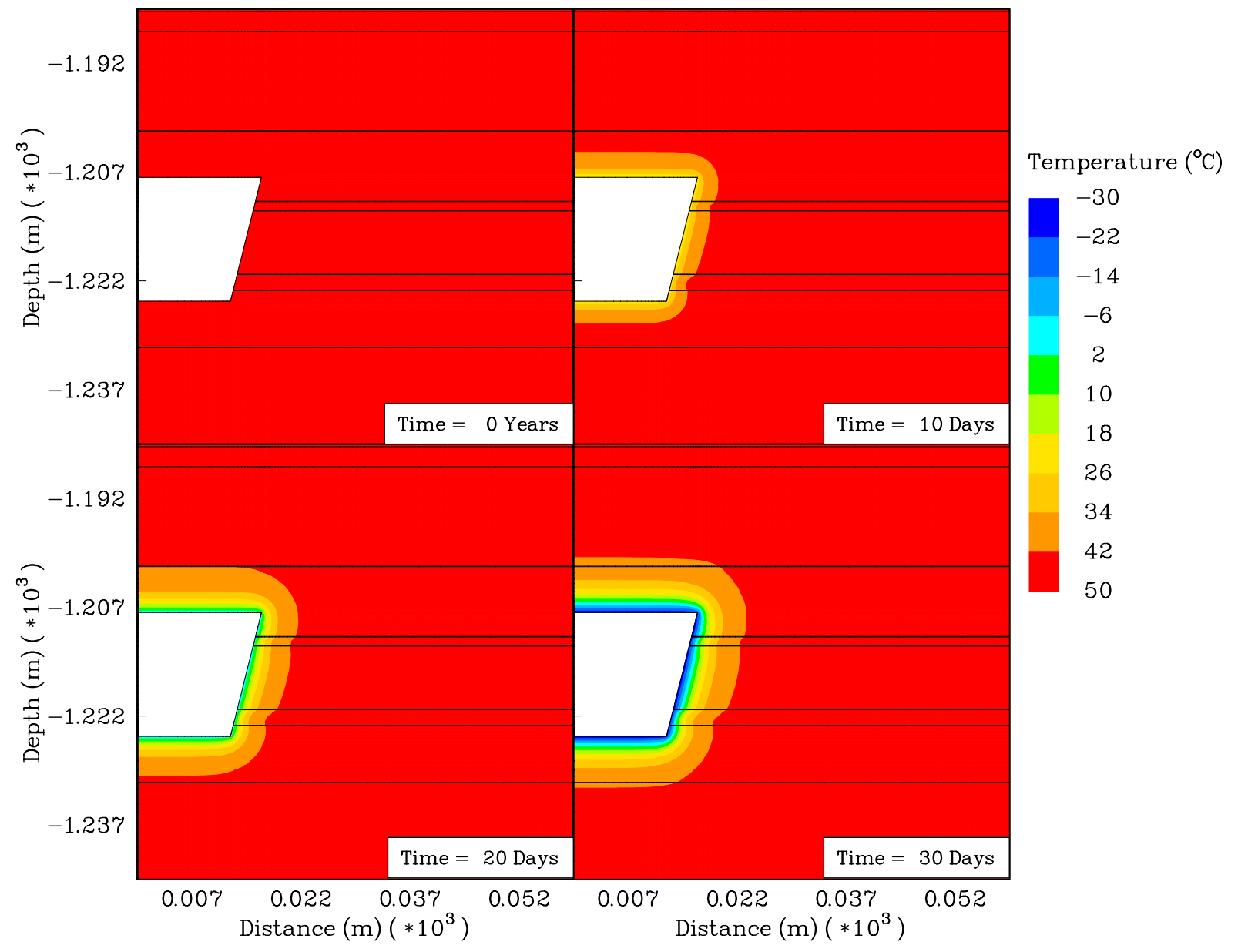

Figure 4-19. Contours of Temperature for a 30-Day Conversion to Refrigerated Storage. 
RSI-621-01-054

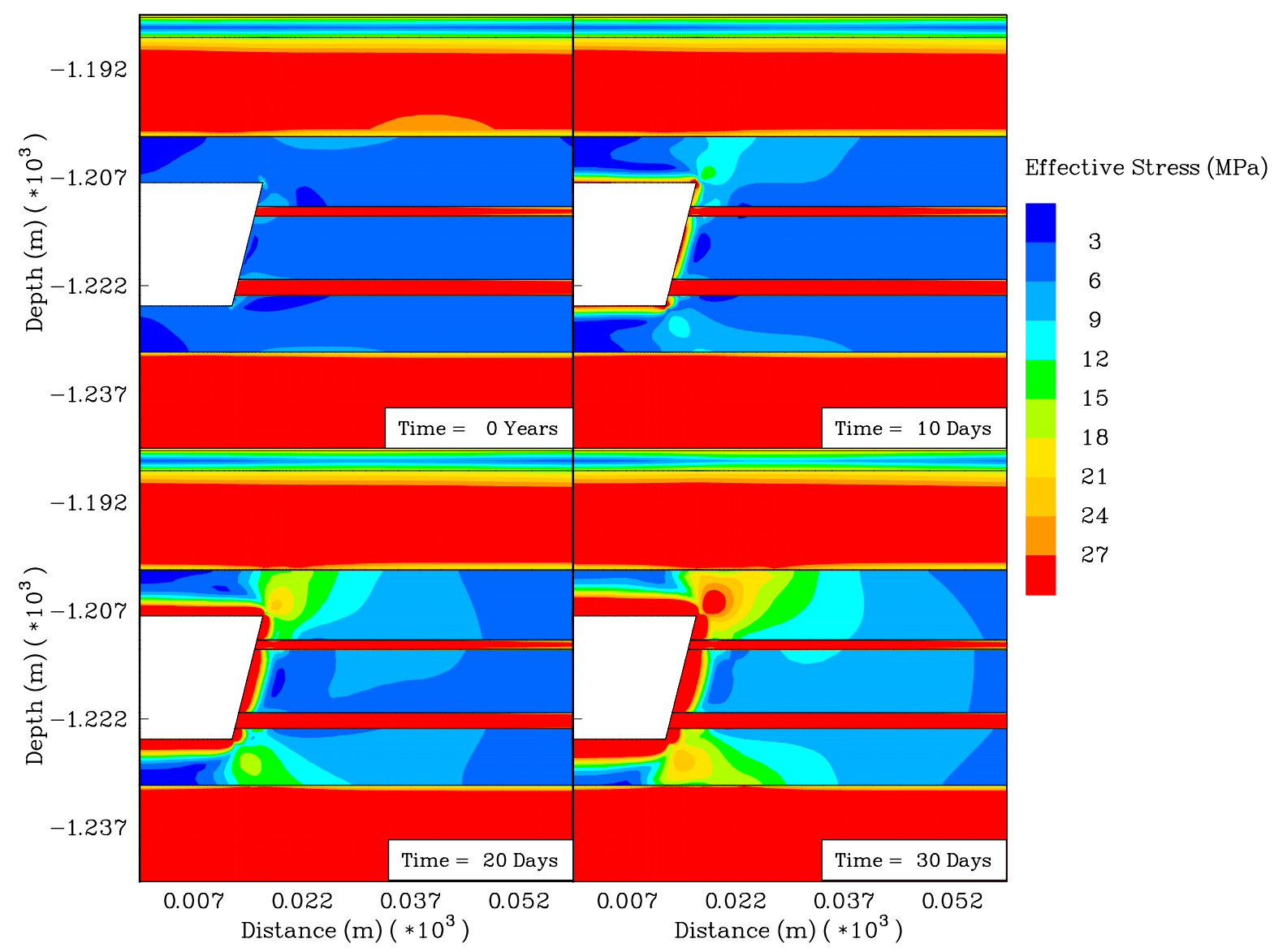

Figure 4-20. Contours of E ffective Stress for a 30-Day Conversion to Refrigerated Storage. 
increases. As the effective stress increases, the salt creeps faster. As the salt creeps, stresses are redistributed to reduce the effective stress by bringing the principal stresses closer together. Because the stress normal to the cavern wall is maintained by the gas pressure in the cavern, the stresses in the other two directions are made more compressive as the salt creeps. Thus the salt creep counteracts the thermoelastic effects of cooling. If the salt could creep fast enough, no tensile stresses would develop. Unfortunately, this is not predicted for the Avoca cavern. At 10 days, when the cavern temperature is about $19^{\circ} \mathrm{C}\left(67^{\circ} \mathrm{F}\right)$, the least-compressive stresses are still mostly compressive except at the corners of the cavern. By 20 days, when the cavern temperature is about $-5^{\circ} \mathrm{C}\left(23^{\circ} \mathrm{F}\right)$, tensile stresses that are much higher than the tensile strength of salt (about $2 \mathrm{MPa}$ ) devel op around the cavern.

Figure 4-21 shows contours of the factors of safety with respect to dilation in the salt at various times for the model with a 30-day cooling period. Within 10 days, the stresses around the cavern will result in dilation of the salt. The region of dilation grows rapidly as the temperature in the cavern and surrounding salt decreases.

Figure 4-22 shows contours of the factors of safety with respect to shear failure in shale at various times for the model with a 30-day cooling period. Factors of safety in the shale remain above 2 during the cooling of the gas. However, after the stresses in the salt reach tensile failure level, the predicted stresses in the shale may not be accurate because the stress redistribution that would occur as the salt fractures is not simulated.

A second simulation was performed in which the cavern was cooled over a 1-year period with the idea that at a more gradual cooling rate, the creep rate of the salt might be sufficient to prevent the generation of tensile stresses in the salt. However, as shown by the contours of the least-compressive principal stress for this simulation in Figure 4-23, this is not the case. When the cavern temperature is about $-5^{\circ} \mathrm{C}\left(23^{\circ} \mathrm{F}\right)$, there is a large tensile zone around the cavern. In fact, the region is much larger than that for the 30-day cooling simulation at the same cavern

temperature. This occurs because the longer time period of this simulation allows more of the salt around the cavern to cool down from the in situ temperature (see Figure 4-24). Figures 4-25 and 4-26 show contours of the factors of safety in the salt and shale, respectively for this simulation.

\subsubsection{Discussion of Results}

Based on the results of both simulations, it is expected that tensile fractures normal to the cavern surface will develop in directions both parallel and perpendicular to the modeled cross section. Tensile fracturing of the cavern roof may result in loss of containment of the gas and/or loss of integrity of the casing shoe, deeming the conversion of this facility not technically feasible. Also, because of the large difference in thermal expansion coefficients between the salt and the shale, it is likely that the contact between the roof salt and shale above it will be broken, resulting in collapse of the roof salt. 


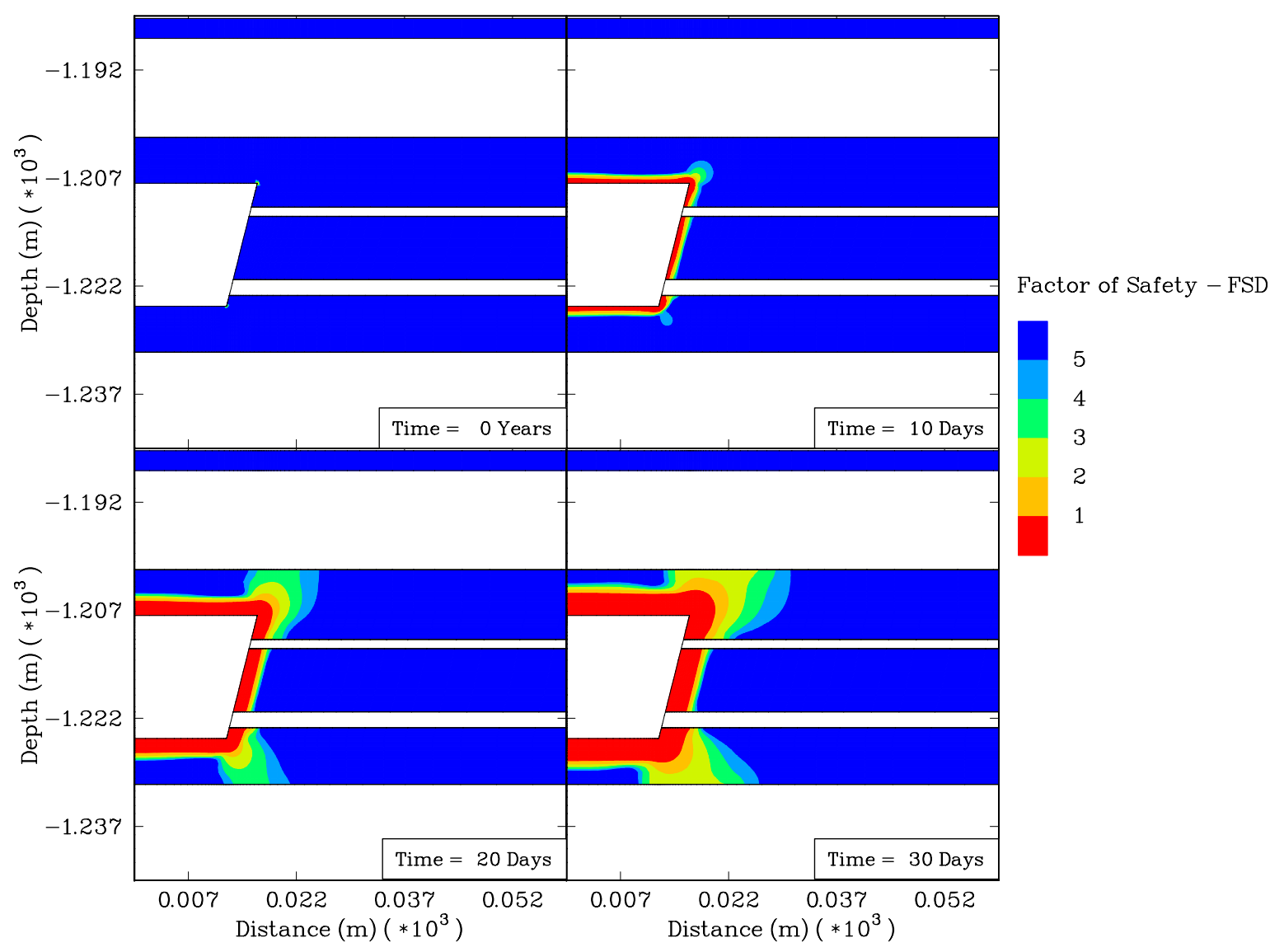

Figure 4-21. Contours of Factors of Safety With Respect to Salt Dilation for a 30-Day Conversion to Refrigerated Storage. 


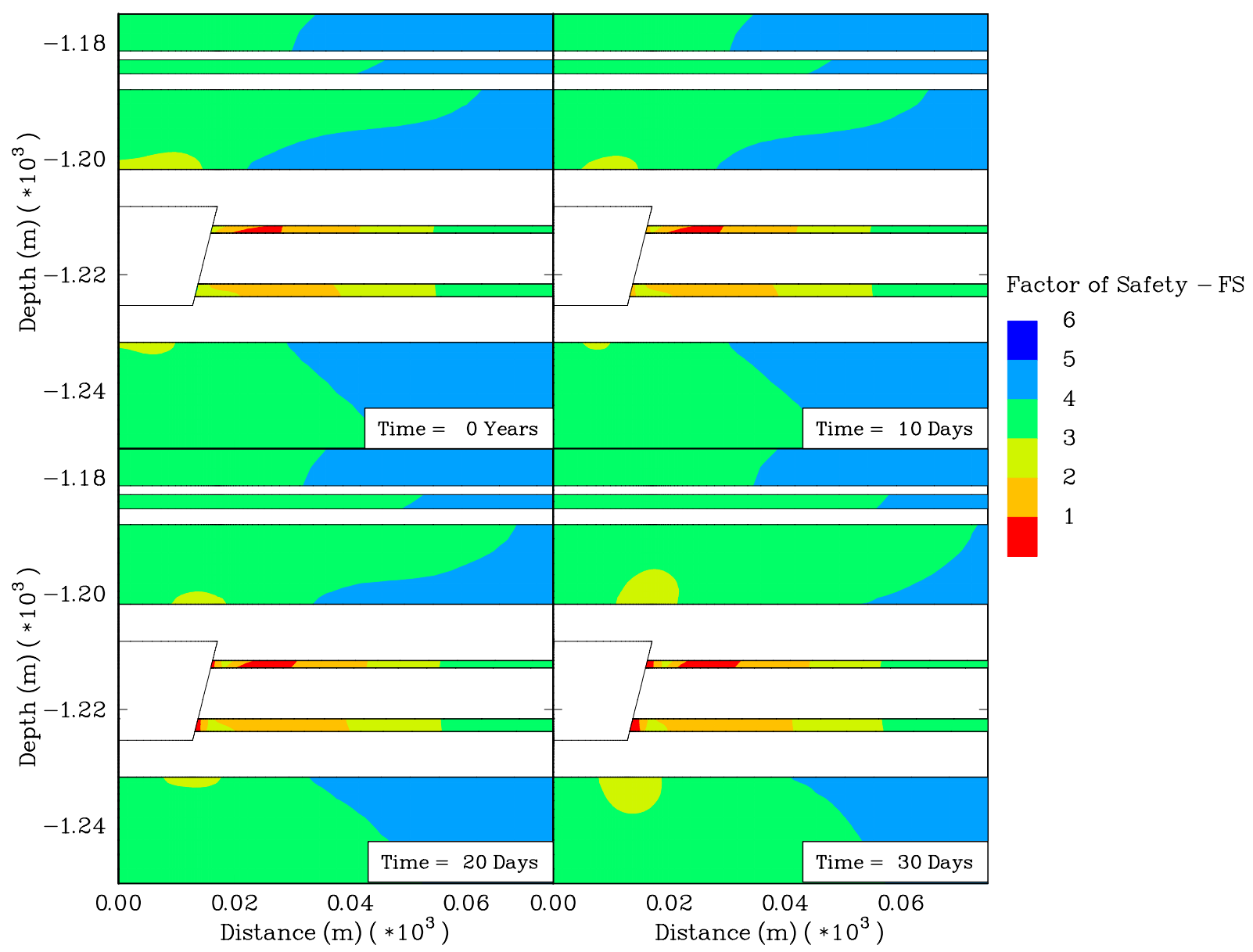

Figure 4-22. Contours of Factors of Safety With Respect to Shear Failure in the Shale for a 30-Day Conversion to Refrigerated Storage. 


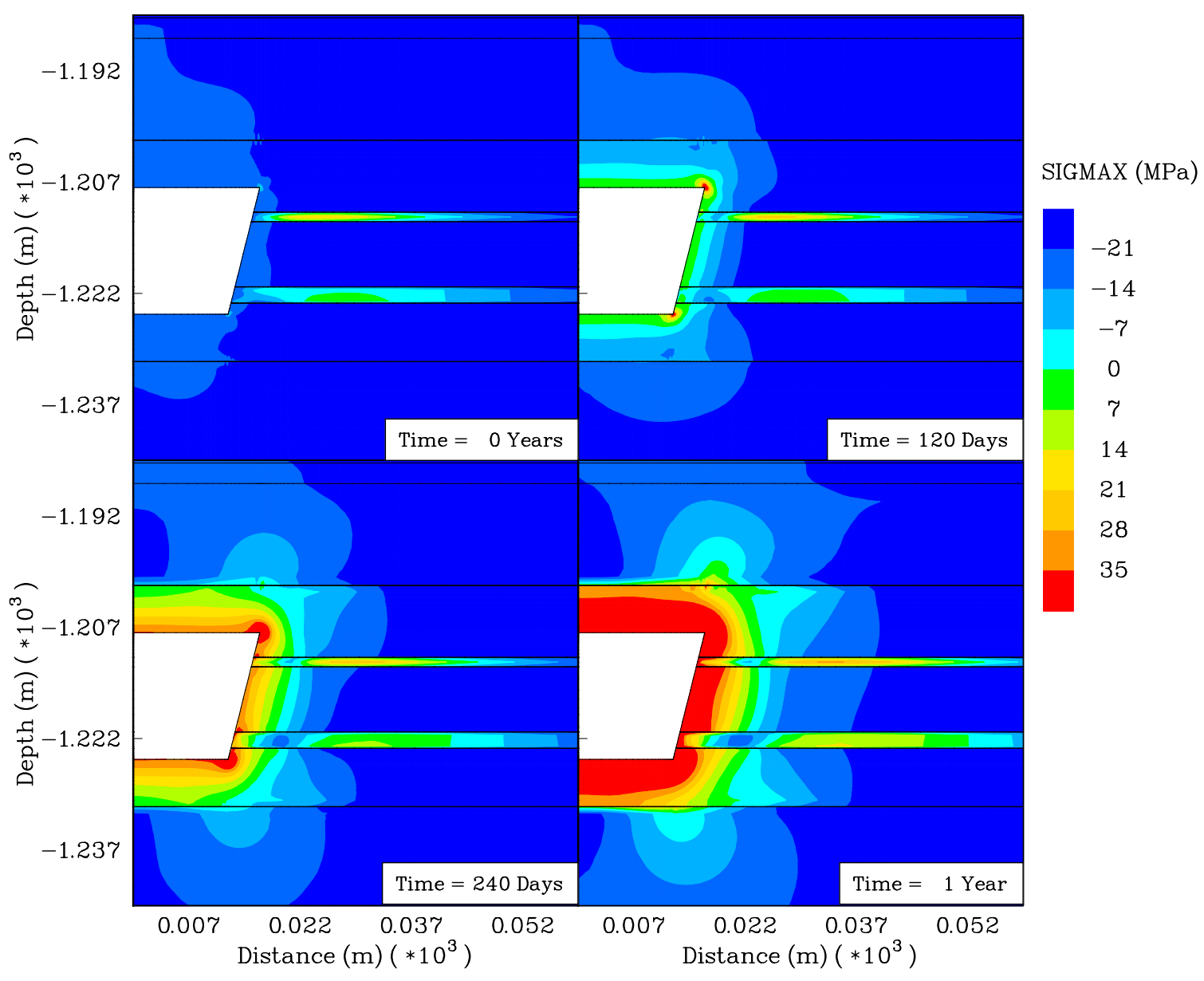

Figure 4-23. Contours of Least-Compressive Principal Stress for a 1-Year Conversion to Refrigerated Storage. 
RSI-621-01-058

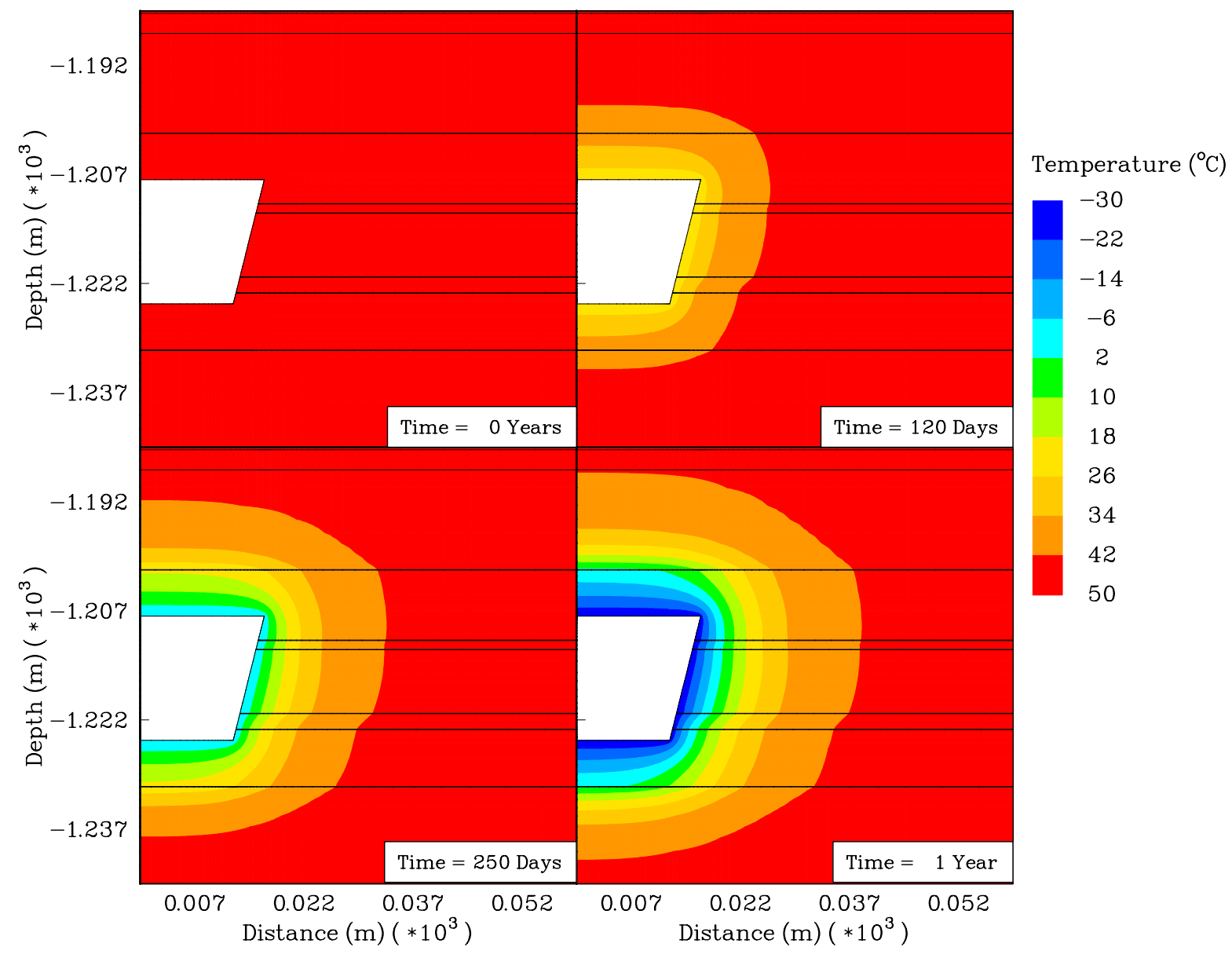

Figure 4-24. Contours of Temperature for a 1-Y ear Conversion to Refrigerated Storage. 


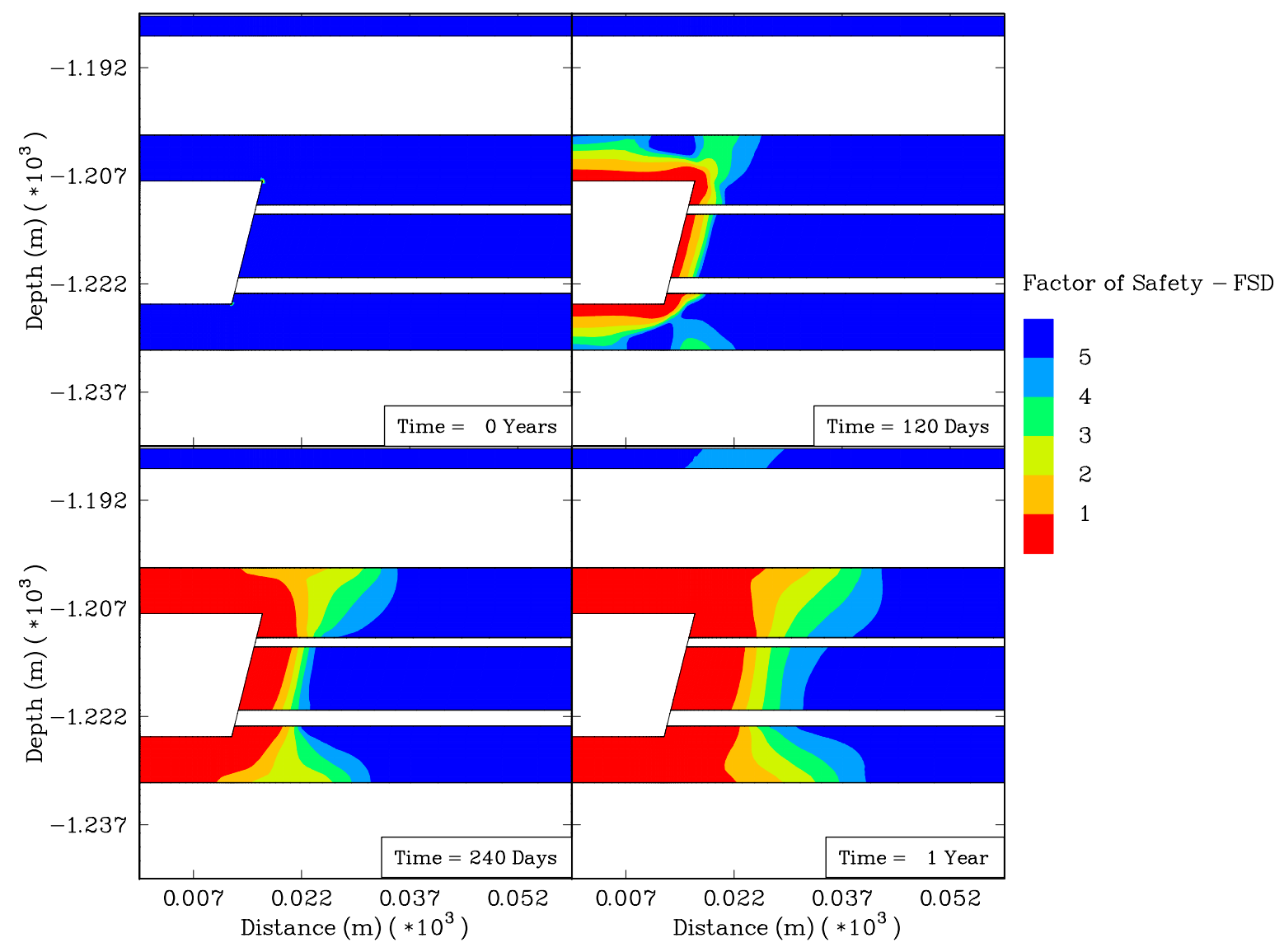

Figure 4-25. Contours of Factors of Safety With Respect to Salt Dilation for a 1-Year Conversion to Refrigerated Storage. 


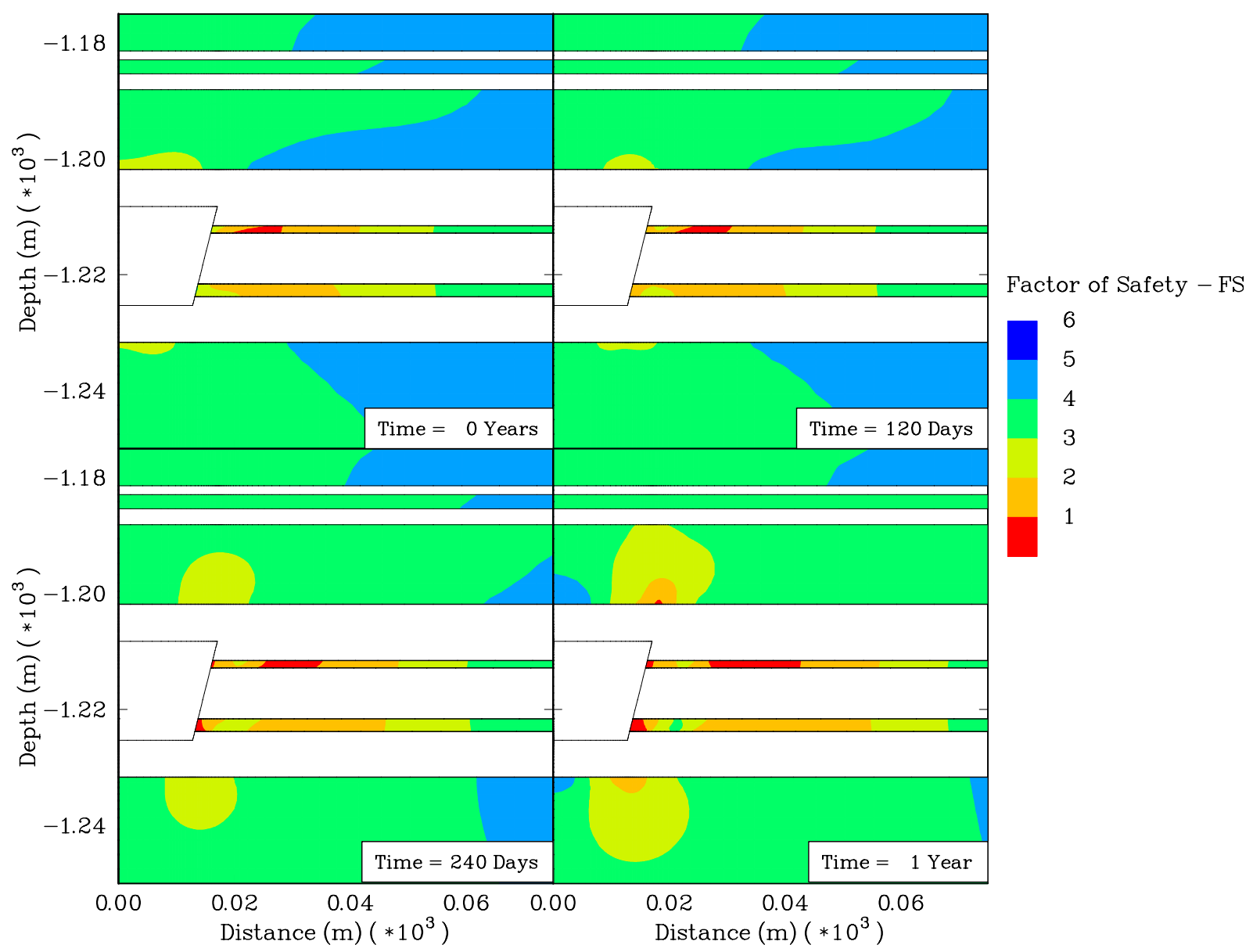

Figure 4-26. Contours of Factors of Safety With Respect to Shear Failure in the Shale for a 1-Y ear Conversion to Refrigerated Storage. 
Once the stresses in the salt become tensile, the results of the model are no longer accurate because the salt is not allowed to fracture in the model. The redistribution of stresses that would occur after fracturing the salt is not seen in the model results. Thus no investigations of the effects of gas cycles on cavern stability after conversion to refrigerated storage were made.

Although the conversion of the facility examined in this study does not appear to be technically feasible, there may be cases where chilled gas storage in bedded salt is feasible. For example, if a site has a competent nonsalt rock overlying the salt that is sufficiently tight to contain gas, it might be used as the cavern roof rather than salt. 


\subsection{SUMMARY AND CONCLUSIONS}

In this study, the planned Avoca natural gas storage facility in Steuben County, New York, was evaluated for conversion from conventional storage to refrigerated storage. By decreasing the storage temperature from the estimated underground temperature of $43^{\circ} \mathrm{C}$ to $-29^{\circ} \mathrm{C}\left(110^{\circ} \mathrm{F}\right.$ to $-20^{\circ} \mathrm{F}$ ), the working gas capacity of the facility would be increased from $1.2 \times 10^{8}$ to about $2.0 \times 10^{8} \mathrm{Nm}^{3}$ (4.4 to about 7.5 Bcf). However, conversion to refrigerated storage does result in additional equipment and additional operating costs.

Because of the large difference between the temperature of the stored natural gas $\left(-29^{\circ} \mathrm{C}\right.$ or $-20^{\circ} \mathrm{F}$ ) and that of the surrounding rock $\left(43^{\circ} \mathrm{C}\right.$ or $\left.110^{\circ} \mathrm{F}\right)$, a large amount of heat will be transferred from the rock to the stored gas. This heat gain must be counteracted with refrigeration to maintain a cavern temperature of $-29^{\circ} \mathrm{C}\left(-20^{\circ} \mathrm{F}\right)$. Laboratory testing was performed to determine the thermal conductivity of salt at low temperatures. Finite element heat transfer calculations were then made to determine the cooling load to maintain the cavern at $-29^{\circ} \mathrm{C}\left(-20^{\circ} \mathrm{F}\right)$. The cooling load after 1 year of storage operations is estimated to be about 4.1 MW (14 MMBtu/hour). After 10 years of storage operations, the estimated cooling load is reduced to about 1.8 MW (6 MMBtu/hour). The J oule-Thompson effect during gas compression results in significant heat gains during gas injection periods and significant heat losses due to gas expansion during gas withdrawal periods. Although these two effects will generally cancel each other out, resulting in no net effect on total cooling load, they will need to be counteracted to maintain a constant cavern temperature.

The total equipment and construction costs for converting the facility from conventional storage to refrigerated storage is estimated to be $\$ 13,310,000$ or $\$ 160$ per thousand $\mathrm{Nm}^{3}$ (\$4.29 per Mcf) of additional working gas capacity. This cost assumes the original design maximum injection and withdrawal rates of $5.9 \times 10^{6}$ and $1.18 \times 10^{7} \mathrm{Nm}^{3} / \mathrm{day}$ (220 and $440 \mathrm{MMcfd}$ ), respectively. This increases the minimum pressure to maximum pressure injection time from 20 days to 34 days and the maximum pressure to minimum pressure withdrawal time from 10 days to 17 days. Increasing flow rates would require additional equipment and processing costs.

The estimated operational costs (those in addition to conventional operation costs) include a maintenance refrigeration cost and additional processing (refrigeration, dehydration, and heating) cost associated with the throughput of gas. The maintenance refrigeration cost based on an energy cost of $\$ 13.65$ per $M W-h r$ ( $\$ 4$ per MMBtu) is estimated to be $\$ 316,000$ per year after the first year and will decrease as the rock surrounding the caverns is cooled. After 10 years, the maintenance cost is estimated to decrease to $\$ 132,000$ per year based on the same energy cost. The throughput operational costs of the facility were estimated per thousand $\mathrm{Nm}^{3}$ of gas injected and withdrawn from the facility. The additional processing costs for refrigerated 
storage per thousand $\mathrm{Nm}^{3}$ of gas injected and withdrawn is estimated to be $\$ 2.05$ (\$0.055 per Mcf) based on an energy cost of $\$ 13.65$ per $M W-h r(\$ 4$ per MMBtu).

Based on the results of the structural stability study, the conversion of this facility is not technically feasible. U pon conversion to refrigerated storage, tensile fractures are predicted to devel op in the cavern roof, walls, and floor. Tensile fracturing of the cavern roof may result in loss of containment of the gas and/or loss of integrity of the casing shoe, deeming the conversion of this facility not technically feasible. Also, because of the large difference in thermal expansion coefficients between the salt and the shale, it is likely that the contact between the roof salt and shale above it will be broken, resulting in collapse of the roof salt.

Although the conversion of the facility examined in this study does not appear to be technically feasible, there may be cases where chilled gas storage in bedded salt is feasible. For example, if a site has a competent nonsalt rock overlying salt that is sufficiently tight to contain gas, it might be used as the cavern roof. 


\subsection{REFERENCES}

Callahan, G. D., A. F. Fossum, and D. K. Svalstad, 1989. Documentation of SPECTROM-32: A Finite Element Thermomechanical Stress Analysis Program, DOE/CH/10378-2, prepared by RE/SPEC Inc., Rapid City, SD, for the U.S. Department of Energy, Chicago Operations Office, Argonne, IL, Vol. I and II.

Clark, S. P., 1966. Handbook of Physical Constants, 2nd Ed., The Geological Society of America, Inc., New York, NY, pp. 488-489.

Coker, A. K., 1993. "Program Calculates Z-Factor for Natural Gas," Oil \& Gas J ournal, February 15, pp. 74-75.

Croff, A. G., T. F. Lomenick, R. S. Lowrie, and S. H. Stow, 1985. Evaluation of Five Sedimentary Rocks Other Than Salt for High-Level Waste Repository Siting Purposes, ORNL/CF-85/2N1, prepared for Oak Ridge National Laboratory, Oak Ridge, TN.

Dahlstrom, D. J ., 1988. Thermal Properties Measurements of Avery Island Salt Core, RSI-0334, prepared by RE/SPEC Inc., Rapid City, SD, for Stone \& Webster Engineering Corporation, Boston, MA.

Gevantman, L. H. (Ed.), 1981. Physical Properties Data for Rock Salt, NBS Monograph 167, National Bureau of Standards, Washington, D.C., J anuary.

J ohnson, K. S. and S. Gonzales, 1978. Salt Deposits in the United States and Regional Geologic Characteristics Important for Storage of Radioactive Waste, prepared by Earth Resource for The Office of Waste Isolation, Union Carbide Corporation, Nuclear Division, U.S. Department of Energy.

MorrilI, D. C., 1996. "Avoca, New York Salt Cavern Gas Storage Facility," Northeastern Geology and Environmental Sciences, Vol. 18, Nos. 1/2, pp. 59-66.

Munson, D. E., A. F. Fossum, and P. E. Senseny, 1989. Advances in Resolution of Discrepancies Between Predicted and Measured In Situ WIPP Room Closures, SAND88-2948, Sandia National Laboratories, Albuquerque, NM.

Osnes, J . D., R. A. Wagner, and H. Waldman, 1978. Parametric Thermoelastic Analyses of High-Level Waste and Spent Fuel Repositories in Granite and Other Non-Salt Rock Types, Technical Memorandum Report RSI-0066, prepared by RE/SPEC Inc., Rapid City, SD, for Office of Waste I solation, Oak Ridge, TN. 
PB-KBB, Inc., 1998. Advanced Underground Gas Storage Concepts Refrigerated-Mined Cavern Storage, DOE Contract Number DE-AC26-97FT34349, prepared by PB-KBB Inc., Houston, TX.

Ratigan, J . L., L. L. Van Sambeek, K. L. DeVries, and J . D. Nieland, 1991. The Influence of Seal Design on the Development of the Disturbed Rock Zone in the WIPP Alcove Seal Tests, RSI-0400, prepared by RE/SPEC Inc., Rapid City, SD, for Sandia National Laboratories, Albuquerque, NM.

Senseny, P. E., F. D. Hansen, J . E. Russell, N. L. Carter, and J . W. Handin, 1992. "Mechanical Behaviour of Rock Salt: Phenomenology and Micromechanisms," International J ournal of Rock Mechanics and Mining Sciences, Pergamon Press, New York, NY, Vol. 29, No. 4, pp. 363-378.

Svalstad, D. K., 1989. Documentation of SPECTROM-41: A Finite Element Heat Transfer Analysis Program, DOE/CH/10378-1, prepared by RE/SPEC Inc., Rapid City, SD, for the U.S. Department of Energy, Chicago Operations Office, Argonne, IL.

Van Sambeek, L. L., J . L. Ratigan, and F. D. Hansen, 1993. "Dilatancy of Rock Salt in Laboratory Test," Proceedings, $34^{\text {th }}$ U.S. Symposium on Rock Mechanics, University of Wisconsin-Madison, Madison, WI, J une 27-30, B.C. Haimson (ed.), International J ournal of Rock Mechanics and Mining Sciences \& Geomechanics Abstracts, Pergamon Press, Vol. 30, No. 7, pp. 735-738. 
APPENDIX A

\section{BALE WELL NO. 1 INFORMATION FROM PREVIOUS INVESTIGATIONS}




\section{APPENDIX A}

\section{BALE WELL NO. 1 INFORMATION FROM PREVIOUS INVESTIGATIONS}

This appendix provides information obtained from previous investigations of the mechanical properties of salt and shale from Bale Well No. 1 located near Cayuta, New York. The information provided include:

- Elastic Properties of Shale and Salt

- Tensile Strength of Shale and Salt

- Salt and Shale Failure Properties

- Salt Creep Properties

- In Situ Stress Conditions.

Each of these items is discussed separately below.

\section{Elastic Properties of Shale and Salt}

Elastic properties were determined for salt and shale specimens from Bale Well No. 1 from quasi-static compression tests. All tests were performed at a temperature of $20^{\circ} \mathrm{C}\left(68^{\circ} \mathrm{C}\right)$. Confining pressures ranged from 0 to $6.9 \mathrm{MPa}(0$ to 1,000 psi) for the tests on shale specimens and from 0.69 to $3.4 \mathrm{MPa}$ (100 to $500 \mathrm{psi}$ ) for the tests on salt specimens. The specimens were solid cylinders having a length to diameter ratio of 2.5 with axes perpendicular to bedding.

The elastic properties determined from the six salt tests are summarized in Table A-1. For the salt, the elastic moduli were determined from unload/reload data. The use of the unload/rel oad data for determining elastic properties is required for salt because virgin loading of salt produces large inelastic strains in addition to elastic strains. The unload/reload procedure utilized in this test minimizes the inelastic components of the strains and therefore isolates the elastic components.

Young's modulus for the salt varied from 20.3 to $30.3 \mathrm{GPa}\left(2.95 \times 10^{6}\right.$ to $\left.4.39 \times 10^{6} \mathrm{psi}\right)$ with a mean and standard deviation of 26.0 and $2.8 \mathrm{GPa}\left(3.77 \times 10^{6}\right.$ and $\left.0.41 \times 10^{6} \mathrm{psi}\right)$. The modulus appears to increase somewhat with confining pressure and is higher for unload data than for rel oad data. Poisson's ratio varied from 0.29 to 0.50 , and in some cases, actually exceeded 0.5.

The elastic properties determined for the shale are summarized in Table A-2. Unload/reload cycles were not performed during the shale tests because it was assumed that the elastic 
properties determined from the initial loading curves would be similar to those determined from the unload/rel oad data.

Table A-1. Elastic Properties Determined From Quasi-Static Compression Testing of Bale Well No. 1 Salt

\begin{tabular}{|c|c|c|c|c|}
\hline \multirow[b]{2}{*}{$\begin{array}{c}\text { Specimen } \\
\text { I.D. }\end{array}$} & \multirow{2}{*}{$\begin{array}{c}\text { Confining } \\
\text { Pressure } \\
\text { (MPa) }\end{array}$} & \multicolumn{3}{|c|}{ Elastic Properties } \\
\hline & & $\begin{array}{l}\text { Load } \\
\text { Segment }\end{array}$ & $\begin{array}{c}\text { Young's } \\
\text { Modulus, E } \\
\text { (GPa) }\end{array}$ & $\begin{array}{l}\text { Poisson's } \\
\text { Ratio, v }\end{array}$ \\
\hline BAL 1/82/1 & 0.69 & $\begin{array}{l}\text { Unload } \\
\text { Reload }\end{array}$ & $\begin{array}{l}23.7 \\
20.3\end{array}$ & $\begin{array}{l}\text { (a) } \\
\text { (a) }\end{array}$ \\
\hline BAL 1/82/2 & 1.38 & $\begin{array}{l}\text { Unload } \\
\text { Reload }\end{array}$ & $\begin{array}{l}28.1 \\
24.8 \\
\end{array}$ & $\begin{array}{l}0.50 \\
0.48\end{array}$ \\
\hline BAL 1/85/1 & 3.45 & $\begin{array}{l}\text { Unload } \\
\text { Reload }\end{array}$ & $\begin{array}{l}30.3 \\
28.4 \\
\end{array}$ & $\begin{array}{l}0.30 \\
0.29 \\
\end{array}$ \\
\hline BAL 1/86-1/1 & 0.69 & $\begin{array}{l}\text { Unload } \\
\text { Reload }\end{array}$ & $\begin{array}{l}25.0 \\
22.7 \\
\end{array}$ & $\begin{array}{l}0.49 \\
0.50 \\
\end{array}$ \\
\hline BAL $1 / 86-1 / 2$ & 1.38 & $\begin{array}{l}\text { Unload } \\
\text { Reload }\end{array}$ & $\begin{array}{l}28.5 \\
25.9 \\
\end{array}$ & $\begin{array}{l}0.33 \\
0.39 \\
\end{array}$ \\
\hline BAL 1/86-2/1 & 3.45 & $\begin{array}{l}\text { Unload } \\
\text { Reload }\end{array}$ & $\begin{array}{l}27.8 \\
26.7\end{array}$ & $\begin{array}{l}0.30 \\
0.37\end{array}$ \\
\hline
\end{tabular}

(a) Poisson's ratio greater than 0.5 .

Table A-2. Elastic Properties Determined From QuasiStatic Compression Testing of Bale Well No. 1 Shale

\begin{tabular}{|c|c|c|c|}
\hline \multirow[b]{2}{*}{$\begin{array}{l}\text { Specimen } \\
\text { I.D. }{ }^{\text {(a) }}\end{array}$} & \multirow{2}{*}{$\begin{array}{c}\text { Average } \\
\text { Confining } \\
\text { Pressure } \\
\text { (MPa) }\end{array}$} & \multicolumn{2}{|c|}{ Elastic Properties } \\
\hline & & $\begin{array}{c}\text { Young's } \\
\text { Modulus, E } \\
\text { (GPa) }\end{array}$ & $\begin{array}{l}\text { Poisson's } \\
\text { Ratio, v }\end{array}$ \\
\hline BAL 1/4/1-1/1 & 0 & 25.5 & 0.12 \\
\hline BAL 1/4/1-1/2 & 3.4 & 29.1 & 0.13 \\
\hline BAL 1/4/2-1/1 & 7.4 & 29.3 & 0.16 \\
\hline BAL 1/21/1-1/1 & 0 & 34.7 & 0.19 \\
\hline BAL 1/21/4-1/1 & 3.4 & 42.3 & 0.23 \\
\hline BAL 1/21/4-1/2 & 7.4 & 47.6 & 0.29 \\
\hline
\end{tabular}

(a) The first three specimens were recovered from a depth of 1,226 meters. The last three specimens were recovered from a depth of 1,234 meters. 
Young's modulus varies from 25.5 to $29.3 \mathrm{GPa}\left(3.70 \times 10^{6}\right.$ to $\left.4.25 \times 10^{6} \mathrm{psi}\right)$ for the shales recovered from a depth of 1,226 meters (4,022 feet) and from 34.7 to $47.6 \mathrm{GPa}$ (5.03 $\times 10^{6}$ to $6.90 \times 10^{6} \mathrm{psi}$ ) for the shales recovered from a depth of 1,234 meters (4,050 feet). Poisson's ratio varies from 0.12 to 0.16 for the shales from 1,226 meters (4,022 feet) and from 0.19 to 0.29 for the shales from 1,234 meters (4,050 feet).

\section{Tensile Strength of Shale and Salt}

Apparent tensile strengths of the salt and shale specimens were determined in the laboratory by means of the indirect tension test, commonly termed the Brazilian indirect tension test. This method is termed an indirect method because a compressive diametral line load is applied over the length of a cylindrical specimen. The compressive load induces a tensile stress at the center of the specimen perpendicular to the diametral line load. As the compressive line load increases, so does the tensile stress.

\section{Tensile Strength of Salt}

Five indirect tension tests on salt were performed at a temperature of $20^{\circ} \mathrm{C}\left(68^{\circ} \mathrm{F}\right)$. It was assumed that the tensile strengths of the salts were isotropic, and therefore, orientation does not matter. Table A-3 summarizes the results of the indirect tension testing of salt specimens. The results show that the tensile strengths of the salt vary from 1.43 to $2.21 \mathrm{MPa}$ (207 to $320 \mathrm{psi}$ ) with a mean and standard deviation of 1.95 and $0.32 \mathrm{MPa}$ (283 and $46 \mathrm{psi}$ ), respectively.

Table A-3. Results of Indirect Tension Tests on Bale Well No. 1 Salt

\begin{tabular}{||l|c|}
\hline \multicolumn{1}{|c|}{ Specimen I.D. } & $\begin{array}{c}\text { Indirect Tensile } \\
\text { Strength, } \mathbf{T}_{\mathbf{0}} \text { (MPa) }\end{array}$ \\
\hline \hline $\mathrm{BAL} 1 / 54 / 1$ & 1.43 \\
\hline $\mathrm{BAL} 1 / 80 / 1$ & 2.13 \\
\hline $\mathrm{BAL} 1 / 93 / 1$ & 1.88 \\
\hline $\mathrm{BAL} 1 / 123-2 / 1$ & 2.21 \\
\hline BAL $1 / 148 / 1$ & 2.10 \\
\hline \multicolumn{1}{|c|}{ Mean $\mathbf{\pm}$ S.D. ${ }^{\text {(a) }}$} & $\mathbf{1 . 9 5} \pm \mathbf{0 . 3 2}$ \\
\hline
\end{tabular}

(a) S. D. - Standard deviation.

\section{Tensile Strength of Shale}

Ten indirect tension tests were performed on the shales. Five tests were performed on specimens oriented so that the compressional line load was perpendicular to bedding (which 
measures the tensile strength parallel to bedding) while five tests were performed on specimens oriented so that the compressional line load was parallel to bedding (which measures the tensile strength perpendicular to bedding). All tests were performed at a temperature of $20^{\circ} \mathrm{C}$ $\left(68^{\circ} \mathrm{F}\right)$.

The results of the indirect tension testing on shale specimens are summarized in Table A-4. The tensile strengths of the specimens oriented so that the line load was perpendicular to bedding ranged from 6.51 to $12.36 \mathrm{MPa}$ (944 to 1,793 psi). The tensile strengths of the specimens oriented so that the line load was parallel to bedding ranged from 3.21 to $8.56 \mathrm{MPa}$ (466 to 1,241 psi). On average, the tensile strengths of the shale specimens loaded parallel to bedding were weaker than those loaded perpendicular to bedding; however, large variability exists in the test results.

Table A-4. Results of Indirect Tension Tests on Bale Well No. 1 Shale

\begin{tabular}{|c|c|}
\hline Specimen I.D. & $\begin{array}{l}\text { Tensile Strength } \\
\text { (MPa) }\end{array}$ \\
\hline \multicolumn{2}{|c|}{$\begin{array}{l}\text { Line Load Parallel to Bedding (Tensile } \\
\text { Strength Perpendicular to Bedding) }\end{array}$} \\
\hline BAL 1/4/3-1/1 & 3.21 \\
\hline BAL 1///3-1/1 & 4.2 \\
\hline BAL 1/14/2-1/1 & 3.52 \\
\hline BAL1/21/3-1/1 & 4.49 \\
\hline BAL 1/25/2-1/2 & 8.56 \\
\hline \multicolumn{2}{|c|}{$\begin{array}{l}\text { Line Load Perpendicular to Bedding } \\
\text { (Tensile Strength Parallel to Bedding) }\end{array}$} \\
\hline BAL $1 / 4 / 2-1 / 2$ & 12.36 \\
\hline BAL $1 / 7 / 1-1 / 2$ & 12.25 \\
\hline BAL 1/14/1-1/1 & 7.32 \\
\hline BAL1/21/1-1/2 & 6.51 \\
\hline BAL1/25/1-1/2 & 8.96 \\
\hline
\end{tabular}

\section{Salt and Shale Failure Properties}

Failure properties for the salt and shale were also determined from the confined quasi-static compression tests performed on the salt and shale specimens obtained from Bale Well No. 1. 


\section{Shale Compressive Strength}

Strength properties for the shale were determined from six quasi-static compression tests performed on shale specimens from Bale Well No. 1. The unconfined and confined compressive strengths are defined as the peak axial stress differences measured during a test. The strength results of the quasi-static compression tests are summarized in Table A-5.

Table A-5. Results of Unconfined and Confined Quasi-Static Compression Tests on Bale Well No. 1 Shale

\begin{tabular}{||c|c|c|c|c||}
\hline \multicolumn{1}{|c|}{$\begin{array}{c}\text { Specimen } \\
\text { I.D. }\end{array}$} & $\begin{array}{c}\text { Average } \\
\text { Confining } \\
\text { Pressure } \\
\text { (MPa) }\end{array}$ & $\begin{array}{c}\text { Strength } \\
\text { (MPa) }\end{array}$ & $\begin{array}{l}\sqrt{J_{2}} \\
\text { (MPa) }\end{array}$ & $\begin{array}{c}\mathbf{I}_{\mathbf{1}} \\
\text { (MPa) }\end{array}$ \\
\hline \hline BAL 1/4/1-1/1 & 0 & 105.8 & 61.1 & 105.8 \\
\hline BAL 1/4/1-1/2 & 3.4 & 76.2 & 44.0 & 86.4 \\
\hline BAL 1/4/2-1/1 & 7.4 & 111.0 & 64.1 & 133.1 \\
\hline BAL 1/21/1-1/1 & 0 & 128.0 & 73.9 & 128.0 \\
\hline BAL 1/21/4-1/1 & 3.4 & 137.9 & 79.6 & 148.2 \\
\hline BAL 1/21/4-1/2 & 7.4 & 175.4 & 101.2 & 196.2 \\
\hline
\end{tabular}

(a) The first three specimens were recovered from a depth of 1,226 meters $(4,022$ feet). The last three specimens were recovered from a depth of 1,234 meters ( 4,050 feet).

(b) Peak stress difference recorded during test.

The strength data for the shales are plotted in the $\sqrt{J_{2}}$ versus $I_{1}$ stress space in Figure A-1, where $\sqrt{J_{2}}$ is the second invariant of the deviator stress tensor and $I_{1}$ is the first invariant of the stress tensor. The stress space describes how the compressive strength of the shale varies with confining pressure and $\sqrt{J_{2}}$ and $I_{1}$ are defined as:

$$
\begin{aligned}
& \sqrt{J_{2}}=\frac{\Delta \sigma_{1}}{\sqrt{3}} \\
& \mathrm{I}_{1}=\Delta \sigma_{1}+3 \sigma_{\mathrm{c}}
\end{aligned}
$$

where:

$$
\begin{aligned}
\Delta \sigma_{1} & =\text { peak axial stress difference, psi } \\
\sigma_{\mathrm{c}} & =\text { confining pressure, } \text { psi }
\end{aligned}
$$




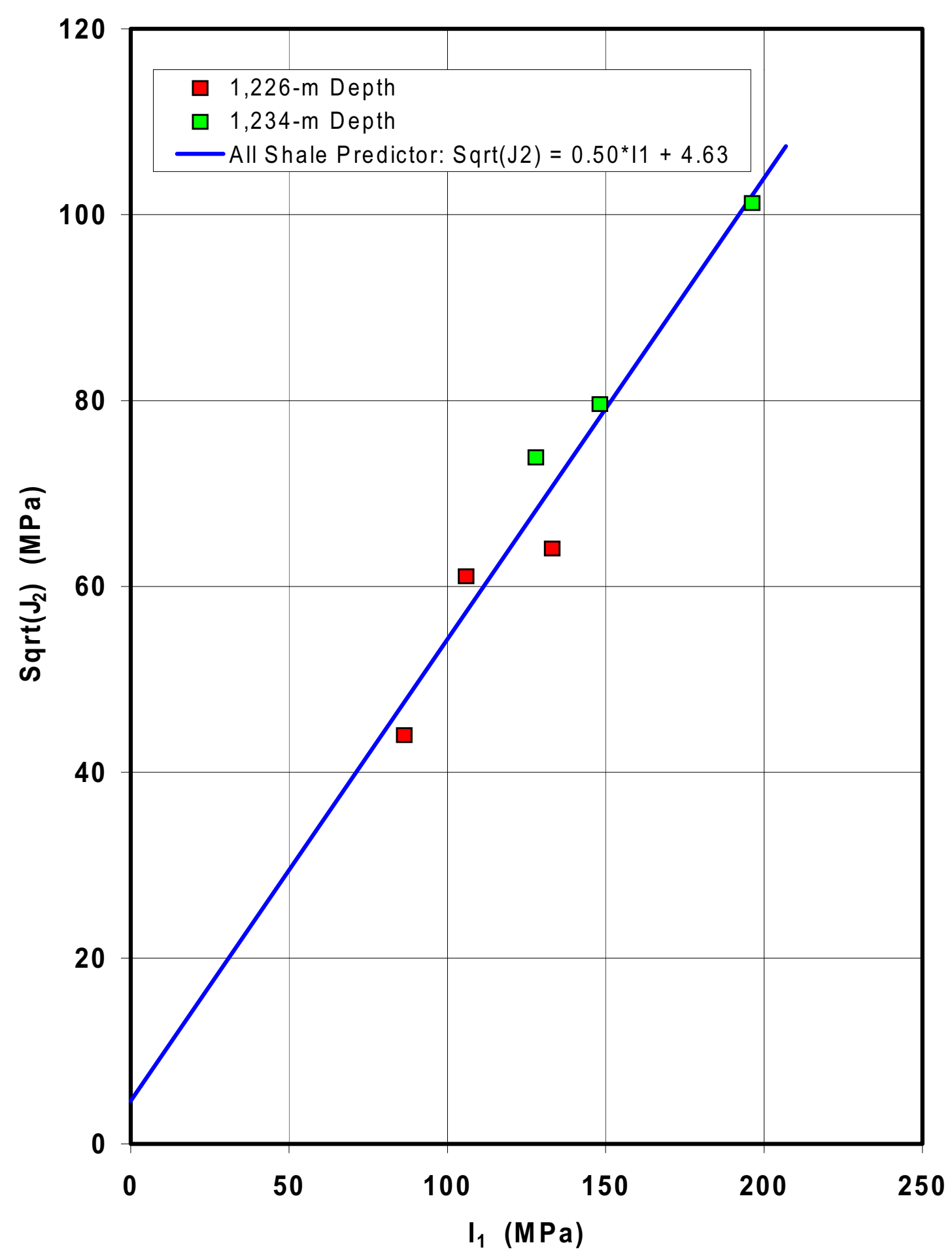

Figure A-1. Strength of Bale Well No. 1 Shale. 
The values of $\sqrt{I_{2}}$ and $I_{1}$ for each test are also given in Table A-5. As shown in Figure A-1, the maximum value of $\sqrt{J_{2}}$ determined from each test is approximately linearly related to $I_{1}$ regardless of recovery depth. The failure relationships for the shales are given as follows:

All shale data:

$$
\sqrt{J_{2}}=0.50 \mathrm{I}_{1}+4.63(\mathrm{MPa})
$$

1,226 - meter shale data only:

$$
\sqrt{J_{2}}=-.41 I_{1}+11.95(\mathrm{MPa})
$$

1,234 - meter shale data only:

$$
\sqrt{J_{2}}=-.41 \mathrm{I}_{1}+20.33(\mathrm{MPa}) \text {. }
$$

The failure relationship for all shale data is shown in Figure A-1 as a predictor of the strength of the shale. The relationships between $\sqrt{J_{2}}$ and $I_{1}$ for the shales divide the stress space into domains of stress that do not fail the shales and stress states that result in failure. For stress states below the $\sqrt{I_{2}}$ versus $I_{1}$ curves, failure of the shale is not expected. Above the curves, failure will occur. The data shown in Figure A-1 also indicate that the deeper shale is slightly stronger than the shallower shale.

\section{Salt Strength and Dilation}

The strength and dilation data determined from the six confined quasi-static compression tests on salt are summarized in Table A-6. The confined compressive strength is defined as the peak axial stress difference measured during the test. As expected, the confined strengths increased with confining pressure. The strength of the BAL1/86-1/2 specimen was not determined because the complete stress-strain curve for the test was not obtained. At a stress difference of about $35.9 \mathrm{MPa}(5,200 \mathrm{psi})$, the data acquisition system of the testing machine malfunctioned and no data were obtained beyond this point.

The dilation stress given in Table A- 6 was defined as the shear stress at zero volumetric strain and is estimated by interpolation of the stress difference versus volumetric strain curve for each test. Also shown in Table A-6 are the two stress measures $\sqrt{J_{2}}$ and $I_{1}$ recorded at the time the peak stress and dilation stress were achieved.

Both the confined strength and the dilation stress are plotted in the $\sqrt{J_{2}}$ versus $I_{1}$ stress space in Figure A-2. As shown, $\sqrt{J_{2}}$ is approximately linearly related to $I_{1}$ for both the strength and dilation stress data. The linear relationships for these data are given as follows: 
Salt strength:

$$
\sqrt{J_{2}}=0.42 I_{1}+3.66(\mathrm{MPa})
$$

Salt dilation:

$$
\sqrt{J_{2}}=0.44 I_{1}+0.94(\mathrm{MPa}) \text {. }
$$

\begin{tabular}{|c|c|c|c|c|c|c|c|}
\hline \multirow[b]{2}{*}{$\begin{array}{l}\text { Specimen } \\
\text { I.D. }\end{array}$} & \multirow[b]{2}{*}{$\begin{array}{c}\text { Confining } \\
\text { Pressure } \\
\text { (MPa) }\end{array}$} & \multicolumn{3}{|c|}{ Strength Data } & \multicolumn{3}{|c|}{ Dilation Data } \\
\hline & & $\begin{array}{l}\text { Peak } \\
\text { Stress } \\
\text { (MPa) }\end{array}$ & $\begin{array}{c}\sqrt{J_{2}} \\
\text { (MPa) }\end{array}$ & $\begin{array}{c}\mathrm{I}_{1} \\
(\mathrm{MPa})\end{array}$ & $\begin{array}{c}\text { Dilation } \\
\text { Stress } \\
\text { (MPa) }\end{array}$ & $\begin{array}{c}\sqrt{J_{2}} \\
\text { (MPa) }\end{array}$ & $\begin{array}{c}\mathrm{I}_{1} \\
(\mathrm{MPa})\end{array}$ \\
\hline BAL/1/82/1 & 0.7 & 24.5 & 14.2 & 26.6 & 18.1 & 10.4 & 20.2 \\
\hline BAL $1 / 82 / 2$ & 1.4 & 41.6 & 24.0 & 45.7 & 27.4 & 15.8 & 31.5 \\
\hline BAL 1/85/1 & 3.4 & 48.4 & 28.0 & 58.8 & 37.9 & 21.9 & 48.2 \\
\hline BAL 1/86-1/2 & 0.7 & 29.5 & 17.0 & 31.5 & 23.5 & 13.5 & 25.5 \\
\hline BAL 1/86-1/2 & 1.4 & (a) & (a) & (a) & 8.1 & 4.7 & 12.2 \\
\hline BAL 1/86-2/1 & 3.4 & 46.9 & 27.1 & 57.3 & 31.5 & 18.2 & 41.9 \\
\hline
\end{tabular}

Table A-6. Strength and Dilation Stress Measures for Bale Well No. 1 Salt

(a) Data acquisition failed during test.

The first relationship divides the stress space into domains of stress that do not fail the salt (i.e., below the curve) and stress states that result in failure (i.e., above the curve). The second relationship also divides the stress space into two domains. Above the curve dilation of the salt occurs. Below the curve, no dilation is anticipated.

\section{Salt Creep Properties}

Three staged confined triaxial compression tests performed on salt core recovered from Bale Well No. 1 provided data to evaluate the time-dependent characteristics of the salt. The timedependent deformation was used to develop a material model for use in numerical analyses. The material model developed is referred to as the Munson-Dawson model ${ }^{1}$. The next two sections describe the three staged triaxial compression tests and the parameter values determined for the Munson-Dawson model that describe the salt from Bale Well No. 1.

\footnotetext{
Munson, D. E., A. F. Fossum, and P. E. Senseny, 1989. Advances in Resol ution of Discrepancies Between Predicted and Measured In Situ WIPP Room Closures, SAND88-2948, Sandia National Laboratories, Albuquerque, NM.
} 


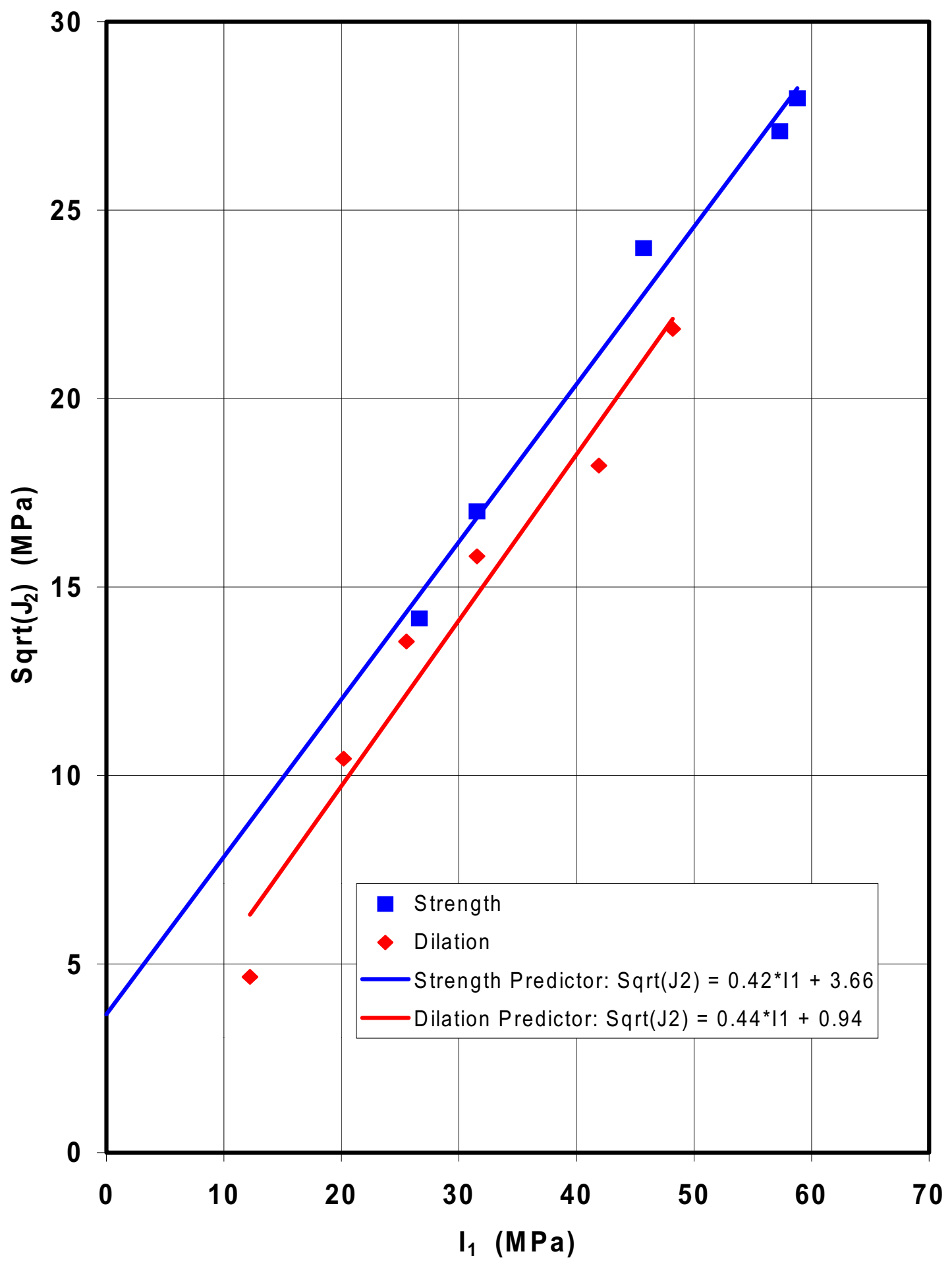

Figure A-2. Strength and Dilation of Bale Well No. 1 Salt. 


\section{Salt Creep Tests}

Three multistage, confined triaxial compression creep (constant stress) tests were performed on Bale Well No. 1 salt. The tests were performed to evaluate the time-dependent deformation of the salt and to investigate the potential for salt dilation. Each test was conducted in stages at a constant temperature of $40^{\circ} \mathrm{C}\left(104^{\circ} \mathrm{F}\right)$. The creep test matrix is shown in Table A-7. The first stage of each test was performed at a confining pressure of $27.6 \mathrm{MPa}(4,000 \mathrm{psi})$ and a stress difference of either $10.3,15.5$, or $20.7 \mathrm{MPa}(1,500,2,250$, or $3,000 \mathrm{psi})$. The stress differences were selected to encompass the range of stress differences expected in the salt near the storage cavern during natural gas service. The confining pressure in the first stage was selected to simulate the in situ lithostatic stresses at the midheight of the proposed cavern and was high enough to prevent salt dilation at the prescribed stress differences. In subsequent stages of each test, the confining pressure was lowered while the stress difference was held constant. This loading sequence was designed to simulate drawdown of cavern pressure and was used to investigate the potential for salt dilation.

Table A-7. Creep Test Matrix for Bale Well No. 1 Salt ${ }^{(a)}$

\begin{tabular}{|c|c|c|c|c|c|}
\hline $\begin{array}{l}\text { Test } \\
\text { No. }\end{array}$ & $\begin{array}{c}\text { Specimen } \\
\text { I.D. }\end{array}$ & Stage & $\begin{array}{l}\text { Axial Stress } \\
\text { Difference, } \Delta \sigma_{1} \\
\text { (MPa) }\end{array}$ & $\begin{array}{l}\text { Confining } \\
\text { Pressure, } \sigma_{3} \\
\text { (MPa) }\end{array}$ & $\begin{array}{c}\text { Duration } \\
\text { (days) }\end{array}$ \\
\hline 1 & BAL 1/87/1 & $\begin{array}{l}1 \\
2 \\
3\end{array}$ & $\begin{array}{l}10.34 \\
10.34 \\
10.34\end{array}$ & $\begin{array}{r}27.58 \\
5.17 \\
1.72\end{array}$ & $\begin{array}{r}17.0 \\
8.2 \\
6.7\end{array}$ \\
\hline 2 & BAL 1/87/2 & $\begin{array}{l}1 \\
2 \\
3\end{array}$ & $\begin{array}{l}15.51 \\
15.51 \\
15.51\end{array}$ & $\begin{array}{r}27.58 \\
5.17 \\
1.72\end{array}$ & $\begin{array}{r}13.9 \\
6.7 \\
7.0\end{array}$ \\
\hline 3 & BAL 1/89/1 & $\begin{array}{l}1 \\
2 \\
3\end{array}$ & $\begin{array}{l}20.68 \\
20.68 \\
20.68\end{array}$ & $\begin{array}{r}27.58 \\
5.17 \\
1.72\end{array}$ & $\begin{array}{r}13.9 \\
6.7 \\
6.8\end{array}$ \\
\hline
\end{tabular}

(a) All tests performed at a temperature of $40^{\circ} \mathrm{C}$.

The axial, lateral, and volumetric creep strain histories for each of the three creep tests are shown in Figures A-3 through A-5, respectively. Axial and lateral strains were calculated directly from measured displacements while volumetric strain was calculated from the axial and lateral strains. The Stage 1 portions of the curves shown in Figures A-3 through A-5 are typical of those obtained for other salts. At early times, the strain rates are relatively high but decrease with time. At later times, the strain rates reach constant or nearly constant values. During Stage 2 of each test, the strains continue to accumulate at about the same rates as those at the end of the first stages of the tests. In Stages 2 and 3 of one test, BAL 1/89/1, the axial and lateral strains accelerate and the volumetric strain rate changes al gebraic sign, indicating that 
- - BAL1/87/1 - -

Stress Difference $=10.3 \mathrm{MPa}$

Confining Pressure =27.6 MPa; 5.2 MPa; 1.7 MPa

Temperature $=\mathbf{4 0} \mathrm{C}$

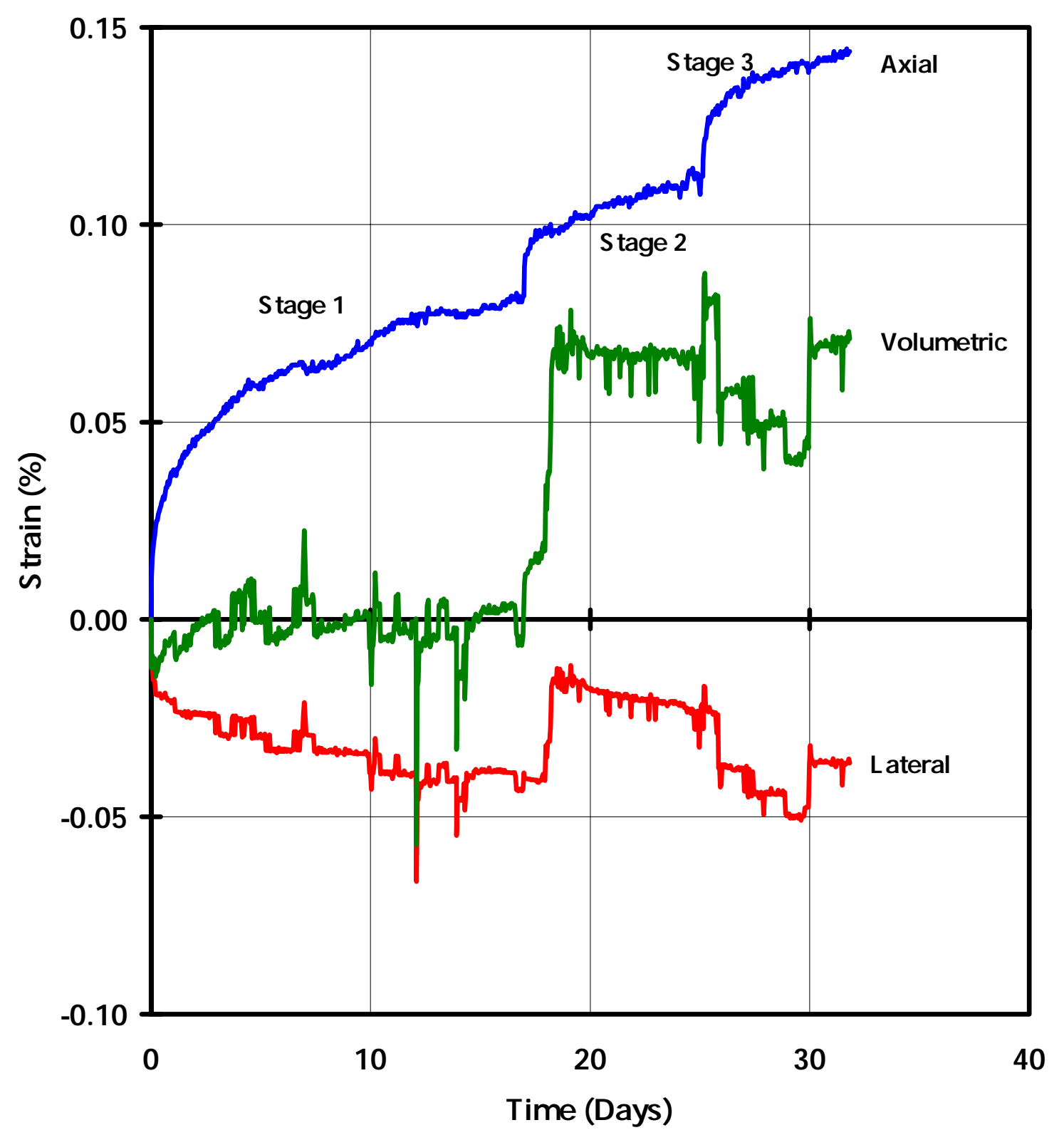

Figure A-3. Axial, Lateral, and Volumetric Creep Strains for Bale Well No. 1 Salt Specimen I.D. BAL $1 / 87 / 1$. 
- - BAL1/87/2 - -

Stress Difference $=15.5 \mathrm{MPa}$

Confining Pressure =27.6 MPa; 6.9 MPa; 3.4 MPa

Temperature $=\mathbf{4 0} \mathrm{C}$

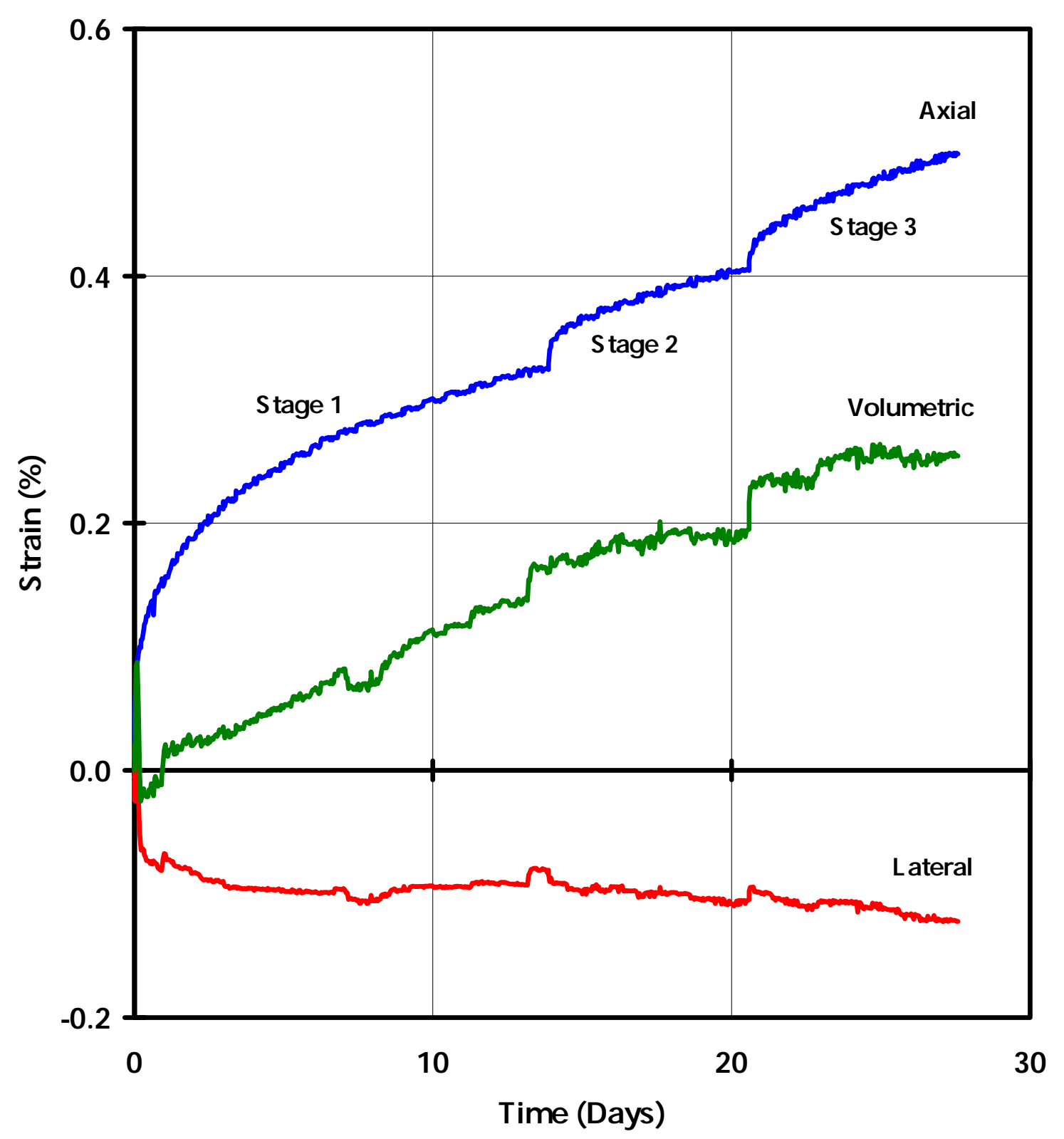

Figure A-4. Axial, Lateral, and Volumetric Creep Strains for Bale Well No. 1 Salt Specimen I.D. BAL $1 / 87 / 2$. 
- - BAL1/89/1 - -

Stress Difference $=20.7 \mathrm{MPa}$

Confining Pressure =27.6 MPa; 10.3 MPa; 5.2 Mpa

Temperature $=\mathbf{4 0} \mathrm{C}$

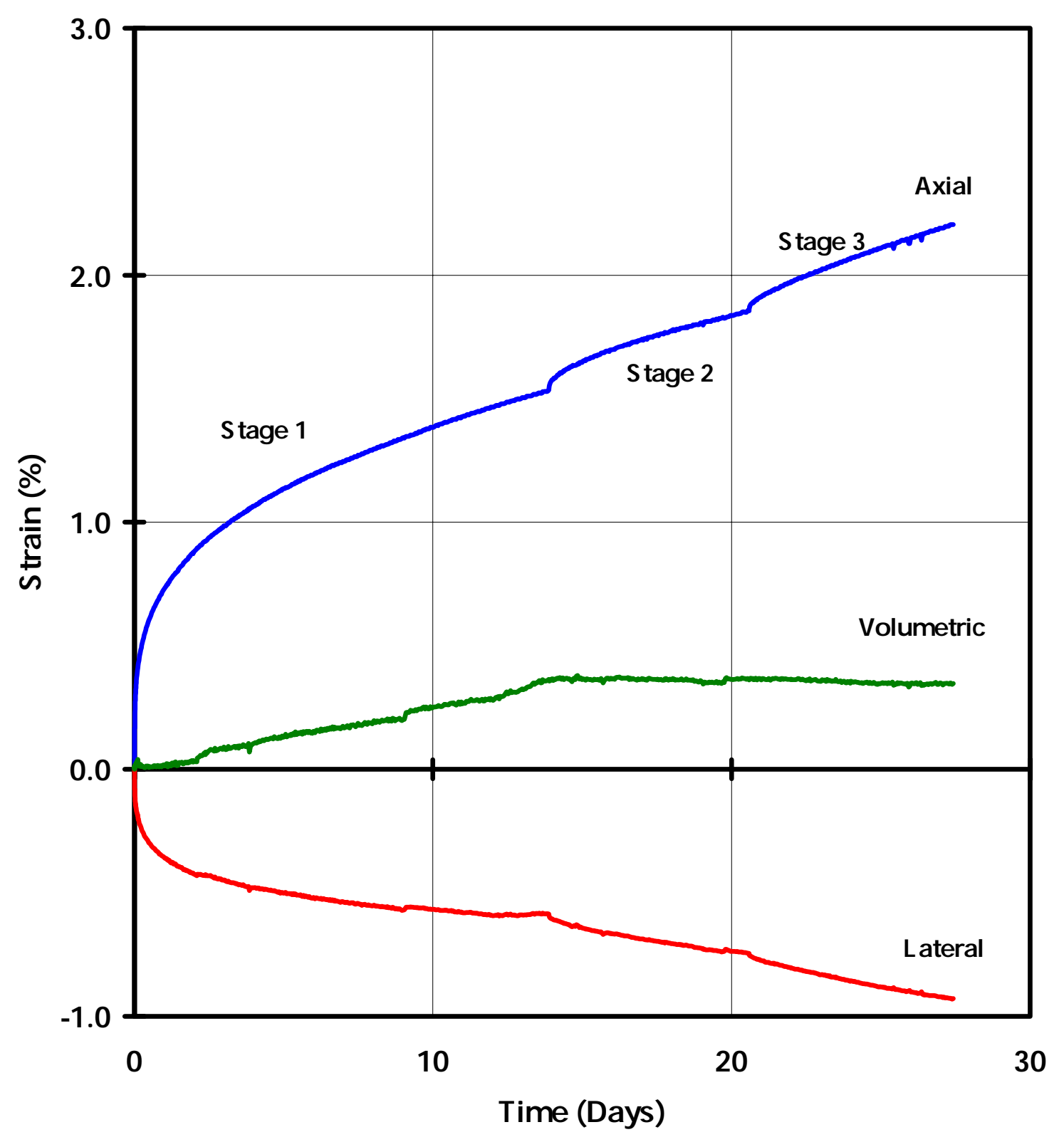

Figure A-5. Axial, Lateral, and Volumetric Creep Strains for Bale Well No. 1 Salt Specimen I.D. BAL1/89/1. 
the specimen may be undergoing dilation (i.e., fracturing resulting in a volume increase). The stress states for each stage of the three confined creep tests plot bel ow the dilation stress curve predicted by the confined quasi-static tests (Figure A-2). Therefore, no dilation should occur during creep. As noted above, Specimen BAL1/89/1 exhibited some dilation during Stages 2 and 3; however, when all the creep data are viewed collectively, the results support, or at least do not contradict, the dilation boundary determined from the confined quasi-static tests.

\section{Munson-Dawson Creep Model Parameters}

Data from the first stage of each creep test were fit to the Munson-Dawson constitutive model to predict the viscoplastic behavior of the salts. Because of the limited number of creep tests on the Cayuta salt, not all of the Munson-Dawson parameters can be uniquely determined. Several Munson-Dawson model parameter values were assumed to be the same as those determined from an extensive study of long-term creep tests on salt from the Waste Isolation Pilot Plant (WIPP) site in New Mexico. Specifically, the parameters $\mathrm{Q}_{2}, \mathrm{q}, \delta$, and c for the Cayuta salt constitutive law are taken to be equal to the WIPP values. Additionally, the ratio of the leading coefficients for each of the three deformation mechanisms to the sum of the coefficients is assumed to be identical in the Cayuta and WIPP salts.

Values for the Munson-Dawson parameters $\mathrm{K}_{0}, \mathrm{~m}, \alpha, \beta, \mathrm{n}_{2}, \sigma_{0}$ and an overall scaling factor for the leading coefficients $\left(A_{1}, A_{2}, B_{1}\right.$, and $\left.B_{2}\right)$ were determined by fitting the creep test data to the Munson-Dawson constitutive model with a nonlinear least-squares fitting procedure. The Munson-Dawson parameter values estimated for Cayuta salt are shown in Table A-8. The creep test data and the numerical predictions using the estimated MunsonDawson parameter values are shown in Figure A-6.

\section{In Situ Stress Conditions}

The integrity of the shale and the salt is directly related to the deviatoric stress state resulting from the in situ stress and the stresses exerted on the cavern walls by natural gas. Therefore, it is important to model in situ stresses which are representative of those in the vicinity of the proposed storage caverns. The in situ stress state at Cayuta is known to be anisotropic. Information obtained from a stress test in Bale Well No. 1 and from a review of the literature indicates that the magnitude of the maximum horizontal stress in this part of New York State varies. Review of the stress measurements in the Bale Well No. 1 and the literature indicates that the minimum horizontal stress is slightly less than the vertical stress and that the maximum horizontal stress is between 1.2 and 1.81 times the vertical stress.

The vertical in situ stress was estimated from the density log of Bale Well No. 1 by integrating the density from the ground surface to the depth of the proposed caverns. Consequently, the vertical in situ stress distribution prior to the excavation of the caverns was assumed to be: 


$$
\sigma_{z}=0.02269(z-1,162.2)+30.76
$$

where $\sigma_{z}$ is the vertical stress in MPa and $z$ is the depth in meters.

Table A-8. Estimates of Munson-Dawson Creep Parameters for Cayuta Salt

\begin{tabular}{||c|c|c|c||}
\hline Parameters & Units & Estimators & $\begin{array}{c}\text { Basis for } \\
\text { Estimators }\end{array}$ \\
\hline \hline $\mathrm{A}_{1}$ & day $^{-1}$ & $1.37\left(10^{27}\right)$ & $\begin{array}{c}\text { WIPP and } \\
\text { Bale Well No. 1 Salt }\end{array}$ \\
\hline $\mathrm{A}_{2}$ & day $^{-1}$ & $1.58\left(10^{17}\right)$ & $\begin{array}{c}\text { WI PP and } \\
\text { Bale Well No. 1 Salt }\end{array}$ \\
\hline $\mathrm{B}_{1}$ & day $^{-1}$ & $9.93\left(10^{10}\right)$ & $\begin{array}{c}\text { WIPP and } \\
\text { Bale Well No. 1 Salt }\end{array}$ \\
\hline $\mathrm{B}_{2}$ & day $^{-1}$ & 495 & $\begin{array}{c}\text { WIPP and } \\
\text { Bale Well No. 1 Salt }\end{array}$ \\
\hline $\mathrm{K}_{0}$ & - & $1.41\left(10^{5}\right)$ & Bale Well No. 1 Salt \\
\hline $\mathrm{m}$ & - & 2.92 & Bale Well No. 1 Salt \\
\hline$\alpha$ & - & 7.01 & Bale Well No. 1 Salt \\
\hline$\beta$ & - & -1.00 & Bale Well No. 1 Salt \\
\hline $\mathrm{q}$ & - & 5,335 & WIPP Salt \\
\hline $\mathrm{Q}_{2} / \mathrm{R}$ & $\mathrm{K}$ & 5,032 & WIPP Salt \\
\hline $\mathrm{n}_{2}$ & - & 5.55 & Bale Well No. 1 Salt \\
\hline$\sigma_{0}$ & $\mathrm{MPa}$ & 15.51 & Bale Well No. 1 Salt \\
\hline $\mathrm{C}$ & $\mathrm{K}^{-1}$ & 0.0092 & WIPP Salt \\
\hline$\delta$ & - & 0.58 & WIPP Salt \\
\hline \hline
\end{tabular}




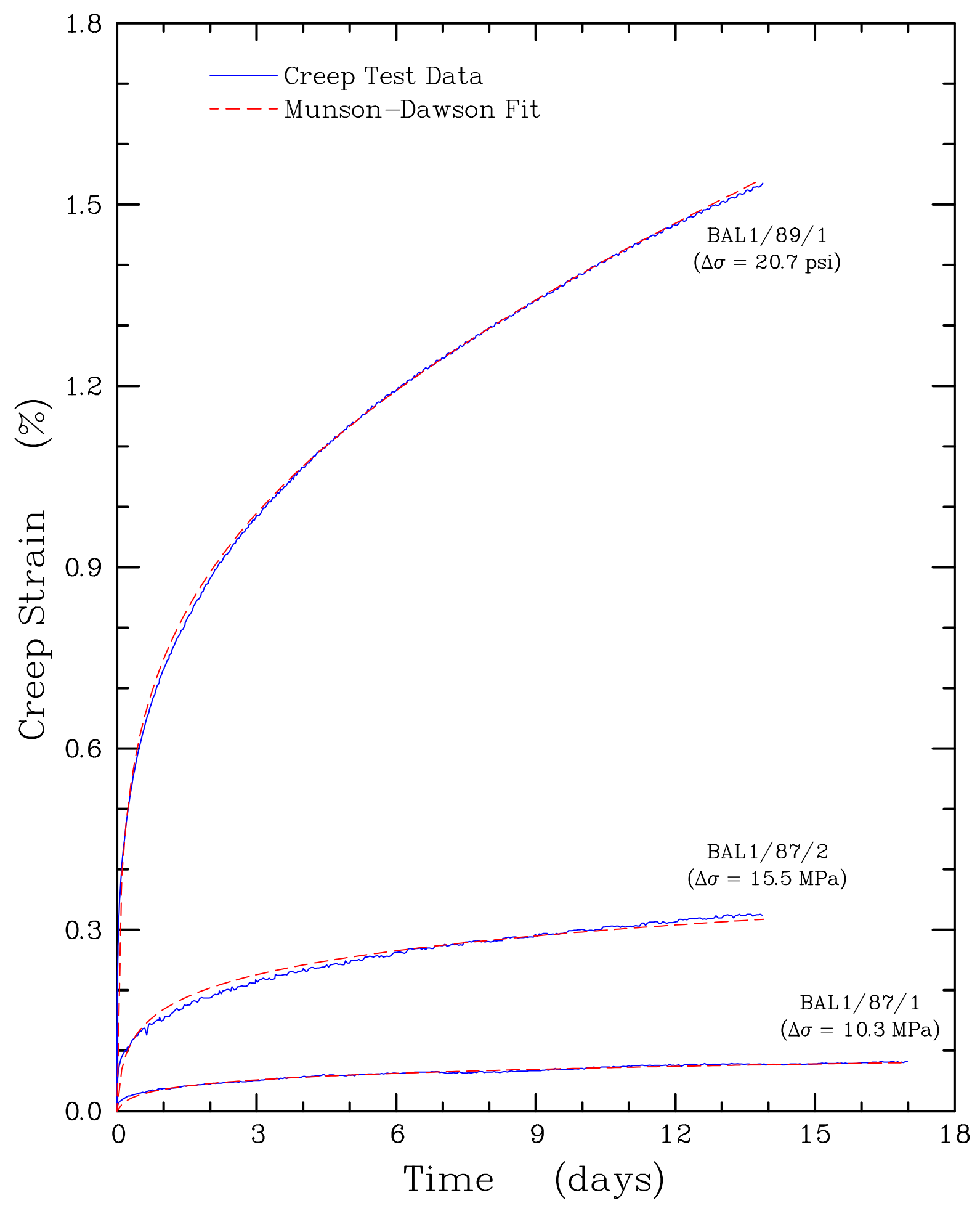

Figure A-6. Measured and Predicted Axial Strains for Stage 1 of the Creep Tests on Salt From Bale Well No. 1. 
APPENDIX B

\section{DESIGN DRAWINGS}




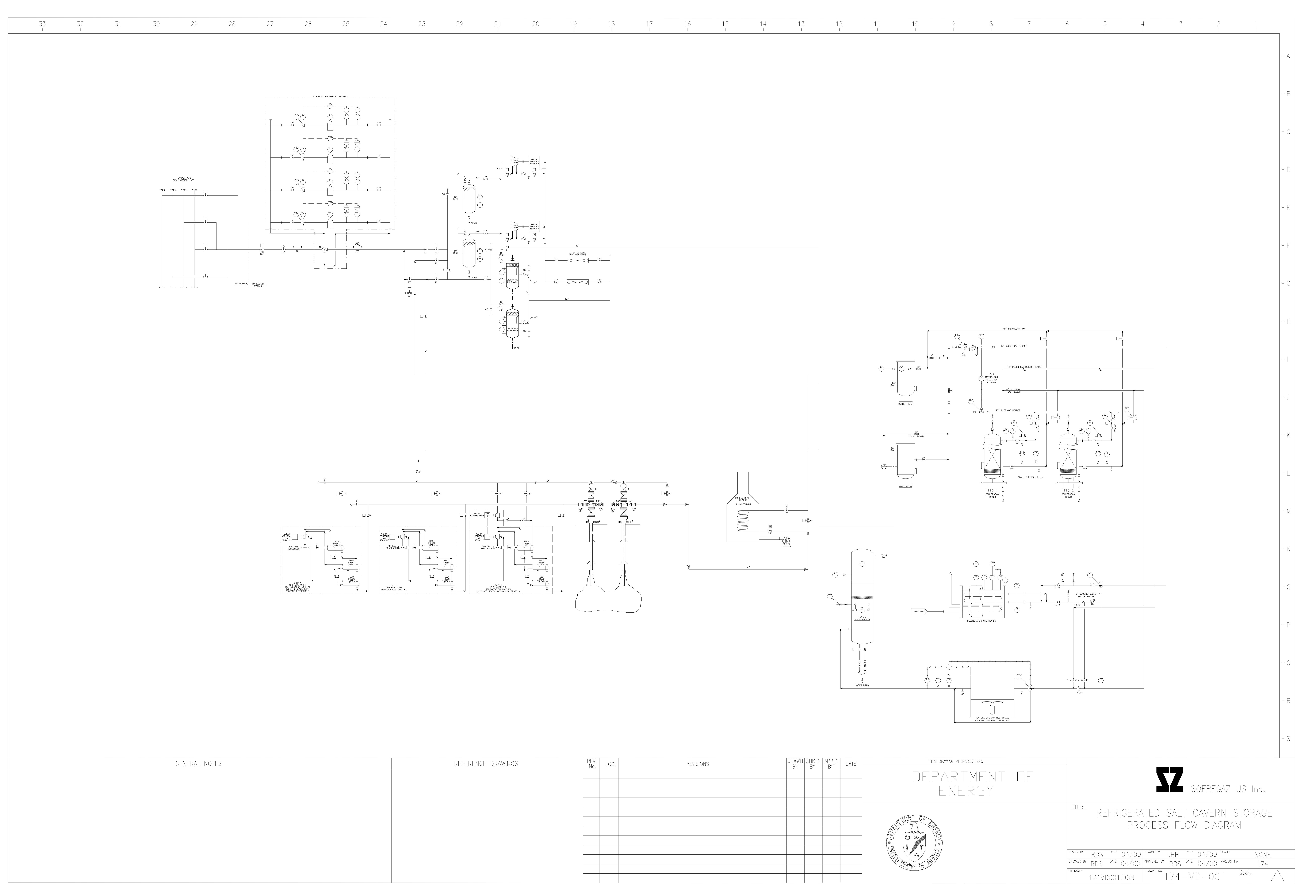




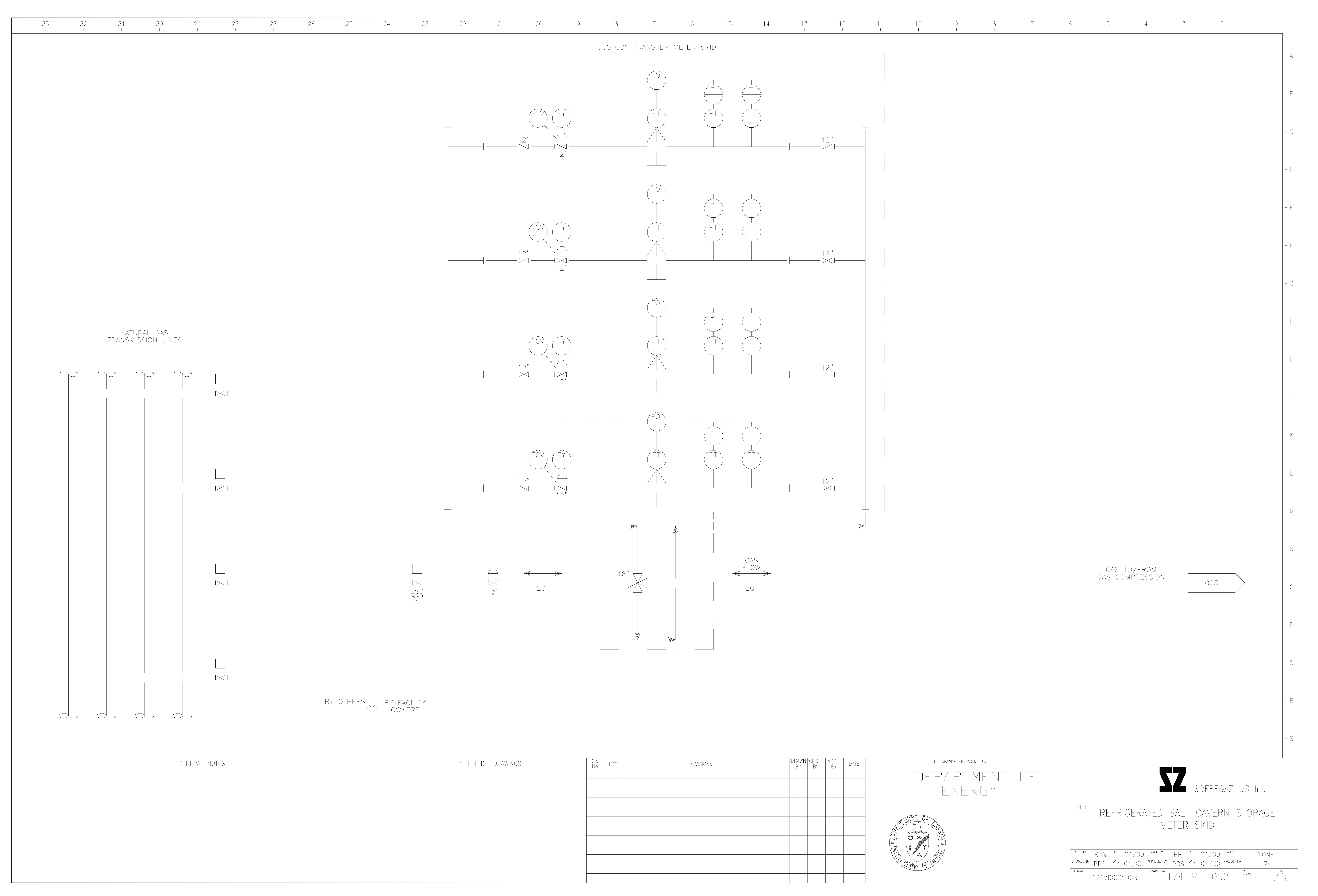




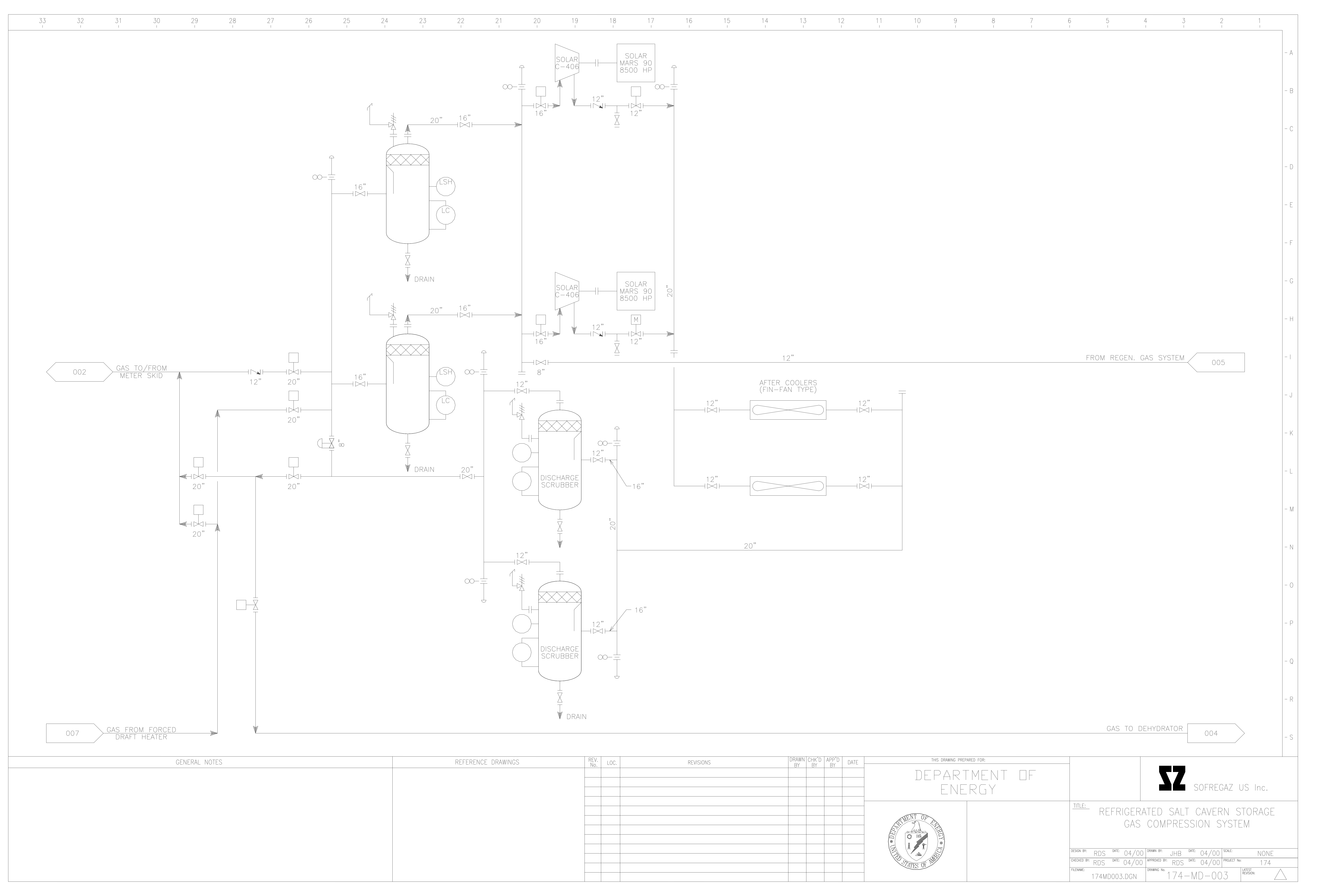




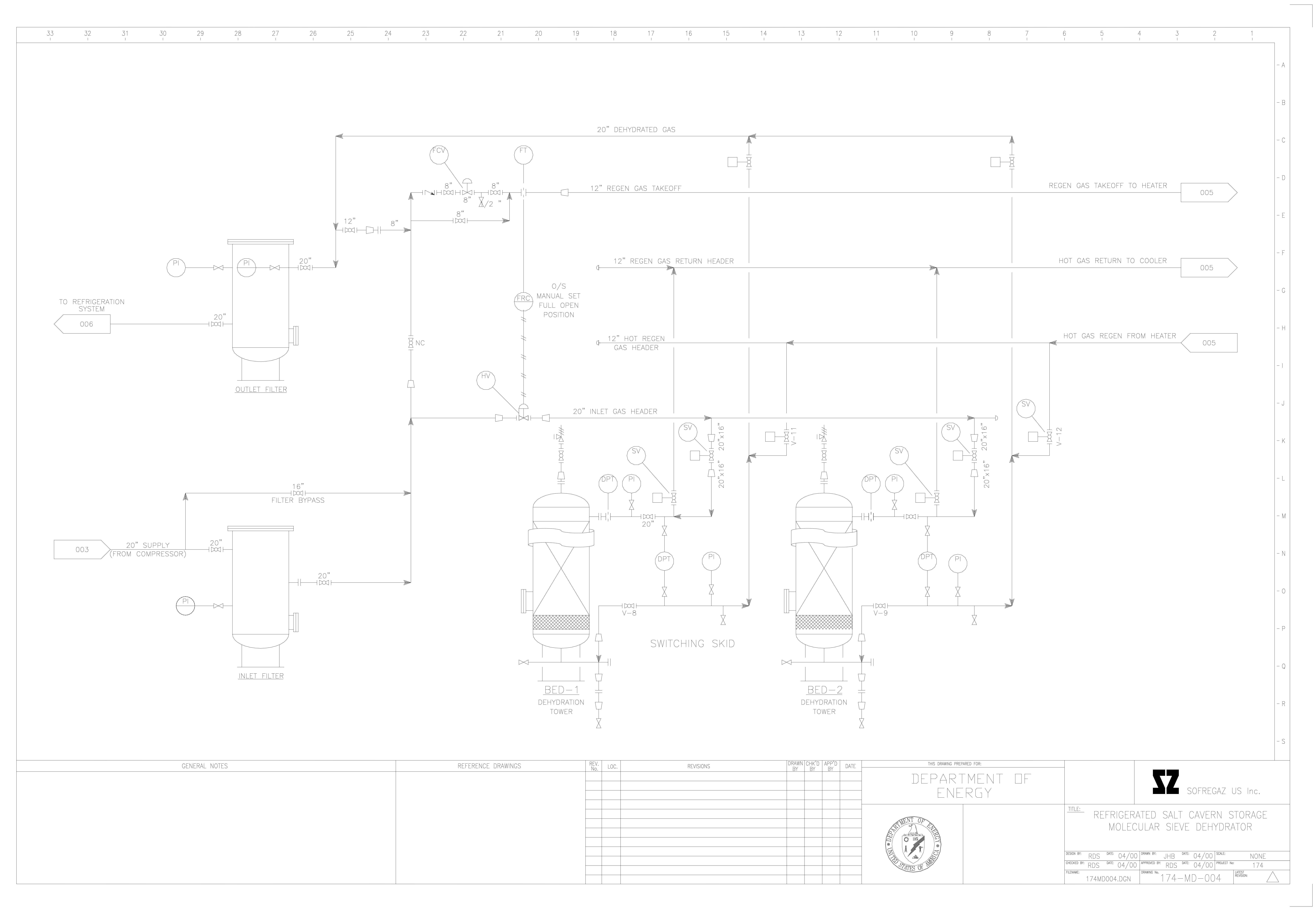




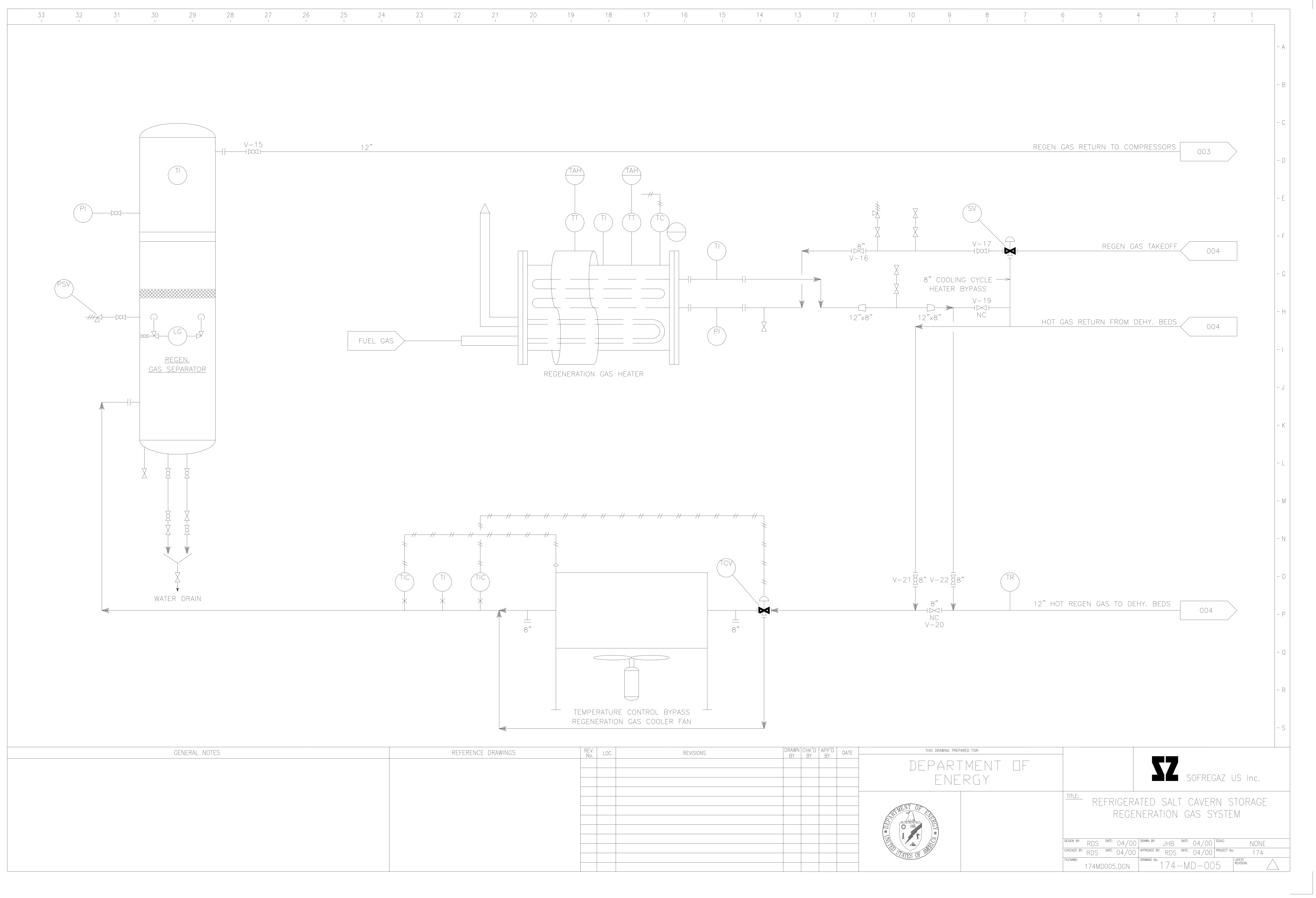




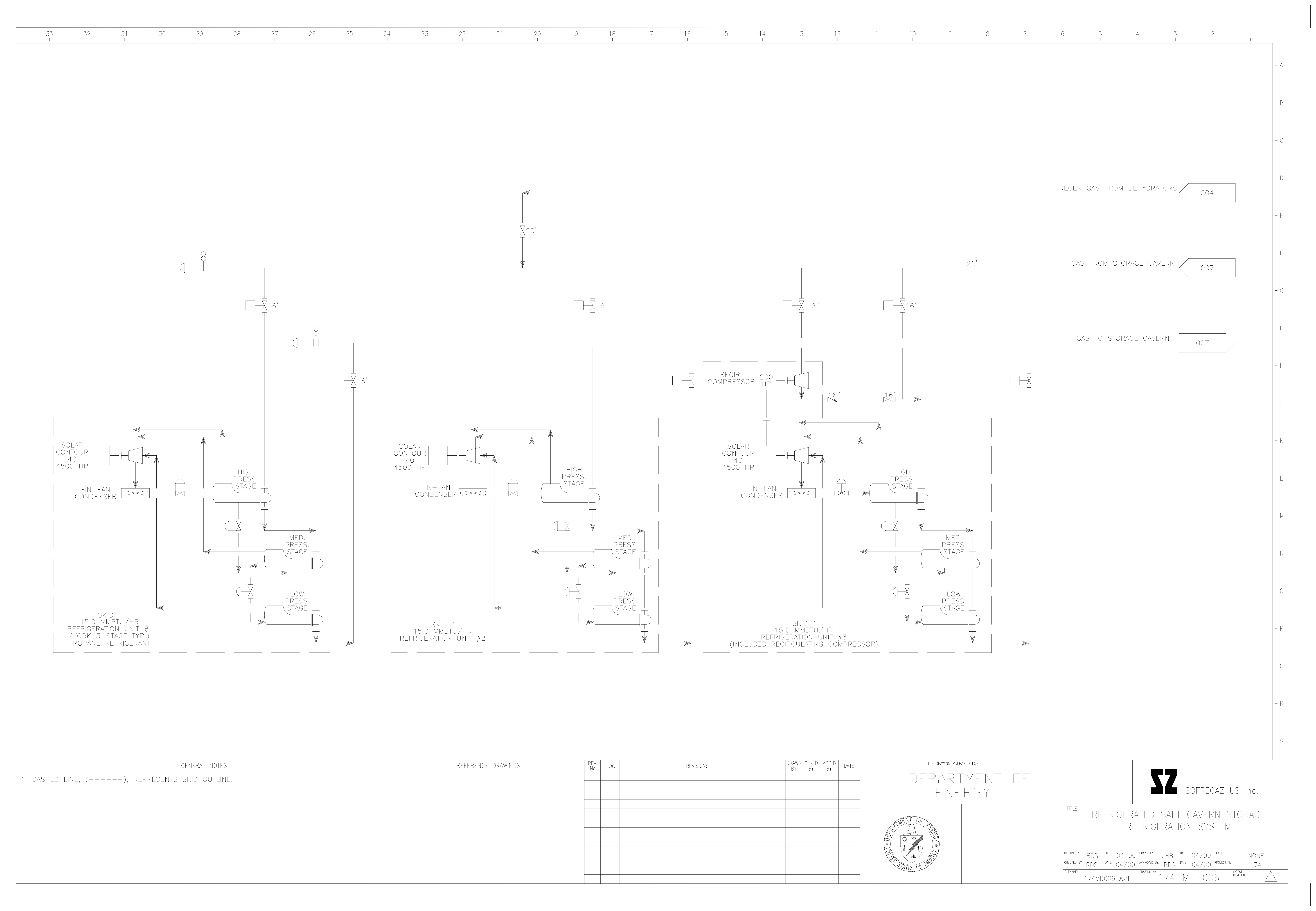




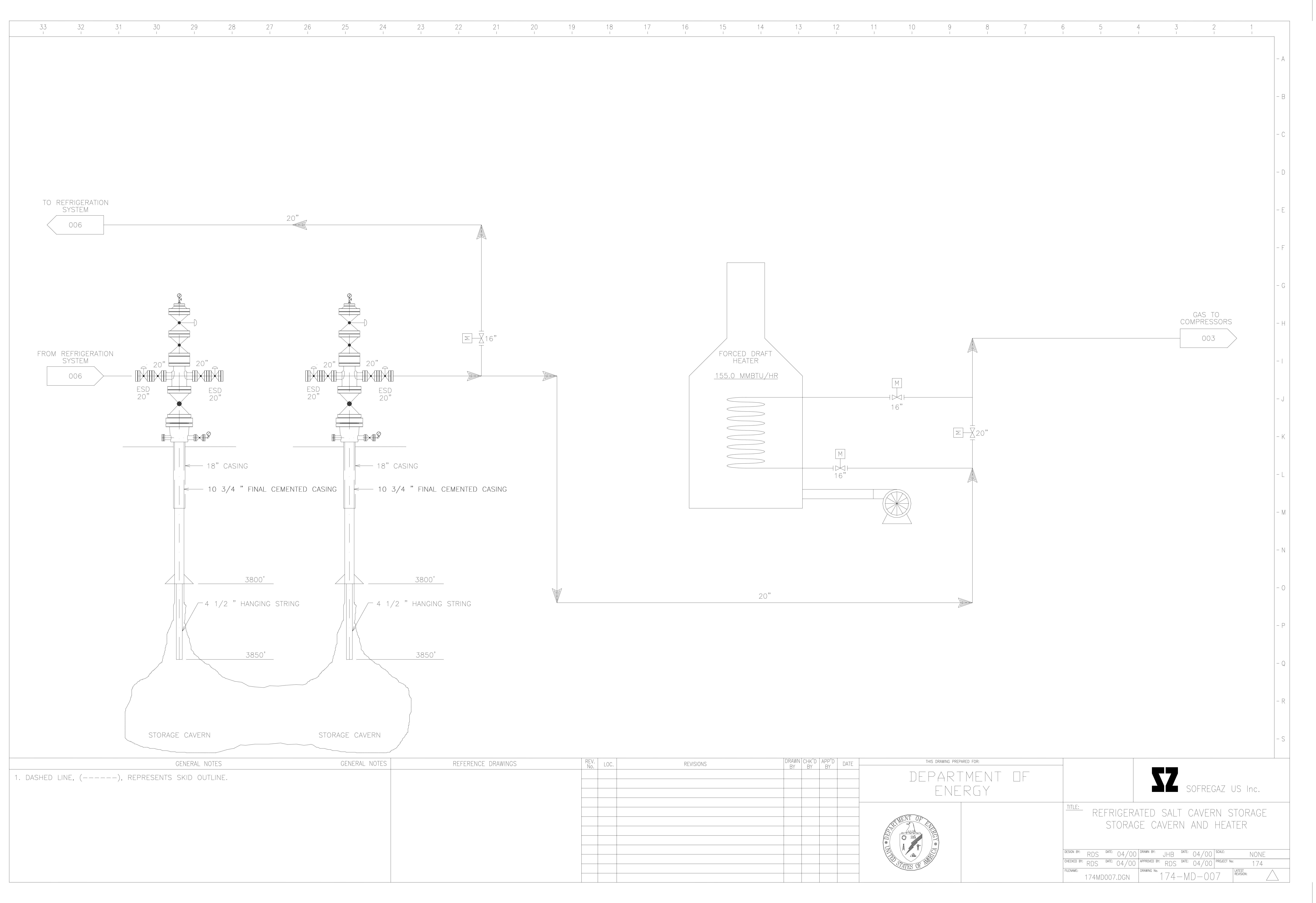

